\title{
WestVirginiaUniversity
}

THE RESEARCH REPOSITORY @ WVU

Graduate Theses, Dissertations, and Problem Reports

2002

\section{Perceptions of moral agency among some preschool special needs teachers}

Stephen Keith Pavlovic

West Virginia University

Follow this and additional works at: https://researchrepository.wvu.edu/etd

\section{Recommended Citation}

Pavlovic, Stephen Keith, "Perceptions of moral agency among some preschool special needs teachers" (2002). Graduate Theses, Dissertations, and Problem Reports. 2455.

https://researchrepository.wvu.edu/etd/2455

This Dissertation is protected by copyright and/or related rights. It has been brought to you by the The Research Repository @ WVU with permission from the rights-holder(s). You are free to use this Dissertation in any way that is permitted by the copyright and related rights legislation that applies to your use. For other uses you must obtain permission from the rights-holder(s) directly, unless additional rights are indicated by a Creative Commons license in the record and/ or on the work itself. This Dissertation has been accepted for inclusion in WVU Graduate Theses, Dissertations, and Problem Reports collection by an authorized administrator of The Research Repository @ WVU.

For more information, please contact researchrepository@mail.wvu.edu. 


\title{
PERCEPTIONS OF MORAL AGENCY AMONG SOME PRESCHOOL SPECIAL NEEDS TEACHERS
}

\author{
Stephen K. Pavlovic \\ A dissertation submitted to \\ the College of Human Resources and Education \\ at West Virginia University \\ in partial fulfillment of the requirements of \\ the degree of Doctor of Education in Special Education
}

\author{
Barbara Ludlow, Ed.D. Chair \\ Wanda Franz, Ph.D \\ Carol Markstrom, Ph.D. \\ Wilfred Wienke, Ph.D. \\ Diane Woodrum, Ed.D.
}

Morgantown, West Virginia

2002

Key words: Special Education, Preschool Special Needs, Morality Copyright 2002 Stephen K. Pavlovic 


\author{
ABSTRACT \\ Perceptions of Moral Agency Among Some \\ Preschool Special Needs Teachers \\ Stephen K. Pavlovic
}

For more than 30 years, research on moral development has been dominated by the work of Lawrence Kohlberg and James Rest who have sought to construct and validate a universal model of moral development. The administration of either the Moral Judgment Inventory (MJI) or the Defining Issues Test (DIT) has been the primary, and frequently the only, methodology used to examine the moral reasoning abilities of various professions. Based on these tests, teachers have shown a disturbingly low level of moral reasoning. Using Rest's Four Component Model of moral deliberation, the study was designed to test the hypothesis that teachers' low mean scores on the MJI and the DIT do not give an accurate picture of their moral development. A Delphi study was conducted to develop a broad picture of the moral experience and moral perceptions of preschool special needs teachers as a group. This was followed by two interviews each of four preschool special needs teachers to gain an in depth picture of their individual perceptions of moral agency. It was found that these teachers face a wide range of moral challenges. They use very little moral language in discussing those challenges, and feel isolated with few options for advice or assistance. The participants showed a marked preference for reasoning about dilemmas based on the outcomes of various options available to them. While there was no evidence that their reasoning corresponds to any of Kohlberg's stages, there was slight evidence of a moral stance similar to an ethic of care. This suggests that, rather than showing poor moral reasoning abilities, teachers may reason in a manner that is not encompassed by Kohlberg's stage theory. It was also found that Rest's Four Component model does not adequately reflect the processes of deliberation used by these preschool special needs teachers. 


\section{ACKNOWLEDGMENTS}

Arriving at the point of completing this dissertation has been an emotional journey. It has forever changed me. Along the way I have had the distinct privilege of meeting, working with, and being encouraged by some true mentors. For many years now, Dr. Barbara Ludlow has provided me with an example of scholarship, integrity, and friendship. If I can meet even half of that example, I will consider myself successful. I would like to thank Dr. Diane Woodrum for her friendship and her unflagging certainty that I would complete this document. I want to thank Dr. Wilfred Wienke for his moral support and for always keeping an eye out for my emotional and financial welfare while he was chairman of the Special Education Department at WVU. I would like to thank Dr. Wanda Franz for sharing her knowledge of child development, for introducing me to developmental meta-theory, and for many conversations about morality. I would like to thank Dr. Carol Markstrom for her introduction to a variety of explanatory theories that helped me to feel comfortable conducting a qualitative approach to understanding human experience, and this research project in particular.

Naturally, this study could not have been completed without the many preschool special needs teachers who were willing to participate in it and gave of their valuable time. I will be forever grateful to them and humbly hope that in some small way my efforts will contribute to their professional well-being. Special thank you's are due to Wilma Philips, Sherry Bunner, and Donna Staggs for the hundreds of small favors they have performed for me over the years. These favors saved me from untold numbers of mistakes I would otherwise have made in negotiating university policies and procedures. Kim Stamm, at the Evansdale library, deserves thanks for her help in finding many obscure texts through the interlibrary loan system.

I want to thank I. Claude Southerly for his emotional support; support without which I could not have reached completion of this project. I would like to thank my parents for 
believing in me and for all the dinners and child care they provided during this process. And last but definitely not least, I want to thank my children, Dwight and Noelle, for their patience and for always letting me know that they still love me even though I haven't been as available to them as I would have liked. 


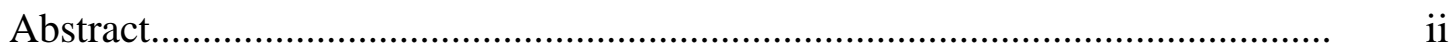

Acknowledgments...................................................................................

Chapter I - Problem Area ….................................................................. 1

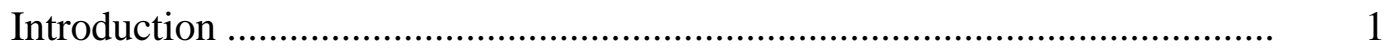

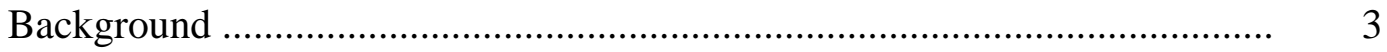

Statement of the Problem ........................................................................ 6

Purpose of the Study ...................................................................... 9

Research Questions ................................................................... 10

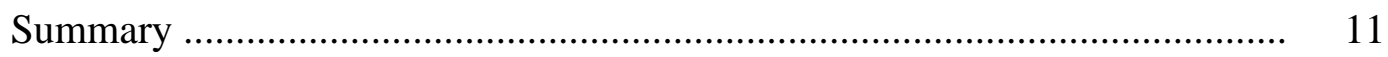

Chapter II - Review of the Literature .......................................................... 12

Introduction .............................................................................. 12

Kohlberg's Stage Theory ................................................................... 14

Feminism and Research in Moral Development ....................................... 18

Women and the MJI and the DIT ....................................................... 30

Moral Reasoning and Moral Behavior .................................................. 33

Rest's Four Component Model ..................................................................... $\quad 39$

Education, Special Education and Morality ................................................... 42

Methods .......................................................................................... 46

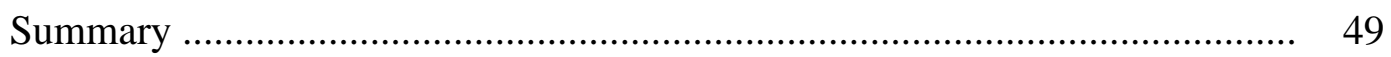


Chapter III - Methods .............................................................................. $\quad 50$

Restatement of the Purpose of the Study ........................................................ 50

Restatement of the Questions Guiding the Study .......................................... $\quad 50$

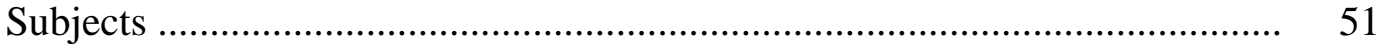

Phase 1 .................................................................................. 51

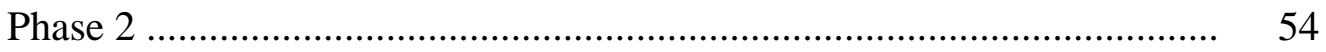

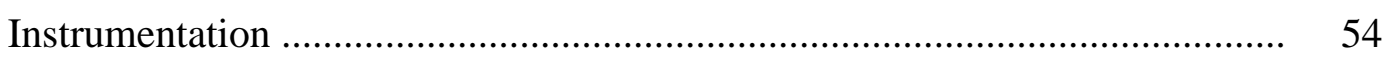

The Delphi Procedure …………………………………....................... 54

Demographic Data ............................................................................. 56

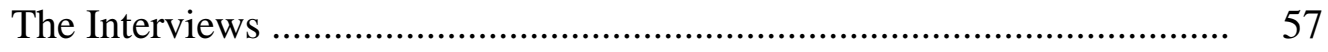

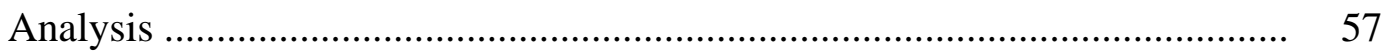

The Delphi Procedures .......................................................................... 57

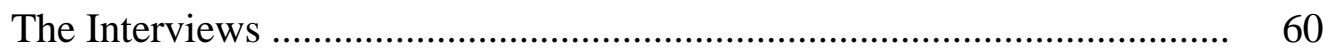

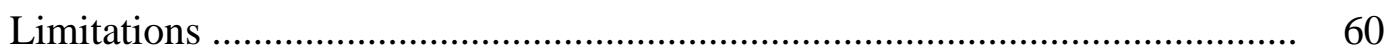

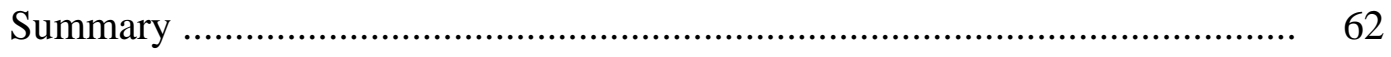

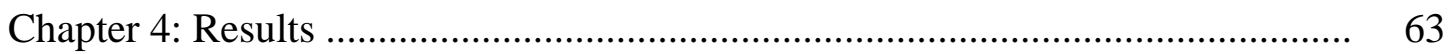

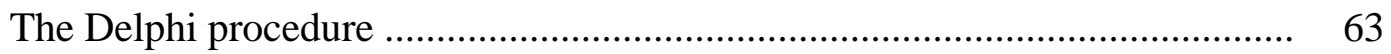

Characteristics of moral dilemmas ........................................................... 63

Processes used in determining an appropriate response .............................. 67

Considerations influencing what action is taken .......................................... 70

Prioritized considerations influencing what action is taken .......................... 73

Summary of Delphi results .................................................................. 76

The moral dilemma scenarios ......................................................................... 77

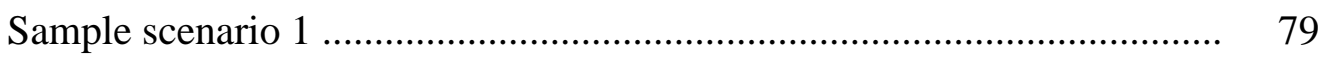

Sample scenario 2 …...................................................................... $\quad 80$ 


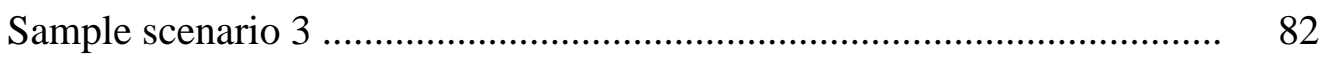

Sample scenario 4 ......................................................................... 84

Summary of the scenario results ............................................................ 84

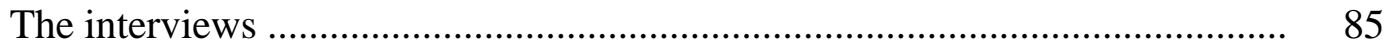

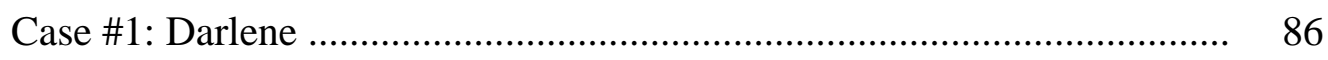

Case \#2: Judith .................................................................................. 107

Case \#3: Beth ................................................................................ 136

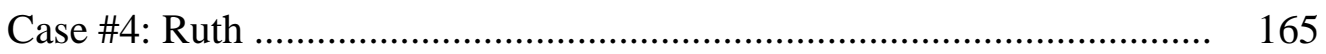

Chapter 5: Discussion ............................................................................... 183

Restatement of the problem and review of the methodology ……..................... 183

Summary and discussion of the findings ................................................... 185

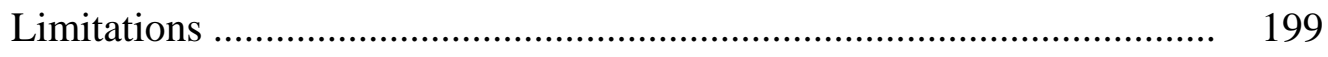

Statement of limitations occurring from researcher bias ............................. 201

Implications for the field of prechool special needs .................................. 201

Implications for moral development theory and research ........................... 203

Recommendations for further research ..................................................... 204

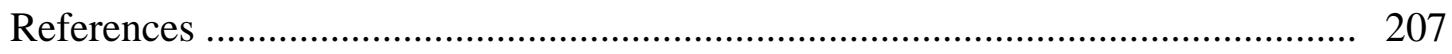

List of Tables

Table 1, Ranked characteristics of a moral dilemma ........................................... 64

Table 2, Ranked processes used to resolve a dilemma ....................................... 68

Table 3, Ranked competing issues ............................................................. 71

Table 4, Prioritized competing issues ……………………………………..... 74 


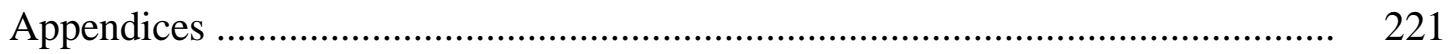

(A) Kohlberg's Stage Theory ............................................................... 221

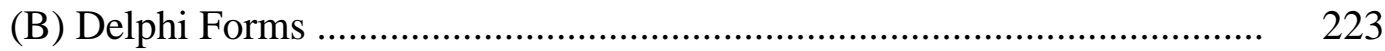

(C) Interview Consent Form …............................................................... 235

(D) County Consent Form ................................................................ 238

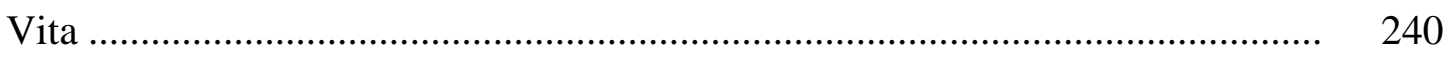




\section{Chapter 1}

$\underline{\text { Problem Area }}$

The inability to convince a majority that a well-delineated class of objectively defined actions is moral or immoral is due, in part, to the fact that some adopt the evaluative frame of an observer, while others adopt the subjective frame of an agent. Philosophers tried to secure a definition that would serve as a universal restraint on actions that were disruptive to a society. Psychologists, who have an empirical bias, are willing to accept the subjective thoughts and emotions of an agent. This realistic position is not frustrated by ethical variation, for it asks only what is treated as moral by a particular person (Kagan, 1984, p xxii-xxiii).

\section{$\underline{\text { Introduction }}$}

In any discussion of teaching as a moral enterprise, it is critical to distinguish between the teacher as the person who imparts moral information to children and the teachers themselves as moral agents. The literature is full of discussions regarding methods for producing a moral child and discussions of what it means to be moral in a democratic society. Advocates for character education, on one side of the discussion (Benninga \& Wynne, 1998; Etzioni, 1998; Glanzer, 1998; Lickona, 1998), view moral development as a process of socialization in which individuals are instructed in moral principles. This instruction is then followed by rote practice, enforced by the social environment, which is believed to develop habits of moral judgment and behavior. These habits are what will carry the individual through times of moral trial. Debate among proponents of character education revolve around questions of whose value system will guide character education (Feinberg, 1990; Fenstermacher, 1990; Goodlad, 1990; Snarey \& Pavkov, 1992; Strike, 1990) Constructivists (Kohn, 1997, 1998; Noddings, 1992; Snarey \& Pavkov, 1992), on the other side of the discussion, posit a far more active role on the part of the individual, in the development of their sense of morality. Debate among constructivists revolves around questions of universality versus relativity (Kohlberg, 1971; Snarey \& Pavkov, 1992). 
From a less philosophical perspective, some excellent studies have examined the teacher's conscious and unconscious responsibility for establishing a moral tone in the classroom, and for acting as a moral model for students, as well as the delivery of overtly moral lessons (Jackson, Boostrom, \& Hanson, 1993; Noblit \& Dempsey, 1996; Sockett, 1989, 1991). Clark (1990) expresses this aspect of the teacher's moral role by stating that "...morally responsible teaching is difficult, complex, and sometimes painful and thankless work. Teaching is a fundamentally moral enterprise in which adults ask and require children to change in directions chosen by the adults."

On the other hand, the literature discussing teachers as themselves moral agents is limited. There is even less written regarding special education teachers. Yet, nowhere is the range of moral challenges more evident than in the field of preschool special needs, where teachers' responsibilities are not only to students but also to themselves, the community, their students' families, administrators, colleagues, and a variety of related service personnel (Bowe, 1995; Gallagher, 1992; Sokoly \& Dokecki, 1992; Yonovitz \& Shipps, 1992). In such a complex role, moral dilemmas are very likely to occur. In a recent survey of special educators (Bennett et al., 1992), one third of those interviewed stated that "...their job roles had at times conflicted with their personal code of ethics (p. 246)." Among the issues cited were "...labeling of children without confirmation of testing, not placing children in the least restrictive environment, lack of individualized services, and neglect in explaining parent and child rights (p.246)."

Despite these many challenges, relatively little has been written regarding teachers as moral agents. Those publications that do address the teacher as moral agent tend to be limited to discussion of professional obligation and outlining possible and actual solutions to moral problems that have made their way into the legal system (Howe \& Miramontes, 1991; Katz \& Ward, 1989; Strike \& Soltis, 1985). While these are invaluable sources of support for teachers, they only just begin to cover the range of moral challenges faced by those teachers and do not even begin to address the perceptions of moral agency among teachers. 


\section{$\underline{\text { Background }}$}

It would be helpful to give definitions of terms at this point. Yet, any definitions would be arbitrary since there is so much continuing debate over the meaning of moral terms. In philosophical circles morality is sometimes defined as a specific code of behavior, and ethics is sometimes defined as the formal study of all moral codes (Angeles, 1981; Rich \& DeVitis, 1985). In practice, the difference between the terms "morality" and "ethics" is less clear-cut (Rest, 1994). The words are often used interchangeably and their meaning is typically left to be construed entirely from the context of the statement that contains them. This imprecision should be the subject of further study. For a researcher to assume specific definitions for moral terms would inevitably exclude much of what the participants in a study have to say about their own experiences. In life and in research, morality and ethics are what people think they are. Nonetheless, the author has chosen to use the more common terms "moral" and "morality" throughout the text, and to altogether avoid the terms "ethics" and "ethical." Operationally, the author considers a moral dilemma any conflict between interests or values. These may occur between individuals or within the same individual.

Philosophers have debated for millennia the question of whether moral principles are universal and generalizable or whether they are socially constructed and relative to the particular circumstances in which an actor finds himself. Historians of morals tend to side with the relativists. MacIntyre (1963) observes that "Moral concepts are embodied in and are partially constitutive of forms of social life," and as a consequence, "...moral concepts change as social life changes (p. 1)." Murdoch (1956) chastises philosophers for their efforts to concretize the language of morals. "In construing meaning for purposes of ethics, philosophers have been anxious to keep as near as possible to a model suitable for simple empirical terms. 'Good' is to have meaning in the same way as 'red', ... (p.41)." Both philosophers and researchers often assume that moral issues can be defined independent of the perceptions of individuals (Thoma, 1994).

Murdoch's comments (1956) were made in the context of a discussion of whether morality or ethics can be meaningfully examined in terms of the individual's efforts at self-creation. In this 
view, individuals (at least some) have an image of the trajectory of their lives (a story or fable) which structures their self-concept. In an over-simplification of this perspective, the moral act is that act that will propel the individual along the trajectory envisioned in the 'fable' and conforms to this 'image.' "Whether a particular argument is rational...or moral is something which we decide, in ways which are hard to summarize, by considering the weight and coherence of the total attitude...(Murdoch, 1956, p. 56)." In referring to research on moral behavior, Murdoch (1956) adds, "If, however, we go back again to the data we see that there are fundamentally different moral pictures which different individuals use or which the same individual may use at different times (p. 57)." More recent work in this vein has been given the name of narrative psychology (Day, 1991; Tappan \& Brown, 1991). Day (1991) describes the value of this approach for research by stating, "...the narrative approach is especially suited to those whose effort is to understand behavior in context, including the context of time--that events and their participants have histories and occur with implications toward futures that also figure in the storied construction of the participants' accounts of their conduct (p.306)." Day (1991) provides an example of what Murdoch termed a story or a fable. He describes a young woman who, because of her Jewishness and her knowledge of prejudice, held a strong self image as someone who does not discriminate and was shocked to find that she routinely devalued the opinions of African-Americans. For this woman, her self concept (fable) allowed her to recognize her failure and thus take actions designed to further her fable; her image of herself as a champion of fairness.

Early research-based knowledge about morality came from ethnographic studies. These studies clearly assumed that morality was socially constructed and varied from society to society (LeCompte \& Preissle, 1993; Spradley, 1979). Methods in these studies consisted of living closely with the subjects, observing them, and asking them to explain how things were done and what meanings they attached these practices. Psychoanalytic explanations, following clinical and ethnographic observations of human behavior, posited psychological structures responsible for the development of self-concept and broader social understanding, of which moral development forms a part (Damon, 1983; Erikson, 1963; Rich \& DeVitis, 1985). Following the structural stage theory 
developed by Piaget in his study of cognitive development, Kohlberg $(1969,1971,1984)$ has searched for empirical evidence of universal stages of development in moral reasoning. He has used the results of his studies to support the philosophical position that there are universal moral principles that ought to be accepted by all (Kohlberg, 1971). Additionally, he posits that moral development is independent of other cognitive structures. Kohlberg (1979) states: "Whereas Loevinger seeks to capture in her ego stages the interpenetration of ego development, cognitive style, self concerns, and moral or character development, we take these different aspects of functioning as governed by different cognitive structures (p. 6)."

The development of valid, reliable, quantifiable measures of moral reasoning based on Kohlberg's work (Kohlberg's Moral Judgment Inventory, and Rest's Defining Issues Test) has had great appeal. Rest (1994) estimates that well over 1000 studies have been carried out using Kohlberg's research as a theoretical basis. Researchers in the field of applied ethics have used Kohlberg's model to assess moral development among the members of various professional groups (Rest \& Narvaez, 1994a). More recently Kohlberg's and Rest's work have been used as the basis of efforts to develop measures of moral reasoning specific to the professions by substituting hypothetical dilemmas that are more familiar to practitioners in those disciplines (Rest \& Narvaez, 1994b).

Explicit in much of this work is the assumption that increases in the level of a person's moral judgment will translate into an increase in moral behavior (Blasi, 1980; Kohlberg, 1984; Rest, 1994; Thoma, 1994). This has led to other research demonstrating that levels of moral judgment can be influenced by various educational interventions (Armon, 1998; Tippins, Tobin, \& Hook, 1993). The purpose of these studies is to find methods for influencing moral behavior indirectly through interventions designed to increase the subjects' levels of moral reasoning.

While some studies have shown that moral reasoning can indeed be influenced by instruction, the research does not support a strong correlation between levels of moral reasoning and moral behavior (Blasi, 1980; Hahn, Smith, \& Block, 1971; Rest, 1994; Turiel, 1983). These findings have led researchers to reconsider competing theories of moral development in an effort to better explain, 
predict, and influence moral behavior. Thoma (1994) states that "...for many, the degree to which we can understand moral action is the acid test for the whole research endeavor (p. 199)." Rest has also come to see the shortcomings of Kohlberg's conception when attempting to explain the concrete behavior of individuals (Rest, 1984; Rest, 1994; Thoma, 1994). This has led him to attempt a synthesis of theoretical approaches to moral behavior resulting in the development of his Four Component Model: "1) Moral Sensitivity, (interpreting the situation), 2) Moral Judgment, (judging which action is morally right/wrong), 3) Moral Motivation, (prioritizing moral values relative to other values), and 4) Moral Character, (having courage, persisting, overcoming distractions, implementing skills) (Rest, 1994, p. 23)." Rest (1994) presents this model as a "...framework for viewing disparate literatures...[and] a theory of what determines moral behavior (p. 23)."

Turiel and his colleagues have further refined our understanding of the domain of moral sensitivity by confirming that individuals distinguish between moral, conventional, and personal domains of choice (Smetana, 1981; Turiel, 1983). Further, these researchers have found, in their studies using non prototypical dilemmas (situations that require the coordination of more than one of the three domains) "...that the moral considerations are not always regarded as prevailing over conventional ones (Turiel, 1983, p.115)." This finding has great potential explanatory power in cases of apparent moral failure.

\section{Statement of the problem}

The traditional approach to studying moral development among professionals consists of identifying a group of individuals, administering either the Moral Judgment Inventory or the Defining Issues Test, tabulating the results and developing a mean score of moral reasoning for the profession represented by the specific group of participants. The statistic that is most frequently used to report levels of moral development is the P-score (Rest, 1994) which ranges from 0 to 95. Among studies of the moral development of teachers, MacCallum (1993) has reported a mean sample P-score of 39.5, Johnston (1989) has reported average sample P-scores of 24.7 (preintervention) and 37.7 (post-intervention), and Johnston and Lubomudrov (1987) have reported an 
average sample P-score of 27.75. These scores would seem to indicate that teachers score at or below the conventional level of moral reasoning (reliance on social conformity). These scores are near or below the average adult score of 40.0 (Rest, 1994). It is quite possible that these scores are anomalous, given that many studies do not publish the specifics of sample scores. Nonetheless, these studies and others have lead many researchers to conclude that teachers typically reason at levels well below the average adult, college student, military enlisted man, and graduate students in business (Chang, 1994; Rest, 1994; Stein, 1995). Even more disturbing is the suggestion that among special education teachers mean levels of moral reasoning are even lower than those for the general population of teachers (Stein, 1995).

Feminists have criticized much of this research (Belenky et al., 1973; Gilligan, 1993; Noddings, 1986). They argue that Kohlberg's conception of moral development is normed on men and represents a justice orientation toward moral issues. They assert that women's development has a different trajectory and is more accurately characterized as an ethic of care orientation. This argument has important implications for any study of the profession of teaching in the public schools. Public schools are predominantly staffed by professional women. Consequently any sample selected will consist primarily of women.

These findings about the moral reasoning abilities of teachers, to say the least, are counterintuitive and, if accurate, are contrary to what society would desire to find in a group of individuals that has so great an influence on the character and well-being of many people. One would hope for more from a group such as preschool special needs teachers, who face many highly complex and difficult issues in addition to those faced by teachers of typically developing children. Recent changes in special education law have called for teachers to work in collaboration with families and professionals from other disciplines in the development of plans for the education of children with disabilities and the implementation of those plans (IDEA, 1997). Additionally, there are professional codes of ethics that have a bearing on teacher perceptions and behavior. These codes contain standards for meeting sometimes incompatible responsibilities and obligations to employing institutions, community, individual students and their families, and the teacher's own 
personal and family responsibilities. These competing roles and responsibilities have greatly increased the likelihood of conflicting values and require teachers to juggle a multitude of competing allegiances.

How do teachers perceive these conflicts and how do they handle them? These two apparently simple questions encompass all four of the components identified by Rest (1994) as determining moral behavior. Yet, until recently, moral judgment researchers have failed to ask these questions. These researchers have relied heavily on hypothetical situations that are assumed to present a moral dilemma. This research assumes that moral situations can be defined independently of the perceptions of the participants and that there is a direct correlation between moral reasoning development and behavior. Rarely do researchers ask subjects if they believe the hypothetical situation contains a moral dilemma. Thoma (1994) states that "...moral judgment theory does not help us define the domain of moral situations, nor do we know when subjects identify it as such (p. 200)." Turiel (1983) and his colleagues have shown that individuals distinguish between moral, conventional, and personal domains of choice but methodologically, these categories are presented to individuals as a basis for sorting various events. As such, it is not clear that subjects would have identified these domains spontaneously.

Harrington (1994) observes that "...we seem to seldom question how teachers know or should know - their epistemological beliefs and development (p. 193)." What is needed is a research base grounded in the perceptions of moral agency of teachers themselves. Whether you accept Kohlberg and Rest's developmental trajectory of moral reasoning, what is needed is some baseline information for how teachers spontaneously perceive and respond to problems in the classroom. This baseline information is essential in the effort to explain the poor showing of teachers on standardized tests of moral reasoning. How do we interpret this apparent failure? Are teachers less developed than others? Are the demands made of teachers so great that they need to restrict their range of consideration when confronted by dilemmas? Is Kohlberg's theory really gender biased and teachers are capable of very high levels of moral reasoning and behavior? 
Clearly, these questions will need to be answered before any profession specific assessments of moral reasoning can be developed, and before any meaningful interventions/curricula can be developed for teacher education programs. It should be noted here that grounded studies of this type will need to be ongoing. Any grounded picture of teachers' experiences will not be a static picture but an ever evolving one. It is expected that research of this type will need to continue as our larger social goals evolve, as society changes, and as educators are expected to work toward new purposes. In Murdoch's words "...there are fundamentally different moral pictures which different individuals use or which the same individual may use at different times (1956, p. 41)."

\section{Purpose of the study}

The purpose of this study was to examine the perceptions of preschool special needs teachers regarding moral issues that arise in the course of their employment. The researcher hoped to begin to explain the findings, based on Kohlberg's and Rest's methods, that teachers score at a conventional level of moral reasoning, in spite of their clear moral charge and moral challenges. At the completion of the study, the researcher expected to have 1) a body of real life moral dilemma scenarios, 2) data indicating broad group consensus regarding moral dilemmas experienced by preschool special needs teachers in the work place, and 3) case studies that explicate the moral fable or story of four preschool special needs teachers.

There were two phases to the research. First, using a three part survey method known as the Delphi method, a large group of preschool special needs teachers were surveyed. The first questionnaire produced a detailed picture of teacher's field experience and provided a body of frequently experienced moral dilemmas or scenarios. These scenarios can be used in teacher education programs to assist in preparing teachers for the challenges they will face on the job. More accurate knowledge of teachers' experiences can also be used to advocate for meaningful supports for teachers in the field.

Questionnaire 1 was analyzed to produce Questionnaire 2. At this point, the data were transformed into more abstract lists of moral characteristics (Moral Sensitivity in Rest's terms), and 
decision making process (Moral Reasoning and Moral Motivation) to look for group consensus regarding moral dilemmas experienced at work. Participants were asked to rank the importance of these items using a Likert scale. The results of these rankings were reported to participants who were then asked to make any changes in their rankings to maximize the agreement among the group. This information can be used to begin development of a profession specific assessment of moral reasoning, and identify areas for further research.

Second, four subjects were interviewed in depth regarding their perceptions of moral agency at work and in their personal lives. The interview protocol was structured in much the same way as the Delphi survey. The results of the survey were used during the interviews to probe for more detail from the subjects. These case studies provide information regarding the development of the individuals' senses of themselves as moral agents within society and the course of their own lifetimes. The researcher hoped to develop an understanding of each subject's story or fable (to use Murdoch's terminology).

\section{$\underline{\text { Research Questions: }}$}

Questions 1-5 address group experiences. Information regarding these questions was provided primarily through the Delphi phase of the research. The interview phase of the research provided greater detail regarding the individual's perceptions of moral agency. Questions 6 and 7 were addressed during the interview phase of the research.

1. What events, occurring in the course of their professional duties, do some preschool special needs teachers consider to be moral dilemmas?

2. From the perspective of these preschool special needs teachers, what specific characteristics of these dilemmas signal that they are moral in nature?

3. What process do these preschool special needs teachers use to determine the proper action to take under the presenting circumstances of a dilemma that they have identified as being in the moral domain? 
4. When preschool special needs teachers make a judgment regarding a moral dilemma, what other factors do they consider when deciding whether or not to act on that judgment?

5. When moral judgments compete with other values, goals, and concerns, how do these preschool special needs teachers prioritize these factors in order to determine the action that they will actually take?

6. Do these preschool special needs teachers feel that they live up to their own standards of moral behavior? If not, how do they resolve the resulting tension and plan for future development?

7. What do these preschool special needs teachers identify as the origins of their moral values and moral beliefs?

\section{$\underline{\text { Summary }}$}

This chapter has briefly outlined the moral development research that lead to this study, described the specific problem area, described the purpose of the study, and detailed the specific research questions that guide this study.

In a complex and changeable world, moral dilemmas are ever present. Teacher preparation programs in early intervention and preschool special needs programs currently include some training in cultural sensitivity and respect for diversity. This is essential due to the age of the students and their closer ties to family and the family's right to self determination. Within these programs there is a need for a greater understanding of moral diversity. One step toward this goal will be to understand the moral experience of teachers. 


\section{Chapter 2}

$\underline{\text { Review of the Literature }}$

\section{$\underline{\text { Introduction }}$}

"Teaching is a constitutively ethical activity. It is a 'moral type of friendship' in which teachers and students work together to construct and achieve common ends (Noddings, 1986, p. 509)." It would be difficult to sum up the basic assumptions of this research more succinctly. Hence, the importance of any study that attempts to record the moral experiences and perceptions of teachers. Noddings clearly places her emphasis on the relationship between the teacher and the student (Noddings, 1984, 1986). There are other relationships to which the educator must attend.

The preschool special needs teacher occupies a unique intersection of human rights, responsibilities, and obligations. She must work to coordinate and mediate between federal, state, and school district laws and policies (Howe \& Miramontes, 1992; IDEA, 1997), community perceptions and expectations (Strike \& Soltis, 1998; Bennett et al., 1992; Yonovitz \& Shipps, 1992; Gallagher, 1992), family rights and goals (Bowe, 1995; Howe \& Miramontes, 1992; IDEA, 1997; Sokoly \& Dokecki, 1992; Yonovitz \& Shipps, 1992), the needs and rights of individual students (CEC, 1995; IDEA, 1997; Howe \& Miramontes, 1992; Katz \& Ward, 1989; Yonovitz \& Shipps, 1992; ), school administrative demands and expectations (Pugash, 1992), standards expressed by professional codes of ethics (Bredekamp \& Copple, 1997; CEC, 1995; Katz \& Ward, 1989; Strike \& Soltis, 1998), competing interests and goals of related service professionals (Bennett et al., 1992; CEC, 1995; IDEA, 1997; Yonovitz \& Shipps, 1992), and, not least among these but notably absent from the literature, her own rights, interests and goals.

Competing rights and obligations are the core of all moral dilemmas. The preschool special needs teacher, as a consequence of this large number of competing interests, is far more likely to encounter moral dilemmas than many other teaching professionals. This provides a potentially rich environment for the study of professional perceptions of moral agency. At the same time, these 
competing interests illustrate the need for an understanding of professional perceptions in order to develop supports for preschool special needs teachers.

In recent years, the field of applied ethics has grown (Rest, 1994) and there has been an increase in research based on profession-specific dilemmas with the goal of developing profession-specific instruments for the assessment of moral reasoning (Chang, 1994; Westbrook, 1994). Much of this research has been based on Kohlberg's work on the development of moral reasoning that clearly assumes that moral development represents a structural change of the whole, and that moral reasoning correlates directly with moral behavior (Kohlberg, 1984; Kohlberg, 1971). Neither of these assumptions has been born out by the research (Blasi, 1980; Haan, Smith, \& Block, 1971; Rest, 1994; Thoma, 1994; Turiel, 1983).

Based on the assumption of a correlation between moral reasoning and moral behavior, the vast majority of studies of moral development have relied on interviews based on a discussion of hypothetical situations (Turiel, 1983). However, it has been noted that individuals perform at different levels of moral reasoning when real consequences are involved and in different contexts (Damon, 1983; Keller \& Edelstein, 1991; Krebs, Vermeulen, Carpendale, \& Denton, 1991; Turiel, 1983; Wark \& Krebs, 1996). Clearly, we have very little research-based knowledge of how individuals themselves define and experience moral dilemmas (Thoma, 1994). Turiel (1983) has conducted some interesting studies where subjects are probed for their conceptions of domains of action. The problem with this research, suggestive as it is, is that the method tends to elicit a particular range of responses and may not reflect the spontaneous descriptions which subjects use to describe their experience (Krebs et al.).

Early studies of morality concentrated on experimentally established dilemmas carried out in real-time under direct observation of the researcher. These studies examined such issues as cheating (Canning, 1956; Dienstbier \& Munter, 1971; Hartshorne \& May, 1929; Hetherington \& Feldman, 1964; Howells, 1938; Johnson \& Gormly, 1972), obedience to authority (Milgram, 1963), volunteering to be a bone marrow donor (Schwartz, 1970) and helping behavior (Darley \& Batson, 1973). In a more recent example of experimentally designed dilemmas, Packer (1985) studied the 
real-time dilemmas resulting from a group of friends playing a game called "The Prisoner's dilemma." Gilligan and Belenky (1980), Gilligan (1993), and Smetana (1982) have studied the reallife and real-time moral reasoning of young women faced with an unwanted pregnancy. However, the study of real-life dilemmas in real-time poses methodological barriers, and can itself pose moral dilemmas for the researcher. More recently several researchers have begun to examine moral reasoning and moral behavior by asking participants to describe an actual moral dilemma that they experienced (Krebs \& Denton, 1997; Wark \& Krebs, 1996). This methodology is very promising and is in keeping with a phenomenological goal of identifying the meanings which individuals apply to their professional experiences.

The purpose of this review of literature is to briefly outline the major research trends in the study of moral development, and to explain the importance of a phenomenological approach to the study of moral development. The positivistic approach has lead researchers to predetermine what is or is not a moral dilemma and has neglected to examine the perceptions of the participants in professional life.

This chapter will begin with a discussion of Kohlberg's research on the development of moral reasoning. His work is generally considered to be of high validity and reliability (Blasi, 1980; Damon, 1983; Rest, 1994; Turiel, 1983) and has strongly influenced the research agenda for the study of moral development. This will be followed by a discussion of Kohlberg's critics with an emphasis on the short-comings of his theory relative to moral behavior (Gilligan, 1993; Krebs, Vermeulen, Carpendale, \& Denton, 1991;Turiel, 1983 ). Others have worked to address these shortcomings from within the Kohlbergian tradition (Rest, 1984; Turiel, 1983; Krebs, Vermeulen, Carpendale, \& Denton, 1991) and these theoretical positions will be discussed. The chapter will conclude with a discussion of methodological issues in the study of moral development.

\section{$\underline{\text { Kohlberg's Stage Theory }}$}

The work of Lawrence Kohlberg is extensive and has influenced a large number of researchers. Much of the appeal of Kohlberg's work has stemmed from the high degree of validity and reliability 
of his methodology and the ease of administering the Moral Judgment Interview (MJI). The Defining Issues Test (DIT) which was developed by Rest and based on the work of Kohlberg offers even greater ease of administration. Kohlberg's conclusions themselves rest upon a vast number of studies including a 20 year longitudinal study of moral development and an array of cross cultural studies. Yet, the underlying theoretical assumptions of Kohlberg's work and the conclusions Kohlberg has drawn from his research are relatively simple to describe.

\section{$\underline{\text { Universality }}$}

Kohlberg set out to demonstrated that in the area of moral development, there exist universal stages of moral understanding that represent structural changes in the individuals social understanding. Each stage absorbs and supplants previous stages and each stage represents an individual's dominant mode of perceiving dilemmas (Kohlberg, 1971; Kohlberg, 1969; Kohlberg, 1984). These changes represent "universal ontogenetic trends toward the development of morality as it has been conceived by Western moral philosophers (Kohlberg, 1971, p. 155)." Kohlberg further elaborates this position into an overtly deontic or universalistic theory of morality and concludes that justice is the principle underlying all morality (Kohlberg, 1971; Schweder, 1982b).

Kohlberg sought to eliminate any traces of a relativistic theory of morality (Kohlberg, 1971). This effort is mirrored by the three levels of moral development into which Kohlberg divided his six stages of development. These are, the preconventional, conventional, and the post-conventional levels. The preconventional level is viewed as egocentric and based on individual needs; the conventional level is based on shared moral values, the maintenance of relationships, and an increasing ability to understand the needs and perspectives of others; the post conventional level strives for universalizability of moral principles and the preservation of individual rights (Gilligan, 1981; Kohlberg, 1984). Kohlberg makes it clear that he believes the post-conventional level represents the apex of human moral development. Kohlberg further states that while moral development follows an ontogenetically determined trajectory, what the individual achieves at the higher stages of moral reasoning, regardless of cultural or personal variations, is no less than "...an 
ultimately adequate, universal, and mature conception of morality...(p. 153)." Kohlberg claims to have resolved the age old philosophical debate between deontic and teleological views.

\section{$\underline{\text { Moral behavior }}$}

Kohlberg states (1969) that cognitive stuctures are structures of action. Thus, the primary mechanism of change is believed to be actual problem solving situations rather than the inculcation of culturally specific moral codes. This assumption also leads to Kohlberg's belief that moral reasoning is mirrored by moral behavior. At each stage, in Kohlberg's view, the individual achieves a dominant mode of moral reasoning, and their actions will reflect that mode. Kohlberg cites Socrates and paraphrases his view by stating that "...not only is the good one, but virtue is the knowledge of the good. He who knows the good chooses the good (1971, p. 232)."

\section{$\underline{\text { Stages }}$}

Kohlberg concluded that there are six stages of development in moral reasoning which are shared by all cultures or societies, regardless of local custom or mores. The six stages are clustered under three levels depending upon the logical basis of each stage. These are the preconventional (Level I), conventional (Level II), and post-conventional (Level III) levels. It is not the purpose of this chapter to discuss these stages in detail; the details of the stage theory can be seen by examining Appendix A. Briefly, the three levels represent a passage from a belief that values or morality reside in events or actions external to the individual, to a belief that morality resides in performing socially defined roles, and to a belief that morality resides in a voluntary "conformity ...to shared or sharable standards, rights, or duties (Kohlberg, 1984, p. 44)." It cannot be overemphasized that Kohlberg specifically sees the stages as hierarchic in nature and that achievement of a specific stage precludes the use of previous stages of reasoning (Kohlberg, 1971; Kohlberg, 1969; Kohlberg, 1984). 


\section{$\underline{\text { Cognitive and moral development }}$}

Many of Kohlberg's assumptions regarding development were directly taken from Piaget's cognitive-structuralist theory of stage development (Kohlberg, 1971). However, Kohlberg only partially followed Piaget's lead in the area of moral reasoning. Piaget limited his interest to what might be called a theory of the understanding of rules in early childhood. However, he predicted that cognitive development and moral development would progress simultaneously (Piaget, 1948; Ginsburg \& Opper, 1988; Klein \& White, 1996). Kohlberg agreed that a relationship exists between cognitive development and the development of moral reasoning, but argued that advancement through the cognitive stages identified by Piaget only provided prerequisite skills for advancement through the stages of moral development. Kohlberg further argued that moral development followed a trajectory of its own, divergent from that of cognitive development (1984). Kohlberg (1981) further isolates moral development by stating:

Whereas Loevinger seeks to capture in her ego stages the interpenetration of ego development, cognitive style, self concerns, and moral or character development, we take these different aspects of functioning as governed by different cognitive structures (p. 6).

\section{$\underline{\text { Kohlberg's influence on research }}$}

In describing the influence Kohlberg has had on the field of research in moral development, Rest (1979) lists seven areas of research. These are:

1. Cross-sectional studies of moral development

2. Longitudinal studies of moral development

3. Cross-cultural studies of moral development

4. Studies designed to demonstrate that an individual's level of moral reasoning can be influenced by intervention

5. Studies designed to demonstrate that subjects can understand reasoning at stages of development lower than their own but have difficulty understanding reasoning at stages of development higher than their own 
6. Studies examining correlations between stage of moral reasoning and individual characteristics

7. Studies aimed at identifying prerequisite components of moral judgment.

The number of studies influenced by Kohlberg's stage theory has increased since that time and now includes an enormous number of studies whose purpose is to examine broad levels of moral development among specific groups of individuals, particularly among the professions. Noticeably absent among Rest's list of specific research projects are studies designed to test a relationship between moral reasoning and moral behavior. Rest simply points out that the validity of Kohlberg's theory does not depend on the existence of such a relationship (Rest, 1979). However, such studies do exist and will be discussed later in the chapter.

\section{$\underline{\text { Feminism and Research in Moral Development }}$}

The field of the education of preschool students with special needs still attracts a predominantly female work force. Consequently, it is relevant to discuss at some length the feminist views of morality, and their critiques of traditional research in moral development. While the goal of this study is to examine the common sense perceptions and beliefs of preschool special needs teachers, it is possible, though by no means probable, that the results of a phenomenological study of those perceptions of moral agency will have some relationship to previous research on the moral development of women.

One of the most ardent critics of Kohlberg's work has been Carol Gilligan. Gilligan's view (1993) is that traditional discussions of morality, and Kohlbergian style research into moral development in particular, center on male constructions of morality that embody the power structure created and perpetuated by men, and ignore or are ignorant of the voices of women. Gilligan argues that male ethics are based on a concern for preserving individual rights and that female ethics are based on a consciousness of relationships and obligations and the lost voice of the self. This female ethic is termed an "ethic of care." 
"In a Different Voice" (1993), is Gilligan's most complete exposition of the ethic of care and the research that lead to her views. The basic assumptions that inform Gilligan's work are developed and elaborated throughout the book but are perhaps best expressed in the introductory material that was added to the second edition.

I find the question of whether gender differences are biologically determined or socially constructed to be deeply disturbing. This way of posing the question implies that people, women and men alike, are either genetically determined or a product of socialization - that there is no voice - and that without voice, there is no possibility for resistance, for creativity, or for a change whose wellsprings are psychological (Gilligan, 1993, p. xix).

This quote mirrors the age old philosophical debate between universalistic and relativistic views of morality. Although not expressed by Gilligan, this debate calls to mind the psychoanalytic image of the id and the superego doing battle in the process of identity formation. Here, Gilligan clearly steps out of the debate (as opposed to settling it) by arguing that the basic questions are misguided. Where Kohlberg sees success or maturity in the ultimate victory of the superego, Gilligan sees success in the free action of the individual relative to the actual environment and events of their life. This emphasis on the relationship between identity formation and moral development clearly separates Gilligan's work from that of Kohlberg.

The emphasis on the individual's perception, thought, and action in real life situations is more explicitly developed throughout the book in what might be called a "consequentialist" view of morality; consequentialist because the reason for moral deliberation and action is the desired outcome of maintained relationship or respect for self and others. Here, Gilligan critiques the common tendency to describe moral conflict in terms of competing interests of self and other (Kohlberg, 1984; Rawls, 1971):

Moral problems are problems of human relations, and in tracing the development of an ethic of care, I explore the psychological grounds for nonviolent human relations. This relational ethic transcends the age-old opposition between selfishness and selflessness, which have been the staples of moral discourse. The search on the part of many people for a voice that transcends 
these false dichotomies represents an attempt to turn the tide of moral discussion from questions of how to achieve objectivity and detachment to how to engage responsively and with care (p. xxix).

Here, Gilligan argues that the wrong questions are being asked in discussions of morality regardless of the gender of the individuals involved. Gilligan further argues that not only is there a false dichotomy, but that a more complete picture of moral encounters would also include considerations of the self. For Gilligan this is true for all individuals but she argues that this is a particular issue for women who tend to put aside their own interest in favor of the interests of others:

The differences between women and men which I describe center on a tendency for women and men to make different relational errors - for men to think that if they know themselves, following Socrates' dictum, they will also know women, and for women to think that if they know others, they will come to know themselves. Thus men and women tacitly collude in not voicing women's experiences and build relationships around a silence that is maintained by men's not knowing their disconnection from women and women's not knowing their dissociation from themselves (p. xx).

In an earlier publication Gilligan (1981) makes it clear that she is not outright rejecting Kohlberg's stage theory but is in fact providing a correction to it. This critique is based on what Kohlberg considered to be an anomalous finding among the college students he studied. In his longitudinal study of high school and college students, Kohlberg found that those high school students who scored in the post-conventional ranges of stages 5 and 6 on the MJI, regressed in their sophomore year of college (Kohlberg \& Kramer, 1969). These subjects, who previously had been willing to make unequivocal judgments about moral decisions, began to feel that such judgments were not possible because there are no universal standards for deciding between conflicting actions. 
Kohlberg and Kramer concluded that this apparent regression was a temporary functional change and not a structural change. This functional change served two purposes (Gilligan, 1981; Kohlberg \& Kramer, 1969):

The first was to free initiative and guilt and allow the psycho-social moratorium that Erikson saw as essential to the search for a post-conventional or "neo-humanist" identity. The second was to integrate the adolescents' awareness of the limitations and hypocrisy of conventional moral thought and thus to set the stage for its replacement by the ethical principles whose discovery, in Kohlberg's eyes, would solve the problem posed by relativism (Gilligan, 1981, p. 145).

This confrontation with relativism resulted from the intellectual challenges presented by higher education (Gilligan,1981). By this reading of the data, the lapse into relativism is necessary to allow the individual to meet the developmental challenges of adolescent identity formation as described by Erikson. Thus Kohlberg did not see these results as a challenge to his stage theory and predicted a subsequent return to a universalistic principled conception of morality.

Gilligan, however, proposes a different interpretation of these findings. First, Gilligan cites Colby who concluded that educational interventions designed to promote principled moral judgment are only successful with subjects who were in the conventional stage of moral development and whose thinking was predominantly formal operational (Gilligan, 1981):

However, since formal operations give rise also to moral relativism, this finding led to a discussion of the relationships between relativism and principled morality, which appeared at the center of undergraduate moral concern (Gilligan, 1981, p. 149).

During the undergraduate years, principled and utopian constructions of morality come into conflict with experiential "facts" (Gilligan, 1981) and these individuals come to see that there is no answer to a moral dilemma independent of the "moral construction in which the problem is framed (p. 150)."

Gilligan goes on to discuss the work of Perry who posited a further stage beyond Piaget's formal operations, stating that adult thought is often "post-logical." For Perry formal operational 
thought could be described as "problem solving" and adult post-logical thought could described as "problem seeking." Gilligan and Murphy (1979) analyzed the data from Kohlberg's longitudinal study and concluded that there exist two trajectories for post-conventional moral development. The first is Kohlberg's stage six principled moral reasoning and the second is precisely the "problem seeking" approach to moral dilemmas that is characterized by questioning of the facts of the situation and the nature of the questions asked.

The problem seeking stage of moral development that is parallel to and different from principled moral reasoning is the position which "In a Different Voice" elaborates. It is here that the problem seeking stage of moral reasoning is concretely equated with female patterns of moral development. It is important to an understanding of the current study to look at the studies which Gilligan conducted and on which she has based her perspective. First, the group of individuals who will be studied in this research will unquestionably be made up entirely of women. Thus, the question of gender differences in the trajectory of moral development is of great interest and mitigates against the use of Kohlberg's research as a basis for studying the moral perceptions of preschool special needs teachers.

Secondly, Gilligan and her colleagues use a combination of observation and interview techniques to carry out their studies. Study participants were asked extensively to describe their own views of morality and their experiences in resolving moral dilemmas. One study in particular, the abortion decision study, actually followed the participants as they actively grappled with the decision of whether to have an abortion, and followed up with interviews regarding their feelings about the choices made. This attempt to closely correlate moral reasoning with moral behavior, outside of the moral reasoning and cheating studies, distinguishes Gilligan's work and provides an example of the type of phenomenographic study that is being proposed here.

Thirdly, and perhaps most importantly, these studies provide an example of research that, among other goals, has the goal of "...asking how people defined moral problems and what experiences they construed as moral conflicts in their lives (Gilligan, 1993, p.3)." 
This is an important difference from the work of Kohlberg that employed predetermined scenarios that were presumed to represent the range of moral dilemmas one might encounter. Kohlberg never asked his subjects what they independently considered a moral dilemma. Kohlberg also never asked about everyday types of moral conflict.

The first of these studies, "the college student study," consisted of interviews of twenty-five college seniors who were chosen from a group who had taken a course on moral and political choice (Gilligan 1993). These students were also interviewed five years after their graduation. In addition, sixteen women who dropped the course before completion were interviewed as seniors but apparently were not interviewed in the follow-up phase of the research. The description of the study provides little information regarding methods and analysis. However, Gilligan does state that the focus of the study was on the relationship between identity and moral development. It appears that the interviews consisted of an elicitation of the subjects' self conceptions and their broad conceptions of morality, followed by discussion of the subjects' actual experiences of moral conflict.

The results of this study are twofold. First, Gilligan reports that women interviewed consistently reported their conception of morality as a desire not to hurt others. These women were more likely to describe moral conflict as a conflict of obligations or responsibilities rather than a conflict of rights as reported by men. Secondly, women experienced a lack of "voice" in their desire not to hurt. That is, they felt constrained from considering their own needs when attempting to balance the needs of others. Gilligan (1993) sums up women's dilemma by stating:

The essence of moral decision is the exercise of choice and the willingness to accept responsibility for that choice. To the extent that women perceive themselves as having no choice, they correspondingly excuse themselves from the responsibility that decision entails. Childlike in the vulnerability of their dependence and consequent fear of abandonment, they claim to wish only to please, but in return for their goodness they expect to be loved and cared for. This, then, is an "altruism" always at risk, for it presupposes an innocence constantly in danger of being compromised by an awareness of the trade-off that has been made (p. 67). 
Gilligan describes the morality of women as not only taking a different form (responsibility versus rights) but also as incomplete as women begin to take responsibility in a male dominated social world and begin to consider their own needs and concerns as part of the moral equation.

The second study, termed "the abortion decision study," was designed to ask "...how people defined moral problems and what experiences they construed as moral conflicts in their lives, rather than by focusing on their thinking about problems presented to them for resolution (Gilligan, 1993, p. 3)." Twenty four subjects, selected through convenience sampling methods, participated and were interviewed during the first trimester of their pregnancy and again a year later (Gilligan, 1993; Gilligan and Belenky, 1980). These interviews followed a similar course to that of the college student study with the addition of questions regarding their pregnancy. The second interview included a discussion of the outcome of the subjects' decisions and how they felt about their decisions.

The abortion study was not designed to examine abortion decisions per se. Rather, consistent with Gilligan's belief that identity and moral development are related, it was designed to determine "...how the structures of thought shape the experience of ongoing events and how experience in turn gives rise to new modes of understanding (Gilligan and Belenky, 1980)." Because the researchers were particularly interested in the observation of subjects while they were undergoing a personal transition, the study was designed to observe individuals while faced with an actual moral dilemma.

The results of the abortion study are complex and the original study concentrated on the evidence of a relationship between affect and cognitive change, and the implications for clinical support during crisis periods. Gilligan later came to view the data as providing evidence of a developmental sequence to the ethic of care (Gilligan ,1993). Gilligan found three stages among her subjects; a sequence that mirrors Kohlberg' three levels of moral reasoning. Consistent with the preconventional level of moral reasoning, these women began with a phase where their concern concentrated on personal need and survival, followed by a transitional phase where this concern was criticized as being selfish. In the second stage, equated with the conventional level of moral 
reasoning, these women showed a greater recognition of the individual's responsibility to others, and the interconnectedness of self and other. The individual's obligation to care for others is to the exclusion of concern for self. However, the tension between the needs of self and those of others lead the subjects to reach a new understanding of the relationship between the two. Gilligan (1993) states:

Care becomes the self-chosen principle of judgment that remains psychological in its concern with relationships and response but becomes universal in its condemnation of exploitation and hurt (p. 74).

Following these studies, it remained for Gilligan and her colleagues to test the hypothesis that different developmental trajectories of moral reasoning exist for men and women. The third study, termed the "rights and responsibilities study," was designed to test this hypothesis. It was a crosssectional study of identity, experience of moral conflict, and judgment on hypothetical moral dilemmas. One hundred and forty-four subjects were interviewed:

This study involved a sample of males and females matched for age, intelligence, education, occupation, and social class at nine points across the life cycle: ages 6-9, 1, 15, 19, 22, 25-27, 35, 45 and 60 (Gilligan, 1993, p.3).

At each age, eight male and eight female subjects were matched, consistent with the researcher's hypothesis of different modes of thinking about morality between men and women and the relationship of these modes to the subjects' conceptions of self (Gilligan, 1993). The results of this study were never published independently. Rather, the study was incorporated into Gilligan's over all theoretical concerns and interwoven into her book. Consequently, a critical analysis of this study is not presently possible.

Gilligan clearly believes her studies provide evidence that women experience different life crises, that women experience these crises differently than do men, and that women's development is still in progress. Indeed, Gilligan states that as women's experience is better understood, we will develop a new and broader understanding of human development and a more generative view of human life. Gilligan acknowledges her debt to the work of James Gilligan (1976) where he makes a distinction 
between morality and psychology, calling for the transcendence of morality. Carol Gilligan's formulation of the merging of justice and care ethics is reminiscent of James Gilligan's transcendence of shame and guilt ethics:

The fundamental distinction between moral and psychological thought is that morality structures interpersonal relations so as to set up moral dilemmas or mutually exclusive choice situations (in which one person can be helped only if another is hurt), even where such dilemmas are not forced on the self by objective circumstances, whereas psychology works constantly to transcend the dichotomy between egoism and altruism, shame ethics and guilt ethics, by finding ways to structure relationships not only in thought but in reality, so that the individual can meet other people's needs through meeting his own (Gilligan, 1976).

Gilligan here makes the further point that moral dilemmas are not inherent in the environment but are dependent upon the individual's mental construction of events. While James Gilligan was making a visionary statement for all individuals regardless of gender, Carol Gilligan sees the source of change in an understanding of women's experience.

The implication of this work for the study of moral development is an assumption of moral relativism. This recognition of the different constructions of moral dilemmas depending on the specific actors and their specific circumstances is very different from the traditional or Kohlbergian approach that views different constructions of moral dilemmas as evidence of lower levels of development. This clinical blindness is complicated by the methodology of asking subjects to judge predetermined scenarios rather than asking about the subject's actual experience. Gilligan avoids this problem by questioning subjects about their actual experience of trying to resolve a moral dilemma. Gilligan's work also points to an understanding that people judge different events using a variety of levels of moral reasoning depending upon the circumstances presented. In the end, Gilligan (1993) calls for a merging of the justice and care ethics as we continue to elaborate a more detailed and inclusive theory of human development.

Belenky et al. (1997) conducted a large scale phenomenological study of women's sense of identity and personal development (including moral development) which adds greater weight to 
Gilligan's work. This study consisted of in-depth interviews of 135 women over a period of five years. These women were selected from current college students, recent college graduates, and women who were currently clients of parenting information organizations. The structure of the study was based on the work of William Perry who studied the "epistemological development of students (Belenky, et al. 1997, p. 9)." Perry developed a "map" or developmental sequence of positions relative to knowledge that are reminiscent of the stages of moral development laid out by Kohlberg, with the exception that Perry sees relativism as the final and appropriate end point of development (Belenky, et al. 1997).

In Perry's view, individuals pass through four positions. First, there is basic dualism that views the world in terms of polarities; good/bad, right/wrong, etc. Here knowledge is absolute and passed on through authority. Second, there is an understanding of multiplicity. Here the individual comes to recognize that authorities may not always have the right answers. There is a growing recognition that the individual's opinion is as good as anyone else's. Third, relativism subordinate is characterized by the beginnings of an analytic approach to the multiplicity of perspectives. Finally, for Perry, there is full relativism in which the individual comes to understand that "...truth is relative, that the meaning of an event depends on the context in which that event occurs and on the framework that the knower uses to understand that event...(Belenky et al., 1997, p. 10)."

Based on their analysis of their interview protocols and reflecting the work of Perry, Belenky et al (1997) describe three "epistemological perspectives (p. 15)" which women take. The authors do not make any attempt to ascribe stage like properties to these perspectives. However it is difficult not to see them as hierarchic in nature. The first perspective described is silence. Here women are unable to voice their own views and are unable to learn from the language of others. Second, the stage of received knowledge is similar to Perry's basic dualism. Third, subjective knowledge

Belenky and her colleagues were not specifically concerned with the moral judgment stages of their subjects. However, they report that the interview protocols were designed to include questions which would allow subjects to be scored using Kohlberg's criteria for moral development. Unfortunately, the results of this scoring are not reported. Regardless, it is easy to see the 
implications of this study. Firstly, by stating that all knowledge, even moral knowledge, is contextual it becomes apparent that the development of personal identity, epistemological development, and, perhaps, general cognitive development are intimately related to moral development and moral perspective; a position which Kohlberg specifically denies.

Second, it points to the importance of an inductive and phenomenological approach to research in moral development. This approach emphasizes the personal perspective and experience of the knower as these affect the identification of and construction of moral dilemmas. Kohlberg's research and much other research is based on the traditional epistemological perspective that the knower and the known are separate and that an objective understanding of the world is possible. The implication of this for research into moral development is that ways of being and knowing which emphasize interrelationship and connectedness are at best categorized as lower levels of development and at worst are ignored altogether (Gilligan, 1993; Belenky et al., 1997). More recent research paradigms that acknowledge the relationship between the observer and the observed are better suited to research in this area (Belenky et al., 1997; Seigfried, 1989; Skrtic, 1995a, 1995b).

Kohlberg's method of assessment was designed to assess the individual's highest level of reasoning. Kohlberg made the assumption that individuals develop a dominant form of reasoning that translates into practice in real life situations. However, later research has not supported this belief in a direct relationship between reasoning and action(Blasi, 1980; Haan, Smith, \& Block, 1984; Rest, 1979, 1994) and has suggested that individuals typically use a variety of modes of moral reasoning (Rest, 1979). The source of variation in the use of moral reasoning has been the focus of much recent research. Further, an understanding that knowledge is contextual changes the practical questions to be asked by moral educators. Where Kohlberg asked, How do we get people to the highest level of moral reasoning?, feminist theorists (if not others) ask, How does the individual develop conviction in the face of relativism (Gilligan, 1993; Belenky et al., 1997)? One might also ask, what forms of reasoning do individuals use in the face of a real dilemma that has real consequences? 
Noddings $(1984,1994)$ makes an even more pointed critique of the traditional approaches to ethics:

Much current work, for example, focuses on the status of moral predicates and, in education, the dominant model presents a hierarchical picture of moral reasoning. This emphasis gives ethics a contemporary, mathematical appearance, but it also moves discussion beyond the sphere of actual human activity and the feeling that pervades such activity. Even though careful philosophers have recognized the difference between "pure" or logical reason and "practical" or moral reason, ethical argumentation has frequently proceeded as if it were governed by the logical necessity characteristic of geometry. It has concentrated on the establishment of principles and that which can be logically derived from them. One might say that ethics has been discussed largely in the language of the father: in principles and propositions, in terms such as justification, fairness, justice. The mother's voice has been silent. Human caring and the memory of caring and being cared for, which ... form the foundation of ethical response, have not received attention except as outcomes of ethical behavior (Noddings, 1984, p. 1).

Here, Nodding indirectly provides the beginning of an answer to the question of why one ought to be moral by pointing out the beginnings of moral development in the individual's memory of lived events. Noddings also appears to call into question the now traditional distinction between moral reasoning and moral behavior by linking the affective aspects of morality with the cognitive aspects.

Noddings also emphasizes the particularity of moral dilemmas. This view echoes the problem seeking approach which Gilligan found among those subjects who had otherwise scored poorly on the moral judgment inventory. These subjects, rather than attempting to simply answer the questions with the available information, were concerned to know more about the individuals involved and the events that lead to the conflict; that is, to clarify the particularity of the situation. Noddings (1984) states:

Since so much depends on the subjective experience of those involved in ethical encounters, conditions are rarely "sufficiently similar" for me to declare that you must do what I must do. 
There is, however, a fundamental universality in our ethic, as there must be to escape relativism. The caring attitude ... is universally accessible (p. 5).

Here Noddings sounds a slightly different note than Gilligan, and Belenky, et al in her desire to avoid the appearance of relativism while maintaining a commitment to the particularity of each dilemma. Indeed, Noddings (1994) takes the concept of caring and relatedness one step further by linking them with the concept of universality:

Rather than ascribing as valid to all others any maxim that I can will to be a universal law, I must submit my maxim to all others for purposes of discursively testing its claim to universality (p. 1).

Thus, for Noddings, there can be no universality without relatedness and the agreement of others.

\section{Women and the MJI and the DIT}

Gilligan has popularized criticism of Kohlberg's stage theory by making the claim that the women studied tended to score at lower levels of moral development than do men. She further states that the average woman studied tended to score at stage three on Kohlberg's scale and the average man tended to score at stage four (Gilligan, 1981, 1983, 1993; Gilligan \& Belenky, 1980; Gilligan \& Murphy, 1979). This view has a great deal of intuitive appeal and has been accepted by at least a few other theorists (Belenky et al., 1997; Noddings, 1984). Yet Gilligan provides precious little evidence (and no data) to support this claim.

Rest (1979) addressed the issue of sex differences in research based on the Defining Issues Test. He discusses a review of twenty-two studies that looked at sex differences and states that only two of the studies examined showed significant differences between the scores of males and females. Of these two, only six percent of the variance is accounted for by gender. Ironically, in these two cases, the female subjects scored higher than did the males studied. Armon and Dawson (1997) in a longitudinal study of moral reasoning development found no significant gender differences. 
Walker (1984) in a review of one hundred and eight studies also examined the allegation of sex differences in moral development as assessed by the Moral Judgment Inventory and the Defining Issues Test. His review did not include any of the studies examined by Rest. Also, in anticipation of the possibility that sex differences might appear at different ages of the subjects, Walker's metaanalysis of the studies was divided into the somewhat arbitrary (as acknowledged by Walker) groupings of childhood and early adolescence, late adolescence and youth, and adulthood.

Walker concluded that of the one hundred and eight studies, only eight showed any significant difference in scores between male and female subjects. Of these studies showing differences, Walker states that they were methodologically flawed by confounding sex and occupational and educational factors. He further states that most of these studies used the old scoring method for the Moral Judgment Inventory. Kohlberg (1984) states that this method tends to highlight gender differences. Methodologically, this may not be a significant criticism of the studies, as the revised scoring system was developed following the findings of Haan, Smith, and Block (1968) who administered the MJI to participants in the free speech movement. Haan et al. were not looking for sex differences in stage scores and found that most of the politically active participants were at either stage two or stage five of Kohlberg's sequence. This finding conflicted with Kohlberg's prediction that (assuming participation in political action is apriori a moral choice) participants would score in the principled range of moral development. To correct for this finding Kohlberg reanalyzed his scoring criteria. As a result, most of the participants who had previously been scored at stages two and five, were scored at stage four and a transitional stage from four to five. An unintended effect of this re-scoring was the elimination of gender differences when protocols were re-scored. Kohlberg and his colleagues have been criticized for their continuous changes in methods and procedures in the administration of the MJI (Kurtines \& Grief, 1974).

Regardless of which scoring method was employed, no significant differences were found in the overwhelming majority of the studies. Walker concludes by stating:

At the same time it is important to realize ... that the lack of stage disparity in moral reasoning between males and females does not preclude the possibility of sex differences in content within 
a stage (e.g. reliance on particular norms) or the preferential use of various orientations in the making of moral judgments (p.88).

Bebeau and Brabeck (1987), in their review of the literature, found similar results. In addition to Walkers review, they cite a study by Thoma that examined 56 samples totaling over 6000 subjects. He concluded that not only did women not score lower than men, but at every age women consistently out scored the men included in the studies. Bebeau and Brabeck conclude from these and other studies that women and men are equally likely to use justice and care responses to moral dilemmas. They do caution that only a small number of studies have been designed to examine this hypothesis specifically and of those, many used small samples and a variety of measures of moral development. Therefore their conclusions are tentative.

Of greater interest to this study is the review of research that examined the responses of individuals when asked to describe a real life dilemma that they had experienced. Lyons (1983, cited in Bebeau \& Brabeck, 1987) and Langdale (1986, cited in Bebeau \& Brabeck, 1987) both found that "...while most males and females use both orientations, females showed a preference for a care orientation and males for justice in these self-identified moral dilemmas (Bebeau \& Brabeck, 1987, p. 192)." On the other hand, other researchers (Nunner-Winkler, 1984; Rothbart et al., 1986; Turiel, 1976) concluded that the choice of moral orientation is not related to the gender of the respondent, but to the type of dilemma in question.

Clearly, moral choice is far more complex than a rating of moral stage can capture. These conclusions add support to Rest's statement (1979) that men and women may score similarly on tests of moral development and still be focusing on different content within moral dilemmas. While these conclusions do not support the standard feminist critique of research in moral reasoning, they do point out that the preferred orientations of men and women are likely to interact with the type of dilemma within real life situations. 


\section{Moral Reasoning and Moral Behavior}

Few would disagree that morality ultimately lies in action and that the study of moral development should use action as the final criterion (Blasi, 1980, p. 1).

Indeed, for many, the degree to which we can understand moral action is the acid test for the whole research endeavor (Thoma, 1994, p. 199).

Research on moral reasoning and development has tended to rely on the use of hypothetical moral dilemmas. In much of this work, subjects are presented with a specific dilemma and asked to decide what action would be most appropriate and to explain how they arrived at their conclusion. These answers are then analyzed according to the particular criteria in which the researchers are interested i.e. moral stages, care vs. justice, etc.. Haan, Smith, and Block (1968) assessed members of the free speech movement using Kohlberg's Moral Judgment Inventory and, contrary to predictions, found that those subjects who participated in active protest tended to score at either stage 2 or stage 5 . It had been predicted that, assuming protest to be a sign of principled moral reasoning, those subjects would score at either stage 5 or stage 6 on the MJI. Following this finding, it has been common to ask the question, How does moral reasoning correlate with moral behavior in real life situations?

Blasi (1980) has undertaken an extensive review of the literature that shed light on this issue. Before going into detail regarding his results, it is important to point out one oddity of this review. Following a detailed and complex analysis of the available research, Blasi concludes that there is considerable support for the relationship between moral reasoning and moral behavior. This conclusion is curiously at odds with the data that includes many studies showing a significant relationship between moral stage and behavior but with remarkably low effect size. Rest (1994) has pointed to this low effect size as proof that the MJI and the DIT are valid measures of moral reasoning development, the argument being that a behavior as complex as moral choice and moral action is dependent upon a large number of factors (moral sensitivity, moral reasoning, moral 
motivation, and moral character). Given this complexity, large effect size would actually indicate poor validity for an assessment of moral reasoning used in research examining the relationship with moral behavior. Nonetheless, Blasi's review is still the most detailed review to date and it helps draw together much of the research that lead Rest to develop the Four Component Model of moral behavior as a response to the criticism that Kohlberg's stage theory provided poor predictions of real life behavior.

The research which Blasi chose to review is that which is specifically concerned with moral judgment and a cognitive theory of moral development. He has intentionally excluded any research that takes a behaviorist, social cognitive, or evolutionary-genetic perspective. Blasi divided the research into five categories for analysis.

The first of these categories examined studies that related moral reasoning and delinquency. Blasi points out two conceptual difficulties with these studies. Among the studies, there is considerable variation in the definition of delinquency and the types and seriousness of the offenses that caused subjects to be classified as delinquent. Further this assumption assumes a trait consistency across reasoning and behavior. However, as Blasi points out, it is likely that many delinquent individuals are characterized by inconsistency of both reasoning and behavior. Keeping these reservations in mind, Blasi reports that 10 of the 15 studies found that delinquent subjects used lower levels of moral reasoning. A further reservation regarding this finding is that, while many studies reported individuals using Stage 1 and Stage 2 reasoning, many other studies reported substantial numbers of delinquent individuals using conventional levels of moral reasoning.

Of those studies that attempted to relate moral reasoning and real life behaviors, Blasi states that the methods for assessing the behaviors are not the most reliable and are subject to "...the halo effect, of the temporary context, and of the idiosyncratic interpretation of the variables themselves (p. 16)." Among these methods, Blasi lists teacher ratings, sociometric nominations, self reports, and observer ratings. Later he states, "Even more important ...is the issue of whether and to what extent the behaviors investigated are relevant to morality and to moral reasoning (p. 16)." He further 
states that the issue of relevance has to do with whether the subjects themselves considered these behaviors relevant. However, none of the studies asked the subjects about their views.

More specifically, Blasi asks questions about the relationship between moral reasoning, and personality development and personality traits in relationship to moral behavior. He argues that the behaviors being assessed by sociometric instruments may be viewed as moral or they may also be character traits that coexist with but independent of moral cognition. Examples of these are ratings of honesty, strength of conscience, organizational participation, altruism, and friendliness.

Of the 12 studies reviewed, 6 reported significant relationships, 3 reported negative relationships and 3 reported mixed results. Blasi draws no overall conclusions regarding the relationship between reasoning and action from these results and states that the studies yielding positive results lead to more questions than answers.

Studies that examined the relationship between moral reasoning and honesty yielded even more equivocal findings. These studies all come under the heading of resistance to temptation (Blasi, 1980). Blasi states, "The general hypothesis is that the more mature is one's moral reasoning, the less one will cheat (p. 17)." Briefly stated, Blasi argues that there is no clearly established functional relationship between reasoning and resistance to temptation and that if one exists much of the effect may be due to other developmental processes. A further methodological problem exists in that many studies include a condition where freedom from detection is guaranteed. For those studies that assume a stage-like development of moral reasoning, this condition would allow those subjects at the conventional level of reasoning to both cheat and feel certain that social stability is maintained (Blasi,1980).

Of the 17 studies related to honesty that were examined by Blasi, 7 studies do not support the hypothesis of a positive relationship between levels of reasoning and honesty, 7 support the hypothesis, and 3 provide mixed results. However, even the positive studies report small effect size. Adding to the uncertainty is that different patterns emerge when studies are grouped by the type of measure of moral reasoning. 
The studies that related moral reasoning and altruistic behavior, viewed globally, provide stronger support to the hypothesis of a relationship between moral reasoning and behavior. Of the 19 studies, 11 report positive results, 4 report negative results, and 4 report mixed results. However, Blasi points out that these studies suffer from many of the same methodological and theoretical flaws as the previous studies. In particular he points out the poor and non-comparable operationalization of the concept of altruism. Further, under this heading are included a variety of hypotheses and theoretical perspectives that further cloud the results. Blasi identifies these as egocentrism, moral realism, authority and rule orientation, equality and equity, and reciprocity. While these may all be implicated in behaviors under the heading of altruism, it is probable that they do not function independently and may function differentially in different situations. Blasi also points out that they are defined differently and take on different roles in different theoretical positions.

The last group of studies reviewed by Blasi are those that related moral reasoning and resistance to conformity. These results are more ambiguous than those of the previous categories. Further, as Blasi points out, it is likely that independence of moral judgment and moral action is likely to be influenced strongly by other psychological factors such as affiliative needs. However, the results of these studies have particular relevance to the present study in that they point to the complexity of moral experience, and the importance of assessing the perceptions and feelings of the specific individuals under study. Quoting Blasi (1980):

Differences in behavior between stages do become more pronounced under certain conditions: when the experimenter is present or when subjects are exposed to the advice to stop. Experiencing a feeling of obligation to the experimenter seemed also to make a difference in behavior...In sum, moral reasoning stages are clearly related to behavioral independence in judgment but less clearly and only under certain circumstances to independence in moral action (p. 37). 
Preschool special needs teachers, as described earlier, are subject to a variety of competing interests. Consequently, any picture of their moral landscape is likely to overwhelm the simple question of the individual's level of moral reasoning.

Thoma (1994), in his brief review of the reviews of the literature draws a similar conclusion:

Overall, the authors agreed that various measures of moral judgment development are related to moral actions however, the magnitude of these relationships is not large. Specifically, the reviews that provide a statistical summary estimate of the strength of the association between judgments and actions put the estimate somewhere within the range of $10 \%$ to $15 \%$ (p. 201). Further, Thoma highlights the importance of the perceptions (moral sensitivity in Rest's term) of subjects within the realm of moral research. This is a curious methodological issue arising within the cognitive developmental tradition that has relied heavily upon Kohlberg's stage theory that views the highest levels of moral reasoning as universal; that is, a deontic view of morality. However, because researchers in this tradition have assumed agreement on what constitutes a moral dilemma, they may have unwittingly contributed to the poor correlation between moral reasoning and moral behavior. Thoma describes this as follows:

...if we claim that Behavior $\mathrm{X}$ is a moral behavior, yet for many of our subjects moral judgments were never used in framing the situation and determining justifiable actions, then our study will most likely find that a measure of moral reasoning is unrelated to Behavior X (p. 201). Again, this implicates many other factors in the study of moral behaviors. The complex picture of moral behavior that arose from the research base is what lead Rest to develop first, the Defining Issues Test and second, the Four Component Model of Moral Behavior. 


\section{$\underline{\text { James Rest }}$}

A stage analysis does not tell us, for instance, how sensitive the subject is in initially detecting that there is a moral dilemma in the first place (Rest, 1994, p.9).

Rest is perhaps best known for his development of an objective instrument for the assessment of moral reasoning development that is based on Kohlberg's stage theory of moral development, known as the Defining Issues Test (DIT). Due to the ease of administration, the DIT has been used to assess the moral reasoning of hundreds of groups of individuals, including men, women, people of different ethnicities, races, professions, intellectual abilities, income, education, and virtually any other characteristic that allows individuals to be grouped. The DIT uses a numerical scale that can be and often is roughly divided into the various stages of development as defined by Kohlberg (Stein, 1995). However, The DIT has low correlations with the MJI. Rest (1979) reports an average r value of .43 .

As Rest (1979) points out, another difference between the DIT and the MJI is that the DIT asks subjects not to identify and justify the most appropriate action, but rather asks subjects "...to evaluate the defining issues of the dilemmas provided (p. 155)." This difference in task appears to provide a slight corrective to the problem of accounting for the individual's definitions of what constitutes a moral dilemma. By emphasizing the nature of the dilemma rather than the solution, the DIT is likely to capture some measure of the individual's moral sensitivity, and perhaps some individual trait characteristics as they relate to moral reasoning. Interestingly, Rest goes to great pains to show that the DIT is a valid measure of a single construct, that is moral development, by examining research which looked for correlations between DIT scores and various psychometric measures. The constructs reviewed by Rest included IQ, aptitude, and achievement measures, measures of moral comprehension, various cognitive developmental measures (including those of Perry, Piaget, and Loevinger), the MJI, the Law and Order Attitude Test, various locus of control tests, and various values assessments. The correlation statistics for all of these measures were low. Of all measures, the largest correlation in this group was $r=.68$ and the lowest $r=.19$. However, as 
reported by Rest, the most consistently high correlations (though still low) were with the measures of moral comprehension. These findings are confirmed by White (1996) who has developed a measure of factors that influence moral decision making among adults.

\section{$\underline{\text { Rest 's Four Component Model }}$}

None of the major theoretical approaches offers an adequate comprehensive view of the psychology of morality: not the cognitive-developmental, the social learning, the psychoanalytic, or social psychology's 'social norm' approach, or the empathy-altruism approach, or the new post-Piagetian information processing approaches, or human decision-making approaches, and certainly not the socio-biological approach (Rest, 1984, p.25).

Rest further states that the study of morality has traditionally been divided into questions of behavior, affect, and cognition with each area being assigned to a theoretical approach. "... behaviorists study behavior, cognitive-developmentalists study cognition, and psychoanalysts study affect (Rest, 1984, p. 25)." He states that each theory deals with only one aspect of moral development and while failing to provide a complete picture, they each can shed light on the overall process. In his view, the apparent conflict between competing theories has resulted less from paradigm differences and more from the aspect of morality that each theory has chosen to examine. Rest agrees with behaviorists that the ultimate point of interest is actual behavior but feels that "The psychologist's interest in 'moral behavior' should be understood to be an interest in the pattern of behavior in real-life contexts with attention to the inner processes that produce the behavior (Rest, 1984, p.26)." Current theory's inability to adequately account for moral behavior lead him to propose a four component model of moral development (Bebeau, Rest, \& Narvaez, 1999; Rest 1984, 1994).

Rest (1984) provides a description of each component, describes the interaction of cognition and affect for each component, and provides examples of research (from a variety of theoretical 
perspectives) relevant to each component. He calls the four component modal "...a framework for viewing disparate literatures (1994, p. 23),..."

Component 1: Moral Sensitivity is defined as "...the awareness of how our actions affect other people (Rest, 1994, p.23)." This is the area where the individual recognizes or fails to recognize that a number of possible courses of action are available and that each will have a different effect on others (Rest, 1984). This is also the point where the individual recognizes that each party involved has different interests and concerns at stake and where the individual's feelings for others come into play. What events the individual identifies as morally relevant will also influence the identification of a moral dilemma.

Under this heading, research in the development of social cognition views moral development as an aspect of broader social awareness (Damon, 1983, 1988) and identity formation (Erikson, 1963; Gilligan, 1983, 1993). Selman (1980) and Hoffman (1976) have examined the role of perspective taking in the development of social awareness and, indirectly, it's role in the development of moral judgment. Kohlberg (1984) acknowledges the important role of perspective taking to moral judgment but does not specifically examine that role in the context of moral sensitivity. Bebeau and Brabeck $(1987,1989)$ have demonstrated that men and women differ greatly in their sensitivity to moral issues but not in their sensitivity to issues of care. This suggests that individuals distinguish between moral and non-moral issues and that moral issues cannot be defined out of context and that subjects differ in their identification of relevant facts. Schweder (1980) has argued that the search for global behavior traits and comparable situations for comparison ignores the individual's ability to discriminate different events.

In an extensive series of studies designed to examine how individuals categorize common events or transgressions, Nucci (1981), Nucci and Nucci (1982), Nucci and Turiel (1978), Smetana (1981a, 1981b, 1993), and Turiel, Hildebrandt, Wainryb (1991), and Turiel and Smetana (1984) have shown that individuals distinguish between moral, social/conventional, and personal issues, and that there are age and gender related differences in these distinctions. Smetana (1981a, 1981b, 1982), in a study of young women contemplating an abortion, found that subjects varied widely in 
their definition of the dilemma as being moral, social/conventional, or personal. It was further shown that this variation in definition was unrelated to the subjects' levels of moral reasoning as assessed using Kohlberg's methodology. Smetana further demonstrated that individuals varied in their ability to coordinate these three domains in cases where moral and personal decisions were in conflict. The results of this study further demonstrated that the choice to have or not have an abortion was unrelated to the subjects' level of moral reasoning. Rather the choice was related to the initial definition of the conflict (Smetana, 1981a, 1981b, 1982; Turiel 1983).

Component 2: Moral Judgment has been discussed above in the discussion of the work of Kohlberg and his colleagues. Rest (1984) states that there are two research foci to moral judgment: those who view moral judgment as the interpretation of social norms, and those who view judgment as following a developmental course that follows the development of an understanding of various social arrangements.

Component 3: Moral Motivation is described as the process of examining competing values (including non-moral values), projecting the outcomes of each set of ideals, and selecting the value to act on. Further there is the question of deciding whether or not to try to fulfill one's moral ideal (Rest, 1984).

Damon (1983) has shown, in experiments with children, that individuals can reason and behave in highly conflicting manners. Darley and Bateson (1973), in an even more dramatic experiment, have shown that individuals' helping behaviors can be influenced by role requirements and time constraints. In this research, a group of seminary students was told, individually, that they must deliver a lecture on the parable of the Good Samaritan. Each was told that they had varying amounts of time to get to the classroom where the lecture was to be delivered. The researchers arranged for each of the students to encounter an unkempt individual who had apparently passed out directly in the path of the students. The results showed that seminary students, who could reasonably be expected to show greater helping behaviors than other individuals, showed decreased helping behaviors as the time constraints increased. Gilligan and Belenky (1980) and Krebs and Denton (1997) have demonstrated that individuals reason at higher levels on hypothetical situations than 
they do in real-life events. One implication of these findings is that individuals, rather than moving through a sequence of stages, retain the ability to reason at previously attained levels.

Component 4: Moral Character is the actual execution of one's intent. This

"... involves figuring out the sequence of concrete actions, working around impediments and unexpected difficulties, overcoming fatigue and frustration, resisting distractions and other allurements, and not losing sight of the eventual goal (Rest, 1984, p. 33)." From a behavioral perspective, Aronfreed $(1969,1976)$ and Bandura ((1969) have shown that what are typically termed moral behaviors can be induced or modified through conditioning of internalized punishment and rewards. These internalized states are termed 'ego strength' or 'self regulation skills (Mischel \& Mischel, 1976; Rest, 1984).' Mischel and Mischel (1976) have demonstrated the interaction of situational variables and self-regulatory behavior. Blasi (1984), Thoma (1987) and Podd (1972) have found evidence of a positive relationship between the formation of a stable self identity, and subjects' level of moral reasoning.

Rest's model provides a more complete description of factors leading to or failing to lead to moral behavior. Taken alone, it presents a linear model of the processes leading to moral behavior but there is evidence of considerable interaction between the various components (Rest, 1984; Bebeau, Rest, \& Narvaez, 1998).

Krebs and Wark (1995) have demonstrated the differences in judgments between real and hypothetical situations, emphasizing the adaptive or survival influences on behavior and judgment. They have also pointed to the interaction of the type of dilemma presented and the individual's stage of development as measured by the MJI (Krebs, Vermeulen, \& Denton, 1991; Krebs, Vermeulen, Carpendale \& Denton, 1991; Krebs and Wark, 1995; Wark \& Krebs, 1996).

\section{Education/Special Education and Morality}

In a study of second, fifth, and seventh grade students and their teachers, Nucci and Nucci (1982) found that teachers respond more frequently to social/conventional transgressions than they respond to moral transgressions. They also found that older children respond more frequently to 
social/conventional transgressions than do younger children. These findings are of interest because they suggest that students are greatly influenced by their experiences in school, and they are consistent with other research that suggests that teachers as a group demonstrate moral reasoning abilities similar to those of recent high school graduates (Chang, 1994) who, as a group have typically achieved the social/conventional stages of moral reasoning as defined by Kohlberg.

Bergem $(1986,1993)$ studied the relationship between a variety of personal characteristics of 83 teacher education students, and performance ratings provided by their supervisors. Bergem states that the results indicate that there is indeed a moral component to teaching. He then concludes that a significant relationship exists between students' levels of social sensitivity and performance ratings but found no relationship between measures of moral reasoning and student performance ratings. This suggests that, while there is a moral component to teaching, teacher educators are more concerned with the mechanics of instruction (social sensitivity) than they are concerned with the moral dilemmas their students will face in their professional lives.

Perhaps the examination of group means has done a disservice to the teaching profession. Other research that does not rely on group means presents a somewhat more positive view of some teachers, and also reveals the profession as far more heterogeneous than has been assumed (Maccallum, 1993). In her study of Australian teachers, Maccallum found that:

The DIT-\%P mean score for the group of 39.5 was lower than expected and closer to the published mean for adults in general (40.0) than the published means of other graduate groups (i.e., 46.4 for staff nurses). The standard deviation of 19.55 and range from 3.3 to 76.7 , resemble the larger variations found in heterogeneous rather than homogeneous adult groups

(Rest et al., 1978) suggesting teachers are a diverse group with respect to moral judgment (p. 3). Johnston (1985) studied the relationship between teachers' DIT scores and their understanding of the concept of "on-task time". The results showed that there was a strong correlation between the subjects "on-task" scores and their DIT scores (.73 was significant at $\mathrm{p}<.01)$. The teachers with higher P scores tended to have a broader definition of "on-task" time and their discussions of the topic centered on contextual factors rather than defining specific observable behaviors. 
In a similar study, Johnston and Lubomudrov (1987) studied 8 teachers enrolled in a master's degree program. These teachers were administered the Defining Issues Test to determine their stage of moral development and were interviewed three times regarding their perceptions and attitudes toward the teaching profession. The results of this study showed that teachers who had higher levels of moral reasoning were far more democratic in their attitudes toward classroom rules and roles. It was also shown that these teachers were more concerned to balance individual and group needs. Johnston and Lubomudrov point out that in spite of their identification of subjects of high and low moral reasoning level, the DIT scores of the pool of available subjects were lower than the average graduate student. In a study of elementary and secondary teachers, Holt, Kauchak, and Peterson (1980) came to similar conclusions.

Novogrodsky (1977), in a study of 35 elementary school teachers examined the relationship between teachers' level of moral reasoning as measured by Kohlberg's Moral Judgment Inventory, and their expressed attitudes toward students as measured by the Minnesota Teacher Attitude Inventory. It was demonstrated that teachers with lower levels of moral reasoning expressed a more authoritarian attitude toward students. Gerety (1980) studied the relationship between moral atmosphere in the classroom and the moral level of reasoning of teachers. No correlation was found. Interestingly, a relationship was demonstrated between moral reasoning level and teacher innovation, and between moral reasoning level and teacher supportiveness.

Johnston (1989), in a study designed to examine the effects of a program to increase teachers' understanding of individualized instruction, found that teachers fell into two broad groups of thought regarding individualization. One group expressed most concern for group performance, felt that poor students were a drain on their energy, and that they (the teachers) knew best what a student needed to learn. The second group expressed more concern for individual interests and contributions to decision making. Further, it was found that there was a positive correlation between these groups and moral reasoning as measured by the Defining Issues Test. McNergney and Satterstrom (1984) examined the relationship between seven personal characteristics and teacher 
performance. They found a modest correlation between ego strength and teaching performance and found no relationship with the other variables, including moral reasoning.

The studies described thus far, while providing suggestive data regarding the relationship between moral reasoning and teacher performance, do not provide information regarding teachers' own perceptions of moral agency in the classroom. Three studies were found which used a combination of research methods, including an interview process that asked teachers to describe a moral dilemma that they had encountered. Joseph and Efron (1993) examined the relationship between teachers' expressed sense of their own moral identity and the teacher's role as moral educator. However, when asked to identify a moral issue which they had experienced, teachers confined their responses to decisions about whether or not to express a moral opinion about a topic and did not discuss dilemmas that required them to make a behavioral choice between conflicting values. The researchers further concluded that many teachers do not feel free to express their opinions regarding moral issues. In studies by Aurin and Maurer (1993) and Yost (1997), teachers again only referred to their moral responsibility to provide meaningful instruction. Teachers did not raise instances of actual moral conflict that had occurred in their work. Rulon (1992) found that teachers were more willing to discuss situations that required a specific moral resolution when they were part of a school wide program to address moral issues.

Oser (1991) and Oser and Althof (1993) distinguish between normative, situational, and professional morality. They believe that professional morality represents a domain specific form of morality, and hypothesized that conflicts occur for teachers when they are called upon to balance considerations of justice, care, and truthfulness. In a study of teachers, Oser (1991) identified five different responses to demands to balance these three concerns. These are avoiding, delegating responsibility to others, unilateral decision making, partial discourse (using a logic believed to be understandable to students), and complete discourse (which assumes the rationality of all those involved). Oser found that these approaches were consistent with the teachers' expressed sense of professional responsibility but did not attempt to relate these behavioral styles to broader measures of moral development. 
These studies present a mixed view of teachers' abilities to recognize and act on moral dilemmas but generally tend to confirm the impression that teachers are less concerned with moral issues than other professional groups of individuals. This is surprising given the almost universal acceptance that education is an intrinsically moral endeavor. One attempt to understand this is a study by Schempp, Sparkes, and Templin (1993). This study followed a group of teachers who had recently graduated from college, as they made their way into their first teaching positions. The results indicated that these beginning teachers were influenced greatly by the culture of the school environment and that their knowledge gained in school was generally devalued by their more experienced colleagues. Many of the subjects expressed the opinion that the pressures to gain and maintain a teaching position out weighed most other considerations. These results suggest that attempts to raise the moral understanding of teachers should be directed toward the school culture as well as teacher education programs.

As discussed earlier in this chapter, teaching is an intrinsically moral activity. Special educators are even more frequently called upon to balance competing values and interests. Given this, it is surprising that only one study was found relating to the field of special education.

Stein (1995) administered the Defining Issues Test to a group of 269 special education teachers representing a variety of disability areas. He hypothesized that due to the increased moral demands of working in the special education environment, special education teachers as a group would have higher levels of moral reasoning. The relationship between moral reasoning and teachers' classroom performance and attitudes also contributed to this hypothesis. Contrary to expectation, this group of special education teachers attained a mean P-score (35.25) even lower than that found for teachers in general.

\section{Methods}

Much of the rationale for this study is based on a critique of the methodology of previous studies of moral reasoning and behavior. Due to this, methodological issues have already been discussed in the review of literature on research in moral development. The purpose of this study is 
not to critique various theoretical models of morality but rather to accurately assess the spontaneous perceptions of moral agency of a group of preschool special needs teachers.

The largest proportion of studies of moral development have been carried out with the use of hypothetical situations (Kohlberg, 1984, 1971, 1969; Rest, 1994,1984, 1979; Rest \& Narvaez, 1994; Turiel, 1983). These studies have contributed greatly to an understanding of the stage development of individuals' moral reasoning. However, it can be argued that the low correlations between moral reasoning and moral behavior point out the limitations of such research (Turiel; 1983). Nucci and Turiel (1978), Nucci (1981), Nucci and Nucci (1982), Rest, 1994; Smetana (1981), and Turiel, Hildebrandt, and Wainryb (1991) in their work on moral sensitivity, have helped to explain some of this dichotomy by showing that individuals distinguish between moral, social/conventional, and personal issues. Here again, there are methodological difficulties. These researchers approached their subjects with lists of common events/transgressions and asked them to sort these events according to the three hypothesized domains of action. This seems to predetermine and limit the range of possible responses of their subjects.

The work of Aurin and Maurer (1993), Gilligan (1983, 1993), Joseph and Efron (1993) Rulon (1992), Smetana (1982), Tappan and Brown (1989), Yost (1997) suggests an approach toward a method for assessing the perceptions of subjects through the use of open ended interviews. Gilligan, Tappan and Brown, and Smetana conducted their interviews during their subjects' pregnancies and assessed their beliefs through the course of deciding to have or not to have an abortion. Gilligan, and Tappan and Brown were looking for evidence of an ethic of care; Smetana was looking for evidence of a coordination of moral and personal reasoning regarding abortion. The salience of the dilemma in these instances greatly facilitated these inquiries into the subjects' perceptions. In the field of education, dilemmas are frequently far less salient and more subject to variation in individual sensitivity, reasoning and sense of professional responsibility. Rulon, Yost, Aurin and Maurer, and Joseph and Efron also used interview methods and specifically asked subjects to recall an instance of a moral dilemma encountered in their jobs. These researchers were looking for change in moral reasoning, as measured by the MJI or the DIT, following a variety of 
intervention strategies. The subjects in these studies, with the exception of Rulon's subjects, confined their attention to issues of instruction indicating a generalized sense of moral responsibility to their students. Rulon's subjects were more willing to discuss instances of clear conflicts of values, and transgressions of moral or school codes.

The Delphi Procedure is a relatively recent addition to research methodology, having been developed by the Rand Corporation in the 1950's (Murray \& Hammons, 1995). Delbecq, Van de Ven, \& Gustafson (1975) describe the procedure as "...a method for the systematic solicitation and collection of judgments on a particular topic through a set of carefully designed sequential questionnaires interspersed with summarized information and feedback of opinions derived from earlier responses (p. 10)." Among the many advantages of the procedure is its ability to survey the opinions of a range of professionals without the expense and difficulty of having all meet face to face (Clayton, 1997; Delbecq, Van de Ven, \& Gustafson, 1975; Murray \& Hammons, 1995; Stahl \& Stahl, 1991). In this regard it also avoids the inevitable conflicts of personality and opinion which can result from such meetings. It also allows participants to express opinions anonymously and presumably encourages more forthright responses (Clayton, 1997; Delbecq, Van de Ven, \& Gustafson, 1975;Murray \& Hammons, 1995; Stahl \& Stahl, 1991).

The Delphi procedure has become a common tool in the field of education. Murray and Hammons (1995) used the Delphi procedure to determine the feasibility of implementing a management audit program for a group of community colleges. Ferretti (1993) used the procedure to identify research directions in the study of interactive multimedia in Special Education. Stahl and Stahl (1991) successfully used the Delphi procedure to identify critical thinking abilities to be targeted for a gifted education program. Linger (1999) used the procedure to develop a curriculum for educating medical students to the needs of individuals with Attention-Deficit Hyperactivity Disorder. 


\section{$\underline{\text { Summary }}$}

This chapter has outlined the literature of moral development, beginning with Kohlberg's attempts to develop a universal stage theory of moral development. These attempts have done much to draw attention to questions of morality, and has resulted in a virtual explosion of research in applied ethics. However, the literature has failed to show a strong relationship between levels of moral reasoning and actual moral behavior. Other researchers have pointed to other relationships that influence both how individuals reason and how they behave. Feminist theorists and researchers have posited an interaction between gender and moral development. Many researchers have looked for an interaction between moral reasoning, moral behavior, and individual characteristics. Turiel and others have shown that individuals distinguish between moral, social/conventional, and personal issues. Rest, Krebs and Wark, and others have shown that individuals reason differently about real and hypothetical situations. Rest has developed a Four Component model that is designed to encompass all the factors that promote or hinder moral action.

The multi-component approach to moral behavior has brought attention to methodological issues. At the core of much traditional research is the assumption that morality is objectively definable. This belief has resulted in a research approach that interprets subjects' responses and behavior in terms of predetermined standards. In contrast, Gilligan, Belenky, and Smetana have all worked in real time with subjects while they wrestled with real life abortion decisions. Yet little research begins by asking individuals to identify events that they personally identify as having moral dimensions. Tappan and Brown have developed a methodology that asks subjects to identify and describe events that have moral implications and to discuss how these issues were resolved. This methodology was discussed as a promising approach to the study of individual perceptions. Finally, in keeping with current research in applied ethics, the use of the Delphi procedure to develop group consensus among preschool special needs teachers was discussed. 


\section{Chapter III}

\section{$\underline{\text { Methods }}$}

\section{Restatement of the Purpose of the Study}

The primary purpose of this study is to examine the perceptions of preschool special needs teachers regarding moral issues that arise during their work. This is a phenomenographic study because it is interested in the experience of individuals and the description of "...people's common sense conceptions with which they explain the physical and social world (Tesch, 1990, p. 49)." The intent of this study is to allow preschool special needs teachers to tell their own stories so that the researcher can develop a grounded understanding of the meanings they apply to the events that occur in their professional lives. This will allow the identification of factors contributing to successful or failed decision-making concerning challenges they personally identify as having moral dimensions during their employment as preschool special needs teachers.

The study consisted of two phases. In Phase I, a Delphi procedure was conducted using questionnaires based on an interview protocol developed by Brown et al. (1989). This phase yielded a bank of 18 real life moral dilemmas identified by participants as being in the moral realm, and ranked lists of factors which participants identified as useful in resolving moral dilemmas. Phase II of this study used the results of Phase I as a structuring mechanism for in depth interviews of four preschool special needs teachers. These four teachers are currently practicing in the field and were selected from the participants in the Delphi procedure.

\section{$\underline{\text { Restatement of the Questions Guiding the Study: }}$}

1. What events, occurring during their professional duties, do some preschool special needs teachers consider to be moral dilemmas?

2. From the perspective of these preschool special needs teachers, what specific characteristics of these dilemmas signal that they are moral in nature? 
3. What process do these preschool special needs teachers use to determine the proper action to take under the presenting circumstances of a dilemma that they have identified as being in the moral domain?

4. When preschool special needs teachers make a judgment regarding a moral dilemma, what other factors do they consider when deciding whether or not to act on that judgment?

5. When moral judgments compete with other values, goals, and concerns, how do these preschool special needs teachers prioritize these factors in order to determinethe action that they will actually take?

6. Do these preschool special needs teachers feel that they live up to their own standards of moral behavior? If not, how do they resolve the resulting tension and plan for future development?

7. What do these preschool special needs teachers identify as the origins of their moral values and moral beliefs?

\section{$\underline{\text { Subjects }}$}

\section{$\underline{\text { Phase I }}$}

The identification of the population that is of interest to this study was quite simple. The population consists of all teachers in the state of West Virginia who hold the job title of Preschool Special Needs Teacher. There are approximately 225-275 preschool special needs teachers in West Virginia. To reach these teachers, attempts were made to contact the special education directors of all 55 school districts in West Virginia. Forty special education directors were contacted and verbal agreement was obtained to consent to the study and to distribute the survey materials to preschool special needs teachers in their district. Of these special education directors, only 19 actually completed the district consent form (Appendix D) and distributed the surveys to the teachers. It is estimated that only 102 surveys actually reached potential participants.

When conducting a Delphi procedure, the optimum number of experts to be surveyed is "...1530 people for a homogeneous population...(Clayton, 1997, p. 5)." The inclusion of 15 participants 
at a minimum ensures that a sufficient number of professionals have been consulted to adequately represent the range of experience within the profession. The maximum of 30 participants increases the likelihood of agreement resulting from the procedure.

In this study, 15 participants were considered as a minimum. The larger number of 30 would have been preferred since one goal of the study is to gather a substantial collection of real life dilemmas and it was not believed that the sample pool would represent a homogeneous group. Dillman (1978) states that, for survey research, a return rate of $25 \%$ should be considered an excellent rate but that $10-15 \%$ would be a typical expected return. The return of 18 surveys represented a return rate of $.176 \%$.

A total of 18 preschool special needs teachers returned their signed consent forms along with the first survey and the demographic survey. These teachers ranged in age from 25 years to 65 years old. Two were in theie twenties, 11 were in their thirties, three were in their forties, one was in her fifties, and one was in her sixties. Five participants stated that they worked in an urban setting and 13 stated that they work in a rural setting. Four of these participants had five or less years of teaching experience, seven had six to 10 years of experience, four had 11-15 years of experience, two participants had 16-20 years of experience, and one participant had more than 21 years of teaching experience. One participant had an undergraduate degree in Psychology, four had previous degrees in Child Development, and thirteen had previous degrees in some area of elementary or secondary education.

All possible applicants received a packet of information regarding the research and the nature of their involvement. These information packets were patterned after Dillman's method and consisted of an explanation of the study, an explanation of the Delphi technique, assurances of the confidentiality of responses, and a discussion of the importance of the study. An addressed and stamped return envelope was enclosed along with Questionnaire 1, a brief demographic questionnaire, and a consent form. The consent form was required to meet the guidelines for the Institutional Review Board. Return of the completed survey and the signed consent form signified 
the individual's willingness to participate in the study. (See Appendix B for copies of the cover letter, consent form, demographic questionnaire, and Questionnaire 1.)

The request for demographic information (mentioned above) was made with the idea of exploring the relationship between personal characteristics and perceptions of moral agency. There are precedents for correlating subject characteristics with moral reasoning and behavior. For example, years of education have been shown to have a positive relationship with levels of moral reasoning, though no relationship exists with moral behavior (Kohlberg, 1983; Rest, 1994; Thoma, 1994). One can hypothesize that teachers working in rural areas will encounter somewhat different problems than will teachers working in more urban areas. One can also hypothesize differences in perspective between teachers based on factors such as age, educational background, employment history, certification status, marital status, and whether or not they are themselves parents. Thus this information was requested from participants. This information was analyzed to clarify the nature of the survey sample and to assist in the selection of the interview participants to ensure that the four interviewees will be sufficiently dissimilar. The demographic information did not yield any wide variation in backgrounds among the participants other than the predicted differences of years of experience, and location in either a rural or urban setting.

Three pilot surveys were conducted in the development of Questionnaire 1. The first survey developed was piloted on a small group of special educators (a group that did not include any preschool special needs teachers). This study had a good return rate but the form of the questions did not yield the type of information desired. A second survey based on the work of Brown et. al (1989) was developed and sent to a group of severe/multiple disabilities teachers. This survey, in spite of personal contact regarding its purpose, resulted in a $0 \%$ return rate. Finally, the second survey was distributed to a group of doctoral students at West Virginia University and a return rate of $33 \%$ was achieved. The variability of return rates led the researcher to expect limited participation by the desired population of preschool special needs teachers. To increase the likelihood of receiving the desired number of completed surveys (bearing in mind that subjects are being asked to return three survey forms), the researcher decided to use a monetary incentive in the form of a 
drawing for $\$ 100.00$. This drawing was held after the completion of the Delphi procedure and only those participants who had actually returned the three surveys were eligible. This method has been shown to be very effective (Dillman, 1978; personal communication, Suha Mansour, 1999) in eliciting survey responses. All 18 participants were contacted with the results of the drawing and an explanation of how the selection was made.

\section{$\underline{\text { Phase II }}$}

The participants in this phase were four preschool special needs teachers who were interviewed in depth. Selection of the four interviewees was made after the Delphi procedure was completed. On the basis of the demographic data received, participants were selected to maximize the differences in years of teaching experience, and to reflect both urban and rural teaching settings.

Specific details regarding these interview participants is contained in the Results chapter where a case study of each is presented. Briefly, the subjects were four European American women of various ages: $30,38,50$, and 55 years old. Two of the teachers had less than five years teaching experience. One of these worked in a rural setting and one worked in an urban setting. Two of the teachers had more than ten years teaching experience. One of these worked in a rural setting and one worked in an urban setting.

\section{$\underline{\text { Instrumentation }}$}

The Delphi Procedure

The primary measure used in this study was the Delphi Procedure. This is a relatively recent addition to research methodology, having been developed by the Rand Corporation in the 1950's (Murray \& Hammons, 1995). Delbecq, Van de Ven, \& Gustafson (1975) describe the procedure as "...a method for the systematic solicitation and collection of judgments on a particular topic through a set of carefully designed sequential questionnaires interspersed with summarized information and feedback of opinions derived from earlier responses (p. 10)." Among the many advantages of the procedure is its ability to survey the opinions of a range of professionals without the expense and 
difficulty of having all meet face to face (Clayton, 1997; Delbecq, Van de Ven, \& Gustafson, 1975; Murray \& Hammons, 1995; Stahl \& Stahl, 1991). In this regard it also avoids the inevitable conflicts of personality and opinion which can result from such meetings. It also allows participants to express opinions anonymously and presumably encourages more forthright responses (Clayton, 1997; Delbecq, Van de Ven, \& Gustafson, 1975; Murray \& Hammons, 1995; Stahl \& Stahl, 1991).

The procedure consists of at least three rounds of questionnaires. The first questionnaire consists of a series of open ended questions (See Appendix B for a copy of this questionnaire) which have been adapted from an interview protocol developed by Brown et. al (1989). These questions are designed to allow for as wide a range of responses as possible and were selected because they ask participants to describe a real life event. Subsequent questions probe for detail and the respondent's perception of the events. The researcher realizes that it is not possible to create a completely bias free questionnaire. In this instance the questions reflect the Four Component Model developed by Rest and to some dgree the research on moral sensitivity by Turiel et al. However, the purpose of this research is to elicit the perceptions of the participants rather than to impose an external standard of comparison. Therefore, an effort was been made to word the questions in a manner that will elicit as much detail as possible regarding the events, and the perceptions of the respondents (Tappan \& Brown, 1989; Tappan, Brown, et. al, 1989).

The second round of questionnaires was developed on the basis of the responses to Questionnaire 1 (See Appendix C for a copy of Questionnaire 2). Questionnaire 2 consisted of four groups of items. These items were developed by the researcher and an independent analyst (this process is discussed in detail in the analysis section of this chapter). This questionnaire did not include a group of scenarios as had been planned by the researcher. Each dilemma described by the participants was unique and did not allow for the development of a small number of representative scenarios. The researcher felt that it would be too cumbersome for the Delphi procedure to include all 18 scenarios and it was decided to save them to use as a basis for discussion in the face-to-face interviews in the second phase of data collection. 
Participants were asked to rate each of the items on Questionnaire 2 as to their relevance to specific aspects of decision making in the face of moral dilemmas. The second questionnaire was sent only to those 18 teachers who responded to the first questionnaire and had expressed a willingness to participate in the entire process. A stamped, self addressed envelope was mailed along with Questionnaire 2.

Finally the third round of questionnaires was developed from the responses to Questionnaire 2. The responses to Questionnaire 2 were summarized in displays of frequency distributions, and mean rank scores (Tables 1-4). Explanations accompanied each display to ensure that all participants understood the information to which they were responding. Participants were asked to review these data and to consider whether they wished to alter their conceptions or to add any information that may have been missed in previous rounds. It was explained that they were under no obligation to alter their original responses. The final packet of information that was sent to participants included 1) printed results from Questionnaire 2 showing response frequencies and means, 2) copies of the participant's original responses to questionnaire 2, 3) Questionnaire 3 with the items rearranged in rank order from highest to lowest, and 4) a stamped, self addressed envelope. No attrition occurred during the process of the Delphi procedure.

\section{$\underline{\text { Demographic Data }}$}

A demographic questionnaire was sent to all participants in the study (Appendix B). This questionnaire was enclosed to identify characteristics of the final pool of participants, and in hopes that significant groups would become apparent and allow later analysis of group response patterns. Questions reflected the need to understand the nature of the participants and also personal characteristics that had been identified in the literature as being relevant to moral reasoning and behavior, such as years of experience and years of education.

These data were not used to analyze the responses to the Delphi questionnaires while the procedure was in progress. The purpose of the procedure is to achieve a consensus regarding moral 
dilemmas in the work place, and group differences were not being sought. Data were used later to identify participants for the interview portion of the study.

\section{The Interviews}

After the Delphi procedure was completed and analyzed, and consent forms had been received from the four participants, two interviews were conducted with each of the four interview participants. Interviews of three participants were conducted in the participants' homes. One participant was interviewed in her preschool classromm. All interviews were audio tape recorded. The tapes of the first interview were transcribed and analyzed thematically before the second interviews were conducted. The initial interviews were conducted using the interviewees' own responses to the Delphi questionnaires as a starting point. The scenarios of the other participants were also discussed. The conceptual constructs which emerged from the Delphi functioned as guides for the interviewer to ask probing questions. This elicited more specific information relating to the research questions and attempted to elicit the interviewees' self-images as moral beings. Transcripts of the first interview were sent to the interviewees for them to review. A second interview allowed the researcher to ask specific questions to clarify each interviewee's original narrative. The interviewees were also asked to review the complete stock of dilemma scenarios and to discuss the issues. Transcripts of the second interview were also sent to the participants for review. A copy of the final written case study was sent to each of the participants and they were asked to comment on the content. Participants did not request any changes.

\section{$\underline{\text { Analysis }}$}

\section{The Delphi Procedure}

Analysis of the data collected in this study is best characterized as qualitative although some basic quantitative methods are incidentally employed. What distinguishes the Delphi procedure from typical quantitative research designs is that analysis occurs at every stage of the data collection 
rather than after all the data have been collected. The procedure begins with open-ended questions and responses that are systematically refined based on the identification and sorting of thematic categories (Delbecq, Van de Ven, \& Gustafson, 1975; LeCompte \& Preissle, 1993; Miles \& Huberman, 1994; Tesch, 1990). This is followed by the calculation of simple descriptive statistics and measures of concordance to determine when the procedure will end (Murray \& Hammons, 1995; Stahl \& Stahl, 1991).

Delphi Round One: Questionnaire 1 consists of nine open-ended questions. These questions were adapted from an interview protocol developed by Brown et al. (1989) and were piloted to ensure they would elicit responses relevant to the research questions of this study. Question 1 asks each respondent to describe an event that occurred during their job duties and that presented them with a moral dilemma. It had originally been the intent of the researcher to include these scenarios in Questionnaire 2. However, each of the 18 scenarios received was unique and did not allow for the development of composite or representative scenarios. The responses to these questions were analyzed for abstract moral concepts by the researcher and an independent analyst who was selected for her similarity in background to that of the Delphi participants. This person was a preschool special needs teacher, with a masters degree in early childhood special education, and who was working in the field at the time. Similarity in background was a requirement for this position as it was believed that this would 1) result in an analysis independent of knowledge of the literature in moral reasoning, and 2) analysis by someone who had similar experiences and would be more likely to identify abstract concepts with which participants would be in agreement.

The independent analyst was given a copy of the returned questionnaires and a typed copy of research questions 2-5. For each question, she was asked to create lists of concepts for each of the 4 questions. The researcher performed the same process. After the lists were prepared, the researcher and the independent analyst met to discuss their findings and to look for agreement and disagreement. There was substantial agreement between the lists and no significant disagreements regarding the concepts identified in each narrative. There were a number of concepts identified by the independent analyst that had not been identified by the researcher and these were added to the 
final list. Because the intent of this procedure was to be inclusive, disagreements were resolved by including disputed items in the final list. Questionnaire 2 asked participants to rank the importance of items and they would be the ultimate arbiters of these items.

The lists of concepts (in random order) were reported in table form on Questionnaire 2 along with a rating scale of 1-5. At this time, participants were asked to rate each item as to its importance to resolving moral dilemmas. Here the focus changes from behavior in a specific circumstance to more general considerations of decision making when faced with dilemmas.

Upon receipt of the 18 completed questionnaires, response frequencies and means were calculated for all items and were displayed along with an explanation to ensure the participants would understand the tables. These tables included all the items that had been included in Questionnaire 2. However, they were ordered according to their mean ranking from highest to lowest. This added a graphical element to assist in understanding the results. These results were then mailed to participants along with their original answers and Questionnaire 3, which was the same as Questionnaire 2 only the order of the items had been changed to reflect the rankings in the data display. Participants were asked to review the results and make any change to their rankings that they may have felt necessary. Only minor changes were made and did not alter the original rankings of the items.

The composite rank ordering provided information for determining consensus (Clayton, 1997; Murray \& Hammons, 1995; Stritter, Tresolini, \& Reeb, 1994), but, Stahl \& Stahl (1991) suggest performing a Kendall $\mathrm{W}$ to produce a coefficient of concordance that will give a measure of the agreement among the participants regarding various aspects of moral judgment and behavior. This was done for each of the four lists of items as a further test of concordance.

The results of the analysis (frequencies, means, standard deviations, rankings of response items) were reported in Questionnaire 3. This questionnaire asked the participants to review the results, and gave them the opportunity to reconsider their responses to Questionnaire 2. The original Likert scale that appeared in Questionnaire 2 followed the results for each question. This allowed participants to make any changes to their original responses to questions in Questionnaire 2. There 
were no significant adjustments to the rankings (based on participants' changes in rankings) made before final reporting of the results.

Correlation statistics (Pearson's r) were calculated between the items on the four lists of items. This was done to look for internal consistency of responses and as a preliminary to the analysis of the results.

\section{The Interviews}

The interviews were transcribed by an independent transcriptionist following each interview. After each interview, the transcripts were given to the interviewees for review, comment, and responses to the researcher's requests for clarification (Emerson, Fretz \& Shaw, 1995; LeCompte \& Preissle, 1993; Spradley, 1979) to ensure accuracy of the transcripts. No changes were requested by the interviewees.

The transcripts were then read by the researcher several times. Notes of questions for clarification in the second interview were made. These notes formed a substantial portion of the protocol for the second interview. Preliminary coding to assist the construction of the final case study was also carried out at this time. This coding most prominently consisted of references to the research questions.

The second interview was also transcribed and shown to the participants for review before coding by the researcher. At this phase, coding began to achieve some stability as consistent themes emerged. Data were sorted thematically, and the researcher began to write up the results. As accurate a description of the participants' views as possible was developed. These writings were then again shown to the participants for review, alteration and clarification. This information will be included in the final draft of the results.

\section{$\underline{\text { Limitations }}$}

Qualitative studies of this type are often assumed to have problems with external and internal validity. Because of the limited sample and the use of interpretative methodology, results will not be 
easily generalizable to other groups of individuals (LeCompte \& Preissle, 1993; Miles \& Huberman, 1994). However, this is an exploratory study whose goal is to describe the perceptions of practitioners in the field of preschool special needs. It is hoped that variables relevant to future studies of moral behavior will become salient in the process of coming to understand the experiences of specific individuals. These experiences can be taken as exemplars that can be analyzed for their match or mismatch with professional codes of ethics and the goals of teacher education programs.

The question of internal validity is a legitimate one in the context of qualitative study because the goal is to describe and explicate the experience of individuals. This is an interpretative process and researchers must be on guard not to apply their own values and meanings to the narratives of their subjects. Clearly there are limitations to the extent that one can truly know what it is like to be someone else. LeCompte \& Preissle, (1992) propose that truth value is not a legitimate goal for a naturalistic inquiry and they propose an alternate standard of credibility. In their view, credibility is achieved through methods for ensuring that the categories of discussion are those of the participant and by having the participant review and edit the results before publication. This study will employ some of these methods by requesting that the coding process include an independent coder, and by several steps in which the participants review and comment on the process and the results.

A more serious limitation of this study is that the methodology chosen does not allow for the direct observation of teacher behavior in real crisis situations. While reflecting upon past events (as this research does) participants may have internal conflicts or motivations that cause them to interpret events in a more positive or negative light than might an independent observer. Additionally, the mind tends to structure the meanings of events as they are experienced. The individual filters out many events during the day and makes others more salient based on the needs of the moment. A more structured methodology would allow for the identification of patterns of behavior and perceptions that may be immediately unavailable to the participants' conscious minds. This might be achieved by a more labor intensive process of observation of on-going events, followed by regular and timely comparison and discussion of the observers and the participants' 
perceptions of events. An exploratory study such as this will give greater depth to later studies carried out directly in the work place. It will allow for the development of more focused coding systems, and the training of observers.

Another avenue of research would be to specifically target those psychological constructs such as ego strength, locus of control, sense of authoritarianism, the ascription of responsibility, and many other internal processes that may influence an individual's perception of events and moral behavior. There are a number of reliable and valid instruments available to assess these and other constructs that might be hypothesized to have a relationship to moral development and moral behavior. These scores might yield interesting insights relative to the component of Moral Character. Assessing a large group would yield data that could then be correlated with scores on the Defining Issues Test (Rest, 1979) or the Moral Judgment Inventory (Kohlberg, 1984). However, the ultimate interest is in actual behavior, and no reliable instruments have yet been developed which can replace the direct observation of actual behavior. On-site observation would create a logistical nightmare for any attempt to uncover correlations in a large population study. Further, the administration of these procedures would require extensive psychometric examination of participants that does not fall within the expertise of this researcher. Such testing would intrude on the privacy of participants, would present almost insurmountable problems for obtaining consent, and would complicate issues of confidentiality and human subject review.

\section{$\underline{\text { Summary }}$}

This study used a combination of qualitative methods (survey and interview) along with some simple statistical procedures to gain a broad sense of the perceptions of preschool special needs teachers regarding the moral demands placed on them by their employment. This chapter has restated the purpose of the study, described the sampling method, detailed the methodological approaches to data collection and analysis, including means for handling threats to validity, and discussed the limitations and strengths of this approach. 


\section{Chapter 4}

$\underline{\text { Results }}$

The presentation of the results of this study will consist of 1.) the results of the Delphi Procedure, and 2.) the results of the interview phase of data collection. The results from the Delphi procedure will consist of the 18 moral dilemma scenarios which participants described in Questionnaire 1, and a discussion of the rank orders of items that were calculated at the end of the procedure. The results of the interview phase of data collection will consist of 4 case studies describing the background of the participants and their sense of self as moral agents within the educational community and their role in society at large.

\section{The Delphi Procedure}

Details of how the final questionnaire items were developed were discussed in the methods section. Briefly, these consisted of lists of items in four categories that correspond to three components of Rest's (1984) Four Component Model: 1) characteristics which signal that an event has moral implications (Moral Sensitivity), 2) processes employed by teachers to resolve a moral dilemma (Moral Reasoning), 3) factors considered after a decision has been made regarding the most appropriate action to take (Moral Motivation), and 4) prioritized items from category 3 which participants indicated they would definitely consider before taking any action (Moral Motivation).

\section{Characteristics of Moral Dilemmas (Moral Sensitivity)}

This question corresponds to Rest's concept of moral sensitivity and addresses Research Question 2, "From the perspective of these preschool special needs teachers, what specific characteristics of these dilemmas signal that they are moral in nature?" The rank orders, standard deviations, and response distributions for items which participants indicated would signal that an event had moral implications can be seen in Table 1. For these items a Kendall's W of .44 was 
Table 1

$\underline{\text { Rank Orders and Response Frequencies for Delphi Items: }}$

Characteristics of Moral Dilemmas/Moral Sensitivity

(Missing Data) (Not important) (slightly important) (moderately important) (very important) (essential) 0 12 2 3

$\begin{array}{lllllll}\text { Std.Dv. } & \text { Mean } & 0 & 1 & 2 & 3 & 4\end{array}$

1. A violation of law, regulation, or policy.

2. Risk of harm to others.

$\begin{array}{llll}0 & 0 & 2 & 3\end{array}$

3. Individuals' rights are ignored.

.62

4.50

$\begin{array}{llll}0 & 0 & 1 & 7\end{array}$

4. A risk of damage to an individual's

.97

4.11

$\begin{array}{llll}0 & 1 & 4 & 5\end{array}$
self respect (including your own).

5. A risk of damage to an individual's reputation (including your own).

.77

6. A conflict of values.

7. A threat to fairness.

8. A risk of bias or the appearance of bias.

.86

3.82

3.78

1.01

3.50

9. A conflict between obligations and self interest (job loss, safety, convenience, self esteem).

10. A conflict between two or more responsibilities.

12. A conflict between two or more obligations.

14. A conflict between responsibilities and self interest. 1.13

3.06

15. Risk of conflict with colleagues.

16. Questions of self determination.

1.12

3.00

.77

3.00

$1 \quad 0 \quad 10 \quad 5$

17. A conflict between two or more duties.

.77

3.00

1

02

$\begin{array}{llll}2 & 0 & 10 & 3\end{array}$

$\begin{array}{llll}2 & 2 & 8 & 4\end{array}$

$\begin{array}{llll}2 & 1 & 9 & 6\end{array}$

$\begin{array}{llll}2 & 2 & 9 & 2\end{array}$

$\begin{array}{llll}1 & 2 & 11 & 4\end{array}$


obtained indicating a moderate level of agreement between the participants. A significance level was obtained performing a chi-square. The computed Chi-square was $106.18(\mathrm{df}=16, \mathrm{p}<.0001)$, which indicates a statist significant level of agreement among the Delphi participants.

These numbers indicate that participants agreed on the characteristics of a moral dilemma but tell us little regarding what kinds of issues are considered to present moral dilemmas for the participants. For this, we must look at the rank orders of items. Examining the item ranks directly, there are no large gaps between items that aid in interpreting the results. No items achieved a ranking of 'essential' to the identification of a moral dilemma. Five items achieved the overall ranking of 'very important.' These ranks ranged from 4.00 to 4.78 . However it is important to point out that in all but one case, the patterns of actual responses to these items indicate that the majority of respondents considered these items to be 'essential' to the identification of a moral dilemma. There was somewhat less agreement on the question of "a risk of damage to an individual's reputation."

\section{$\underline{\text { Internal consistency of responses }}$}

A simple correlation between the 17 items was run to see if there were any patterns to the responses. There was a significant correlation $(r=.80, \mathrm{p}<.0001)$ between item 12 , 'a conflict between 2 or more obligations,' and item 10, 'a conflict between 2 or more responsibilities'. There was a significant correlation $(\mathrm{r}=.82, \mathrm{p}<.0001)$ between item 12 , 'a conflict between 2 or more obligations,' and item 17, 'a conflict between 2 or more duties'. There was a significant correlation (r $=.84, \mathrm{p}<.0001$ ) between item 10, 'a conflict between 2 or more responsibilities,' and item 17, 'a conflict between 2 or more duties.' These correlations do not tell us about the nature of the relationship between these items. The concepts of obligation, responsibility, and duty are closely allied and the correlation could indicate a recognition of their related status on the part of the participants in the Delphi. It could also indicate that the concepts and terms are used interchangeably and indicate that the participants do not readily distinguish between them. Each of 
these items received a different rank (see Table 1) but the differences are not striking. These items are also ranked as moderate in importance to identifying a moral dilemma.

The words obligation, responsibility, and duty appear rarely in the narratives (obligation $=4$, responsibility $=2$, duty $=0$ ). Consequently, a specific question about them was added to the interview protocol as a probe to determine if participants assumed that they were closely related yet distinct concepts or if they could be used interchangeably. Either case would result in a significant correlation. The fact that these concepts had to be interpreted from the context of the responses suggests that participants do not clearly label their relationships to others. A review of the coding notes from the first survey suggests that the coders did not attempt to make a clear distinction between the three concepts. This was not entirely an oversight but also reflects the desire to be inclusive rather than exclusive of moral concepts. As a result many items were labeled with all three of the terms, with most items having two labels i.e.. responsibility and obligation. The coding of these concepts and the use of them by the Delphi participants suggests that the relationship between the concepts of obligation, responsibility, and duty is similar to the relationship discussed earlier between the concepts of morality and ethics. That is, they are closely related concepts and sometimes used interchangeably, with the exact meaning of the words highly dependent upon the context of a given statement.

Another set of correlations also reflects a pattern of relationships between the concepts of obligation, responsibility, and duty. There was a significant correlation $(r=.82, p<.0001)$ between item 11, 'a risk to relationship between individuals,' and item 10, 'a conflict between two or more responsibilities." There was a significant correlation $(\mathrm{r}=.81, \mathrm{p}<.0001)$ between item 11 , 'a risk to relationship between individuals,' and item 17, 'a conflict between two or more duties.' There was a significant correlation $(\mathrm{r}=.78, \mathrm{p}<.0001)$ between item 11 , 'a risk to relationship between individuals,' and item 12, 'a conflict between two or more obligations.' Here again, it is difficult to interpret the exact nature of the relationship. These items were all ranked as 'moderately important' and thus less critical to the identification of a moral dilemma. Nonetheless, it is tempting to see here some evidence of an ethic of care. The words obligation, responsibility, and duty may be taken to 
define the nature of relationships between individuals. Keeping in mind that it is not clear whether the survey respondents clearly distinguish between these concepts, the correlation between those items and the item pertaining to the maintenance of relationships may indicate that the survey respondents are (consciously or unconsciously) sensitive to the nature of relationships between individuals.

\section{Processes Used in Determining an Appropriate Response (Moral Reasoning)}

These items roughly correspond to Rest and Kohlberg's concept of moral reasoning and address Research Question 3, "What process do these preschool special needs teachers use to determine the proper action to take under the presenting circumstances of a dilemma that they have identified as being in the moral domain?" The rank orders, standard deviations, and response distributions for processes which participants indicated they would use when determining what action to take when faced with a moral dilemma can be seen in Table 2. For these items a Kendall's W of .51 was obtained and the computed chi-square was $129.39(\mathrm{df}=14, \mathrm{p}<>0001)$, These numbers indicate a moderate, but statistically significant level of agreement among the Delphi participants.

Over all, respondents indicated that there were a wide range of options available to them when making decisions about dilemmas. Thirteen of 15 items were ranked as 'moderately likely' or 'very likely' to be used. The participants as a whole were only moderately likely to 'base decision solely on basis of legal obligations'. This contrasts somewhat with the previous indication that a violation of law, regulation, or policy is 'very important' to the identification of a moral dilemma. Survey respondents also were very likely to 'base a decision solely on the welfare of the child.' This suggests that, while the identification of legal issues is more clear-cut than the identification of child welfare, considerations of child welfare are likely to take precedence over other considerations. On the other hand, the item 1, 'consider the concerns of all those involved,' item 2, 'weigh the risks and benefits of various actions,' and item 3, 'consider consequences of alternate choices' were ranked much higher than either of these items, i.e. 4.67. Keeping in mind that none of the ranked items are mutually exclusive, this ranking reflects the related nature of these items and strongly indicates that 
Table 2

$\underline{\text { Rank Orders and Response Frequencies for Delphi Items: }}$

Processes Used in Determining an Appropriate Response (Moral Reasoning)

(Missing Data) (Not important) (slightly important) (moderately important) (very important) (essential) 0 1 23

Characteristics

1. Consider the concerns of all those involved.

2. Weigh the risks and benefits of various actions.

3. Consider consequences of alternate choices.

4. Gather documentation.

5. Request further information.

6. Seek advice from supervisor.

7. Base decision solely on welfare of child.

8. Seek advice from colleagues.

9. Require that decisions be made as a team.

10. Compromise.

11. Base decision soley on basis of legal obligations.

12. Seek help from other service agencies.

13. Provide information to persuade other parties.

14. Find safe way to postpone decision.

15. Decide without consultation with others.

$\begin{array}{lllllll}\text { Std.Dv. } & \text { Mean } & 0 & 1 & 2 & 3 & 4\end{array}$

.49

4.67

4.67

4.67

4.33

4.33

4.22

4.17

4.11

3.94

3.83

3.83

3.78

3.50

2.61

1.72

$\begin{array}{llll}0 & 0 & 0 & 6\end{array}$

$\begin{array}{llll}0 & 0 & 0 & 6\end{array}$

$\begin{array}{llll}0 & 0 & 2 & 2\end{array}$

$\begin{array}{llll}0 & 0 & 2 & 8\end{array}$

$\begin{array}{llll}0 & 1 & 0 & 9\end{array}$

$\begin{array}{llll}0 & 0 & 1 & 12\end{array}$

$\begin{array}{llll}0 & 0 & 2 & 11\end{array}$

$\begin{array}{llll}0 & 0 & 2 & 12\end{array}$

$\begin{array}{llll}0 & 0 & 6 & 7\end{array}$

$\begin{array}{llll}0 & 0 & 5 & 11\end{array}$

$\begin{array}{llll}0 & 1 & 3 & 12\end{array}$

$\begin{array}{llll}0 & 0 & 5 & 12\end{array}$

1.15

.98

.96 $\begin{array}{llll}2 & 0 & 6 & 7\end{array}$

$\begin{array}{llll}3 & 4 & 8 & 3\end{array}$

$\begin{array}{llll}10 & 4 & 3 & 1\end{array}$ 
the survey respondents take a consequentialist approach to the resolution of moral dilemmas rather than basing decisions on an appeal to universally shared moral principles. The high ranking of the item 'consider the concerns of all those involved' could also be taken as an indication of an ethic of care, indicating a desire to balance the interests of all concerned parties and thus hopefully maintain the relations between those parties.

\section{Internal consistency of responses}

Correlation statistics were calculated to look for relationships between the response patterns for all the items ranked in this section of the survey. This was done to look for consistency in the rankings as further evidence of the internal validity of responses. No items approached the desired level of significance but two correlations approached significance. A strong relationship $(r=.71, p$ $<.001)$ was noted between item 3, 'consider the consequences of alternate choices' and item 2, 'weigh the risks and benefits of various actions'. This correlation suggests an understanding that the consequences of actions may be labeled as either risks or benefits. A second relationship ( $r=70, p$ $<.001$ ) was noted between item 9, 'require that decisions be made as a team' and item 5, 'request further information.' Team decision making can be taken as a forum for the input of different perspectives and additional information, lending support to a belief that the responses of participants were internally consistent. Participants were only moderately likely to require that decisions be made as a team, an interesting finding in a field where all major decisions are required to be made as a team rather than by a single individual. The participants may be distinguishing between day to day moral dilemmas and the legal responsibility to consult the IEP team for issues which effect the nature of service delivery to the student. Balancing this, item 15, 'decide without consultation with others' was ranked as not likely to be used. This suggests that, while these individuals do feel some autonomy in decision making, there are limits to the sense of autonomy or individual moral responsibility in practice. 


\section{Perceptions of Moral Agency}

\section{Considerations Influencing What Action is Taken/Moral Motivation}

These items correspond to Rest's concept of moral motivation and address Research Question 4, "When preschool special needs teachers make a judgment regarding a moral dilemma, what other factors do they consider when deciding whether or not to act on that judgment?" The rank orders, standard deviations, and response distributions for items which participants indicated might influence whether they actually took what they considered to be the best action regarding a moral dilemma can be seen in Table 3. For these items a Kendall's W of .22 was obtained and the computed chi-square was $52.24(\mathrm{df}=13, \mathrm{p}<.0001)$. These numbers indicate a small but statistically significant level of agreement among the participants.

When analyzing the item ranking, it is important to remember that these items represent considerations taken after the appropriate response is determined. That is, these considerations might offer further encouragement to take the appropriate action. If the appropriate action conflicts with other considerations (personal values or personal safety, for example), they also might prevent one from taking the appropriate action. One example of a consideration of this nature was a respondent who felt compelled to report a family for sexual abuse. She stated that she hesitated making the report because the father of the child in question had been known to take revenge upon the families of those by whom he felt wronged. Another example was a respondent who reported not calling Child Protective Services for suspected neglect because she wished to maintain a good relationship with a child's mother and also because she felt she could affect the situation in another manner.

Any interpretation of these rankings is necessarily tentative in the absence of concrete examples of situations where the morally most appropriate choice conflicts in some way with other concerns. At this time it was not possible to survey respondents about the examples they had in mind when ranking these items. Without such concrete examples, the rankings are somewhat abstract in nature.

Looking at those items which the participants indicated they would be "very likely" to consider, no easy summary is possible. The item "the best interest of the child (if in conflict with responsibility, law, etc.)" received the highest rank (4.56). An example from the scenarios of this 
Table 3

$\underline{\text { Rank Orders and Response Frequencies for Delphi Items: }}$

Considerations Influencing What Action is Taken/Moral Motivation

$\begin{array}{cccccc}\text { (Missing Data) } & \text { (not likely } & \text { (somewhat likely) } & \text { (moderately likely) } & \text { (very likely } & \text { (definitely would) } \\ 0 & 1 & 2 & 3 & 4 & 5\end{array}$

Characteristics

Std.Dv. Mean $\quad \begin{array}{lllll}0 & 1 & 2 & 3 & 4\end{array}$

1. The best interest of the child (if in conflict with responsibility, law, etc.)

.71

4.56

$\begin{array}{lll}0 & 0 & 2\end{array}$

4

2. The rights of those involved.

.86

4.50

$\begin{array}{llll}0 & 1 & 1 & 4\end{array}$

3. Your personal values.

$\begin{array}{llll}0 & 0 & 3 & 6\end{array}$

4. Consequences to others of acting or not acting.

.75

4.28

$\begin{array}{llll}0 & 0 & 3 & 7\end{array}$

5. Responsibility to employer.

6. Consequences to yourself of acting or not acting (job loss, safety, convenience, self esteem).

7. Your role as a member of a team.

8. The interests of those involved.

9. Personal responsibility vs. professional. responsibility.

10. The feelings of those involved.

11. Your personal reputation.

12. The responsibility of others to resolve the dilemma.

13. Your relationship with the individuals involved.

14. Your relationship with colleagues.

$\begin{array}{llll}1 & 2 & 8 & 6\end{array}$


conflict is the teacher who was asked to conduct a developmental evaluation of a child and found that she had some delays but not enough to qualify her for preschool services. This teacher felt that this child's delays would increase over time due to her environment, and she considered altering the test results so that the child would qualify for preschool services. In the end, this teacher chose to follow the regulations for eligibility. She was able to articulate what was at stake here for the child but did not answer the question of what was at stake for herself if she had chosen to change the results.

The item 'the rights of those involved' followed with a rank of 4.50. This ranking is consistent with the ranking of individual rights as 'very important' to the identification of a moral dilemma. However, this is an interesting result as none of the participants described having encountered this conflict. This item was included in the list because an issue was raised in one scenario but appeared to go unnoticed by the author of the scenario. In a conversation with the teacher, a mother with mental retardation had expressed a desire to have another child so she could have a daughter. The teacher encouraged the mother's custodial parents to have her sterilized.

The item "your personal values" received a rank of 4.33 which places it at the lower end of "very likely" and close to "moderately likely" to be considered. An example of this from the scenarios involved a family that was experiencing poverty to the extent of harm to their child and possible homelessness. The individual involved made appropriate referrals to social service agencies. However, contrary to accepted professional practice, this teacher also intervened on her own as a private citizen by convincing her church to provide relief. She did not express her reasoning in so many words, but gave the impression that helping others was a fundamental human value. She later regretted having gotten involved when the family failed to follow through on their part of the arrangements. The teacher stated that in the future she would only make the referrals to other agencies.

Two items which represent consideration of the consequences of various actions were ranked as 'very likely' to be considered. Item 4, 'consequences to others of acting or not acting' received a rank of 4.28, item 6, 'consequences to yourself of acting or not acting' received a rank of 4.17. 
Categorical considerations of right and wrong were represented by the items 'your personal values', ranked 4.33, and 'the rights of those involved' ranked 4.50. The items 'the best interest of the child' and can be taken as either a categorical consideration or as considerations of outcome depending on interpretation. This appears to contrast somewhat with the emphasis on considerations of consequences that appears in the moral reasoning portion of the results.

\section{Internal consistency of responses}

Correlation statistics were calculated between the response items as a check for internal consistency. No items achieved the desired level of statistical significance but two items approached that level and lend support that at least some level of internal consistency exists. A strong relationship $(\mathrm{r}=.79, \mathrm{p}<.0001)$ was found between item 13 , 'your relationship with the individuals involved' and item 14, 'your relationship with colleagues.' The meaning of this is clear and suggests that the researcher perhaps should have collapsed these into one item. A strong relationship $(\mathrm{r}=$ $.75 . \mathrm{p}<.0001$ ) was also found between item 3, 'your personal values' and item 6 , 'consequences to yourself of acting or not acting (job loss, safety, convenience, self esteem.' At first glance this seems a logical relationship, because they both involve aspects of the self. It further suggests that there is an intimate relationship between one's values, and one's sense of well-being, be it physical or psychological. Unfortunately it was not possible at this time to test the direction of this relationship. It is, however, reminiscent of the perspective of narrative psychology which relates moral decision making directly with one's internal sense of self (Murdoch, 1956).

\section{Prioritized Considerations Influencing What Action is Taken}

These items address Research Question 5, "When moral judgments compete with other values, goals, and concerns, how do these preschool special needs teachers prioritize these factors in order to determine the action which they will actually take?" The rank orders, standard deviations, and response distributions for the prioritized items from category 3 items can be seen in Table 4 . A Kendall's W of .19 was obtained and the computed chi-square was $44.70(\mathrm{df}=13, \mathrm{p}<.001)$. These 
Table 4

$\underline{\text { Rank Orders and Response Frequencies for Delphi Items: }}$

Prioritized Considerations Influencing What Action is Taken/Moral Motivation

The original ranking scale is displayed as a reminder of the meaning of the numbers. The numbers which appear under the heading (0) indicate how many participants would not consider this item at all.

Rank the items from 1 - 5 with $5=$ most important, $1=$ least important, $0=$ did not consider this item at all

Characteristics

1. The rights of those involved.

2. The best interest of the child (if in conflict with responsibility, law, etc.)

3. Consequences to others of acting or not acting.

4. Your personal values.

5. The interests of those involved.

6. Consequences to yourself of acting or not acting (job loss, safety, convenience, self esteem).

7. Personal responsibility vs. professional responsibility.

8. Responsibility to employer.

9. Your role as a member of a team.

10. Your personal reputation.

11. The feelings of those involved.

12. The responsibility of others to resolve the dilemma. 1.15

13. Your relationship with the individuals involved.

14. Your relationship with colleagues.

$\begin{array}{lllllll}\text { Std.Dv. } & \text { Mean } & 0 & 1 & 2 & 3 & 4\end{array}$

2.14

2.47

1.98

1.79

2.03

1.86

1.97

1.83

1.77

1.57

1.38

1.56

1.44

1.33

1.1

2.67

2.33

6

0

8

2

20

$0 \quad 0$

0

$\begin{array}{lllll}10 & 0 & 2 & 3 & 0\end{array}$

$\begin{array}{lllll}9 & 2 & 2 & 1 & 3\end{array}$

$\begin{array}{lllll}12 & 0 & 1 & 0 & 3\end{array}$

$\begin{array}{lllll}13 & 0 & 0 & 1 & 3\end{array}$

1.1

13

0

$1 \quad 1 \quad 0$

1.06

12

1.06

11

0.61

15

0.56

15

0.50

15

0.33

16

0.28

17

1.18

.

$\begin{array}{lllll}17 & 0 & 0 & 0 & 0\end{array}$




\section{Perceptions of Moral Agency}

numbers indicate a rather low but statistically significant level of agreement among the Delphi participants. T] finding is quite startling and was considered unlikely for these items. Participants were asked to rank any sut the 14 items based solely on their having received a ranking of 5 (definitely would consider) from question 3 questionnaires. Given the variation of responses on Question 3 and the freedom to rank items from those sut the researcher had assumed there would be no agreement at all among the rankings.

The mean ranks of these items look different than those seen in Tables 3. The means listed in Table 4 do not translate into levels of likelihood but rather represent the relative importance of items should they come in conflict with each other. This is due to the variability of subsets chosen by the participants as being important considerations which left many data cells blank. It is also important to remember that any analysis of these items is more tentative than with previous questions because the standard deviations for these items are larger than those for previous questions. This is true for both the absolute numbers themselves and for their size relative to the individual rankings.

The rankings for these items were also surprisingly consistent with the rankings in Table 3 . The differences are also quite consistent and suggest that the participants viewed this as a forced choice version of the previous question. If this is the case, their responses to this question may represent the type of choice they might make under less than ideal circumstances. That is, circumstances like

those experienced in real life. The ranking of neighboring items was reversed by participants. These reversals represent a change to a more utilitarian view, i.e. an attempt to maximize the total good. As a result 'the best interest of the child' (2.67) traded places with 'the rights of those involved,' (2.33). 'Your personal values' (1.44) exchanged places with 'consequences to others of acting or not acting,' (1.56), and 'the interests of those involved' (1.33) almost traded places with 'responsibility to employer' (1.06). In each of these cases, the item that had to do with the welfare of a number of individuals was ranked higher than the item that had to do with the welfare of an individual.

In contrast, at the lower end of the scale of importance "your personal reputation" (.61) exchanged places with "the feelings of those involved" (.56). In this instance an individual concern took precedence over the concerns of a group. This may not be as self serving as it seems and may 
represent a recognition of personal responsibility in decision making. In support of this is the fact that the ranking of "responsibility to employer" dropped considerably in the forced choice circumstance and "personal responsibility vs. professional responsibility" moved up two places in the rankings.

\section{Internal consistency of responses}

Correlation statistics were calculated to look for relationships between the response patterns for all the items ranked in this section of the survey. There was a statistically significant relationship (r $=.85, \mathrm{p}<.0001)$ between item 11, 'the feelings of those involved' and item 13, 'your relationship with the individuals involved.' There was a statistically significant relationship $(\mathrm{r}=.80, \mathrm{p}<.0001)$ between item 11, 'the feelings of those involved' and item 14, 'your relationship with colleagues.' There was a statistically significant relationship $(r=98, \mathrm{p}<.0001)$ between item 14 , 'your relationship with colleagues' and item 13, 'your relationship with the individuals involved.' These findings suggest that while the participants do not necessarily make decisions on the basis of the consequences for relationships, they are, however, quite sensitive to the issues surrounding relationships.

\section{$\underline{\text { Summary of Delphi results }}$}

The results of the Delphi Procedure begin to clarify how preschool special needs teachers view themselves as moral agents. These teachers report a large number of characteristics that can signal that a dilemma has moral dimensions (Table 1). The most important of these, to the participants, were legal violations and the risk of harm to individuals. Similarly, they reported a large number of processes which aid in making an appropriate decision (Table 2). At the highest levels of probability of use are considerations of risks and benefits to those involved, suggesting a consequentialist mode of reasoning.

Under the heading of moral motivation, participants reported that once a judgment had been made there were a wide range of considerations which might influence whether they actually 
followed that judgment (Table 3). At the top of the list was item 1, 'the best interest of the child (if in conflict with responsibility, law, etc.).' Of the eight items ranked as "very likely" to be considered, four can be grouped as considerations of consequences and four can be grouped as questions of moral principle. This gives a picture of a mix between considerations of consequences and categorical or principled concerns. The prioritized items shown in Table 4 give a similar view with the exception that the welfare of the group took precedence over the welfare of the individual.

The Moral Dilemma Scenarios

The responses to Questionnaire 1 can be found in Appendix F. There is little commonality between these scenarios, contrary to expectation, and therefore they are somewhat difficult to summarize. Another problem in summarizing these scenarios is related to the lack of moral language used by the participants. The word 'responsible' appears only once. The word 'responsibility' appears only twice, both times in the same scenario. These words refer to professional or legal responsibility. There are no direct references to personal responsibility although it is suggested in two incidents. In both cases, the narrator was satisfied that she had met the letter of professional and legal responsibilities. In both cases the teacher felt that more should have been done, suggesting some feeling of personal responsibility for the outcome.

The word 'obligation' appears four times within one scenario only. The word 'values' appears twice; also within one scenario. In two cases concerning a child's legally protected rights, the word 'right' , used as a noun, appears once in each scenario. These are the only time the word appears, even though several other scenarios discuss situations where there is a clearly defined right in question. Finally, the word 'moral' appears only two times in the 18 scenarios. Commonly, participants stated 'It was wrong.' or 'It was not right.' when indicating that an action had moral consequences. Consequently, understanding the experiences of the participants from a moral perspective has required some transformation of the material.

On a descriptive level, these scenarios can be divided into groups based on the perceived source of the precipitating events which resulted in a moral dilemma for the preschool teacher. Ten of the 
dilemmas can be said to have resulted from actions taken or not taken by the parents of a preschool student. These precipitating events ranged from sexual abuse and neglect at one end of the spectrum, to the parents' inability to accept their child's disability, to a parent's wanting his child in a different school at the other end of the spectrum.

Two scenarios described events which were initiated by the actions of administrators. In one case, the preschool special needs teacher was asked to create false documentation for a child. In the other case, the teacher was pressured by her supervisor to graduate a child to another program even though, in the teacher's opinion, the child would be better served in the preschool special needs program. A third scenario can be grouped with these scenarios although it did not result from any specific action on the part of an administrator. Rather, it resulted from the teacher's interaction with state and county policies. In this instance, the teacher carried out a developmental assessment for a child that indicated that she displayed some delays but did not qualify for preschool special needs services. The dilemma came from the teacher's belief that this child was at risk for further developmental delays due to the quality of her home life even though she did not meet state and county eligibility requirements.

Three scenarios described events which related to the participants' relationship with other teachers. The first of these scenarios described a child who had transitioned into a special education program for children with mental impairments because he had turned six years old and was no longer eligible for the preschool program. The special education teacher and the kindergarten teacher were not able or willing to use a picture communication system or sign language with this child and recommended that he be placed back in the preschool program even though this would not be in compliance with state and county policy. The second scenario resulted from a teacher refusing to work collaboratively with the preschool special needs teacher as required by her supervisor. The third scenario began when a preschool teacher (not the person describing the scenario) was asked to conduct a developmental assess for a child who spoke only Spanish. The assessment was carried out in English without the aide of an interpreter whose presence is a legal 
requirement for assessments. Consequently the child qualified for preschool special needs services and was inappropriately placed in the program.

Finally, there were two scenarios which did not fit neatly into any of these categories. In the first, the survey participant had been asked to carry out a developmental assessment of her own nephew. This teacher felt that if the results showed a developmental delay, then friction with her sister and brother-in-law would result. It is interesting to note that the risk of conflict in itself was not the object of concern. Rather, it was the risk to the welfare of the child should conflict arise and the parents refuse to accept the results of the assessment. In the second of these scenarios, the teacher was assigned a child with aggressive behavior problems. The teacher did not feel that she could control this child and protect the other children due to a temporary disabling condition of her own.

As would be expected, all of the scenarios had to do with the welfare of one or more young children. Each scenario had its own complexity and combination of issues which needed to be balanced in the events. Seventeen characteristics which might indicate a moral dilemma were identified from the dilemmas. However, each scenario was unique and each contained more than one of the identified characteristics of a moral dilemma. Four scenarios have been selected for detailed discussion to illustrate this variety.

\section{$\underline{\text { Sample scenario } 1}$}

The first scenario describes a relatively simple dilemma (Scenario 009, Appendix F). In this case, the mother of two boys who were in special education expressed her desire to have another child because she would like to have a daughter. The mother herself had mental retardation. The dilemma for this teacher stemmed from the question, "Should people who have special needs be allowed or encouraged to have more children?" There is no mention in the narrative that the woman's parents asked the teacher's opinion on this subject, but the tone of the narrative suggests that they did not and that the teacher was motivated to approach them on her own. The narrator urged the grandparents to have their daughter sterilized. 
An interesting aspect of this narrative is that it was initiated by events which lead one to expect a discussion of the individual's right to self determination vs. the effects on other people and the effects on society of providing support to individuals with limited capacity to make appropriate life choices. However, she did not pursue this direction and based her argument on the consequences to the grandparents and the effects on the children should the grandparents die and no longer be available for support.

In looking at the processes used by the narrator to come to a decision about what action to take, it appears that the narrator chose to 'decide without consultation with others.' In terms of other considerations which might have influenced her decision, the narrator states that "nothing was at stake for me." She seems to have been motivated entirely by concern for the welfare of the grandparents and the grandchildren. She wrote, "I considered that this parent already had children and did not need another child for the elderly parents to care for." If she considered the rights of the mother at all, it was not mentioned and could only have been done in a fleeting manner. Without further discussion with the participant, it is impossible to know the circumstances of these events. In rural areas, teachers and students and their families often are neighbors and friends. As a result, the role differentiation between professional and private citizen frequently becomes blurred. This may have played a part in this scenario although it was not expressed by the narrator.

\section{$\underline{\text { Sample scenario } 2}$}

The second scenario (Scenario 011, Appendix F) represents a more complicated moral dilemma. This narrator described a child who had turned six and consequently had to be moved to another program. The child was placed in kindergarten with support from a mental impairments resource teacher. After several months, the special education teacher called an IEP meeting and recommended that the child be returned to the preschool special needs program. The plan was approved by the committee and administrators over the objections of the preschool teacher. The choice of actions was to either take the child and do the best she could for him or to fight the decision by filing a grievance. The narrator felt that if she chose to accept the student, she would be a party to a 
placement made in violation of state policy, and she would be doing the job of those teachers who were properly responsible for educating this student. She further mentioned that the special education teacher had made no effort to obtain special training in communication skills necessary to provide adequate services to this student. On the positive side, she knew she could provide appropriate services and that the child would progress if she accepted the placement in her classroom.

The participant was also concerned that if she chose to fight the placement by filing a grievance, she would be risking her working relationship with the other teachers in the school, and putting the student in a negative situation where he would be unhappy and would not make progress. The general tone of the narrative emphasizes the propriety of following procedures and a need to clearly identify individual responsibilities (although the word responsibility was not used at all). In the end, however, the welfare of the child outweighed the importance of other considerations. The narrator summed it up as follows:

The conflict was, I know that state laws do not cover me as a Sp.Ed. Pre-k/k teacher after a child is 6 . Just because that school staff was not prepared to use a picture communication system or sign to this student was not my problem. I knew however after observing the situation that this child would regress.

This scenario highlights the complexity of many moral dilemmas experienced by preschool special needs teachers and illustrates a number of the factors identified as characteristics of a moral dilemma:

1. a violation of law, regulation, or policy - state and county age requirements for placement

2. risk of harm to others - to the student, to the participant

3. individual's rights are ignored (this was not discussed in the narrative directly but hinges on the student's right to an appropriate education in the least restrictive environment)

4. a risk of damage to an individual's reputation - the participant could gain a reputation of being difficult to work with 
5. a risk to relationship between colleagues - her working relationship with the special education teacher and the kindergarten teacher would be damaged

6. a conflict between two or more responsibilities - the participant has a responsibility to follow state and county policies, and a responsibility to her supervisors

With regard to the processes used to determine the most appropriate action to take, this scenario is interesting because, in the end, other considerations took precedence over what the teacher considered the best action. As seen in the quotation above, the teacher initially considered that this was not her problem because the state and county policies governing the situation are clear. The ideal outcome would be for the special education teacher to request training and to continue working with the student. The preschool teacher first contacted the State Department of Education to reassure herself that her perception of the situation was correct. Then she informed her supervisors of the situation and received no support. Finally, she states, " I told the M.I. teacher he should definitely receive more training to keep him current or look for a new job." In the absence of this ideal outcome, the preschool teacher was left with two options. Either she file a grievance to obtain the right outcome as defined by state and county policy or she acquiesce and accept the child. In the end, she "weighed the risks and benefits of various actions" and chose the outcome that appeared to be best for the child.

\section{$\underline{\text { Sample Scenario } 3}$}

In the third scenario (Scenario 014, Appendix F), an agency referred a child to the preschool program for a developmental evaluation because they suspected she had delays. The narrator of the story carried out the evaluation. She found that the girl did in fact have some developmental delays and that her scores bordered on the scores required for eligibility. In her words, the dilemma was:

Morally, I felt terrible that this child would not have any services, and that the home situation was not 'a good one,' and the child would be in a safer, warmer and more loving environment, if not in the home. 
At first glance, the choices here are relatively simple. She could follow the guidelines provided by county policies or she could find a way to 'make' the child qualify for preschool services. She states:

I considered doing a re-evaluation right then. But I knew I shouldn't. I also considered making sure each question was answered correctly or that I hadn't made an error in adding, or re-determining/interpreting the child's answers.

It is interesting that in this case the teacher takes a consequentialist view of the possible outcomes for the child but takes a unilateral approach to the policies. She states:

The deciding factors were truly the 'letter of the law' and the 'regulations.' Since

the regulations are very specific, I followed those.

What makes this interesting is that there are concrete consequences which argue in favor of following the letter of the law. If she did not, she risked censure by her employer and the very real possibility of placing a child with mild delays in a preschool "spot" which would then not be available if a child with more severe delays was later referred to the program. As with the first scenario, the narrator appears to have made her decision relying on her knowledge of policies. No mention is made of consulting any one else.

In this case, the characteristic that made this a moral dilemma (a risk of harm to others) is also the extra consideration which the narrator made after determining the appropriate action. However, the narrator did not find that the welfare of the child could override policy. In contrast to this emphasis on procedures, she later states:

I however, should have 'spoken up' and stated that the child start in the program or be reevaluated sooner or under a different situation. And/or possibly, I should have pursued the agencies that I felt were doing nothing for the child.

This suggests that under other circumstances and under less pressure, she night have acted differently. In this instance the competing interests were all strong enough t o prevent her from making what she otherwise considered to be the best choice. 


\section{$\underline{\text { Sample scenario } 4}$}

The fourth scenario (Scenario 015, Appendix F) involves a much more serious dilemma. This teacher was told by one of her students the details of being sexually abused by a family friend. The teacher knew that the proper course would be to make a report to Child Protective Services. The narrative does not describe discussing this with anyone. There were a number of considerations which she weighed prior to her decisions to actually make the call to CPS. If she make the call: 1 ) would the father guess who had made the report and harass her and her family (he had done this before)? 2) would the parents punish the child for telling the teacher about the abuse? 3) would the case worker be able to understand the child's speech well enough to be convinced of the child's sincerity? and 4) would the case be dropped and her life disrupted to no purpose? If she didn't make the call: 1) she would ensure the safety of her own family, 2) she would not be carrying out her job duties, and 3) she would be open to a fine for not reporting the incident. The teacher wrote, "...I had to consider the safety of my family, along with the obligation of my job. Although I knew I could not let this continue happening to this child."

In the end, the teacher reported the suspected abuse. In contrast to the previous scenario where procedural propriety and child welfare were in opposition, in this instance procedural propriety and the welfare of the child coincided and made the course of action clear. It appears that these two considerations together were required to overcome her concerns for her own family's safety. It is interesting that this teacher did clearly weigh the 'consequences to others of acting or not acting,' and the 'consequences to yourself of acting or not acting.'

\section{Summary of the scenario results}

The purpose of this section has been to give a general discussion of the scenarios that were submitted in response to the first questionnaire. It is clear that these participants, regardless of their moral orientation, did not often use moral language or moral terminology beyond stating that something was either wrong or right. This raises several questions. Is this lack of moral language a result of participants' limited writing skills, the structure of the questions, or both? Does this lack of 
moral language limit their thinking with regard to dilemmas? Any attempt to answer these questions would be speculative.

The discussions of the specific scenarios lend support to the idea that, under ideal conditions, these preschool special needs teachers favor a consequentialist/ utilitarian approach to the solution of problems as opposed to a principle based mode of decision making. Further, all of the 18 scenarios contained some weighing of the risks and benefits of different choices, but the extent and consistency of these considerations varied considerably across the scenarios. Under more stressful situations, preschool special needs teachers may be more inclined to enact what might be termed a rule based mode of choice, i.e.. following the letter of the law or definition of job duties. In the preceding discussion of the rankings, it was suggested that under a forced choice condition, these preschool special needs teachers tended to act more in favor of group benefits rather than individual benefits. These findings would seem to be at odds with each other. It may be that participants in this study view the purpose of laws as designed to maximize the common good rather than as designed to protect the rights of individuals.

Finally, given the wide range of scenarios and means of responding to the circumstances, it is tempting to conclude that how an individual reasons about a dilemma is dependent upon the details of the situation as described by Gilligan and Belenky (1980) and Krebs and Denton (1997). However, this would require knowledge of how an individual would respond to a large number of dilemmas and is beyond the scope of this research. Some tentative conclusions regarding this will be made in the discussion chapter.

\section{The Interviews}

In this section of the results, the background and self images of the four individuals who were interviewed will be discussed, and the transcripts of the interviews will be analyzed in terms of the seven research questions which structure this research. The research questions will appear as subject headings. The research questions were designed to elicit information relating to Rest's (1984) Four Component Model: 1) characteristics which signal that an event has moral implications 
(Moral Sensitivity), 2) processes employed by teachers to resolve a moral dilemma (Moral Reasoning), 3) factors considered after a decision has been made regarding the most appropriate action to take (Moral Motivation), and 4) prioritized items from category 3 which participants indicated they would definitely consider before taking any action (Moral Motivation).

Whenever possible, precedence will be given to the words of the individual over those of the researcher. However, it is important to point out that the content of this discussion has been reorganized and does not reflect the sequence of topics as they were discussed in the interviews. The names used for the interview participants are pseudonyms to maintain confidentiality.

\section{Case \#1: Darlene}

Darlene is a 37 year old preschool special needs teacher who lives with her family in an urban area of West Virginia. She is married to a university professor and has one adoptive son, three years old. Darlene and her husband are planning to adopt another child.

Darlene was born and raised in New England. She has a fraternal twin sister and two older sisters. She described her relationship with her sisters as close. She is particularly close to her twin sister whom she describes as assuming a care-taking role toward all of the sisters. The strength of her bond with her family was summed up when she said, "They always say you come into this world alone and you leave alone, well I didn't come in alone and I'm not leaving alone."

Prior to their marriage, Darlene's mother attended the Episcopal church and her father attended the Catholic church. The children were raised Catholic until their parents divorced, at which time they began to attend the Episcopal church. During the interview, Darlene did not mention a specific current church affiliation and expressed a belief that church attendance was not a true measure of a person's spirituality or moral development.

When Darlene was in the fifth grade, her parents divorced, followed soon after by her father's death. After the divorce, the girls and their mother went from affluence to poverty. They moved frequently to avoid bill collectors and they were dependent on Medicaid for medical care. In spite of this, Darlene stated that the family values did not change. Darlene described herself as having been 
rather oblivious to events surrounding the divorce and stated that her sisters are much more likely to blame the divorce for emotional issues that they experience as adults. It is interesting to note that when she was asked if she had any mentors or individuals who had made a difference in her life, she thought of someone from this period of her life. Her fifth grade teacher took note of her journal entries relating to the divorce and talked to her about her feelings.

When asked if she could characterize the values in her home she said:

.....when I was growing up the only rule we had was to be nice......and it was the only rule. But it was the rule. And I remember growing up my mother said, always said, be nice. You know, treat people the way you want to be treated. Be nice. And in that, I mean, everything fell under that. You don't hit people if you're nice and I mean everything fell under that, but I mean, that's kind of like growing up, my mother was just and my father, it was just, we're going to be nice people. We're going to treat people the way we want to be treated and that was sort of the philosophy of growing up and if you did something wrong you admitted it and you moved on you didn't get reamed every day about something you did two weeks ago, and you loved each other, you loved your family. You loved your family. You do, and it wasn't something said, you have to love your family, it was just something that was there, it was just there. When someone needed a pick me up you gave them a hug and a kiss and if a neighbor needed help, even it you didn't want to you helped them because it was the thing to do and so basically I feel like, my mother really instilled in us a really good sense of treating people nicely, you know, the way that you want to be treated, and maybe education wasn't high on her list, you know, sit down and do homework and all that, but as far as being a good human being, that was the highest on her list, you know, you know, it doesn't matter if I'm smart and I'm a trash man, a good person, that's all that's good, that's all that she asked.

In the context of a discussion about how kindergarten expectations have changed over the years, Darlene talked about her own experience with early education:

If I was kid today, I would have been in a, I wanted to play, I wanted to hang out with my friends, and I've learned everything because I had to, not because I wanted to. It was time to tie 
my shoes because nobody else was going to do it for me. It was time to ride a bike because everyone's riding bikes and I didn't know how to ride a bike, and if I wanted to go with them, I had to ride a bike. Telling time. No one's telling me the time anymore. Time to do, I had to figure that out. So I didn't learn because I had a genuine interest in learning, I learned because it was functionally ready, time to learn. And I know that if I was the same kid today that I was 38 years ago, I'd be in big trouble right now. I'd be in big trouble. I'd be in my preschool special needs class, you know, or my mother would have gotten a note home saying look out, this kid's going to be special needs. You know. So that's just how time's have changed.

Darlene has a bachelors degree in psychology. She did not have a career goal in mind as she entered college and, when the time came that she was forced to chose a major, she chose a subject that would get her out of college quickly based on the course work she had already completed. Majoring in psychology allowed her to finish college in four years. Even though she enjoyed most of the classes she took in psychology, she was not sure it was something she wanted to do as a career.

Darlene met her husband in college. She described her husband and their marriage in the context of the effects of her parents' divorce:

But it also, I think it affected a lot of who I chose to be with. I chose to be with someone that is extremely nice, that treated me like gold, and wanted to support me no matter where, me and whoever we were with, family-wise, wherever we went he was going to be there. And his family is extremely stable. And I think that that was a big draw for me...because I had that and then lost it, I sort of wanted it back. And I think it was a good opportunity, every opportunity given, you know, I'm taking it and I'm running, you know that kind of thing.

After college, Darlene worked as a mental health professional in group homes for children with developmental disabilities. When she and her husband moved to West Virginia, Darlene considered working toward a degree in deaf education. She had become interested in deaf education as a result of a childhood friend who has a hearing impairment. Unfortunately, no program was available in 
her area and she was unwilling to separate from her family to pursue that degree. Darlene's experience working in the group homes gave her a desire to teach and lead her to complete a Masters' degree program in preschool special needs.

Darlene has been teaching preschool for three years in different settings. Currently, she is employed by the county school system and works in a combination Headstart/Preschool setting. Darlene also teaches courses in the Preschool Special Needs Program at the university where she got her masters degree. When she was asked about balancing family and career, Darlene said, "...I think the key to a happy life is to have the family that you always wanted...but part time work,..." She also stated that without some work outside the home, she would eventually feel that her life was constrained.

\section{Darlene and the research questions}

1. What events, occurring in the course of their professional duties, do some preschool special needs teachers consider to be moral dilemmas?

During the first interview, Darlene was asked to comment on 15 of the 18 scenarios which were submitted by the Delphi participants. She was not asked about all of the scenarios received because one was Darlene's own scenario, and one scenario was from a time when the participant was working as an early intervention specialist and the details of the events were not meaningful to the preschool special needs teachers. A third scenario was left out of the interview phase because the researcher was unable to get important clarifying information from the participant who submitted the scenario.

Of these 15 scenarios, Darlene found that 10 of them would pose a moral dilemma for her. Of these 10, two scenarios had to do with overt violations of special education law, five dealt directly with the risk of harm to a child, one had to do with the welfare of a child and the reproductive rights of a parent with mental retardation, and two involved the relationship between special education regulations and the welfare of students. 
2. From the perspective of these preschool special needs teachers, what specific characteristics of these dilemmas signal that they are moral in nature?

Rather than discuss all of the scenarios which posed a moral dilemma for Darlene, two scenarios will be discussed because they provide an interesting insight into what the processes Darlene engaged in to determine the exact nature of a dilemma. The first of these is a dilemma from the Delphi scenarios and the second is a dilemma raised during the course of the interviews.

The first scenario involved a teacher who was asked by her special education director to write and sign an IEP for a student as if a meeting had been held. The student was the son of an attorney. This scenario is interesting because it illustrates how the details of the events and the actors involved can influence how the individual responds to the events. The dilemma here seems to stem from the teacher's knowledge of special education law, her responsibility to the student, her concern for her own well being, and her loyalty as an employee.

Darlene's first reaction to the scenario was to say unequivocally that she would not sign the IEP. Then she qualified it by saying,

...it depends too, if you have a trustworthy team member, that you know is professional and is doing everything appropriately and you know that they wouldn't compromise professionalism, I might have a tendency to sign it.

She went on to state that the combination of lack of confidence in the administrator and the knowledge that the father was an attorney would unquestionably lead her to decline to sign the document. Darlene further stated that the reason for not holding the IEP meeting would effect her response. If the reason were purely procedural and would not ultimately effect the welfare of the student, she might be more favorably disposed to signing the document. While there is a dilemma for Darlene here no matter who the actors are, the degree of discomfort she would feel is related to her relationship to the other individuals involved.

Darlene's consideration of the nature of the dilemma is directly related to the question of the two options for action, i.e., to sign or not to sign. At first glance this seems to be a question of the reasoning about the dilemma rather than the identification of the dilemma phase. However, 
examination of the details suggest that the specific facts of the events are seen as influencing the seriousness of the dilemma. For Darlene, there is an interaction between the projected possible outcomes (reasoning) and the information available for the understanding of the nature of the dilemma (identification or moral sensitivity).

Darlene described the second dilemma when she discussed working for Headstart. She said, So, that's the hardest part about being a preschool teacher. You want to do a good job and a lot of this, especially where I am now, they say do not do anything at home, do not spend any of your own money, do not bring any of your own toys in, so as much as they can say that, it doesn't work well unless you do all those things. And most preschool teachers do bring in their own stuff, spend their own money and use their own time.

Darlene did not feel that this posed a moral dilemma in itself, ...because it's what's best for the kids. But when they're telling us, like CNR or whoever monitoring system comes in and asks us that question [Do you work at home and spend your own money for supplies?], we have to say we're not doing that. That is an issue for me. Not being able to be honest with saying, yeah, my classroom runs well because I take that opportunity to do that for the kids. But instead I have to say, yeah, I get everything I need, I get plenty of planning time, I get, so that sort of not being able to be tRebeccaful is a dilemma for me.

Clearly, being asked to lie was the heart of the dilemma, but there were many other issues that came up in discussion. While planning at home and using her own resources were disturbing to Darlene, this activity had a direct effect on the welfare of the students. Even more disturbing to her was having to do excessive amounts of paperwork at home as a result of conflicting and sometimes redundant program requirements. The trade off between duty and family was not acceptable to Darlene. This caused a great deal of resentment even though she understood that the request to hide the fact that she worked at home was motivated by her supervisors' desire to please reviewers and preserve the income they provide to the Headstart Program. On the other hand she doubted that the job could be done within the time and with the resources provided. Being asked to lie about 
activities she engaged in that directly affected the success of the school program did not seem fair to her.

Darlene went on to speculate that perhaps with experience she would have a stock of lesson plans to select from that would allow her to stop working at home but,

... if you're a good teacher you could use what they have in a minimal way, and I'm talking minimal way, to do what you need to do. But it's not going to be exciting for kids and not going to be fun for you.

This suggests that Darlene believes this poses a dilemma because of her inexperience. However, she later changed her view, stating,

...but these requirements, don't do any work at home and don't use any of your own money and don't use any of your own time. I'm sorry, if none of us used our own time or our own money that job would never get done.

She also expressed the opinion that any reviewers would have been in the same position and would know that she used her own resources regardless of what she told them. She seemed disturbed by the absurdity of the scene that would result if she should be asked directly about her work hours.

Later, Darlene expressed the feeling that she was short changing her family to do a good job at work but didn't see this as posing an ethical problem, almost viewing it as a selfish motive.

Not that it bothers me to put my own money in, because I know that it's going to kids, I'm sending stuff home or I'm working, it's making, it's helping the, it's helping. But the time spent, the time away from my family. I'm a 37-hour-a-week on paper, but I'm a 60-hour-a-week realistically. Realistically. And that bothers me. And that has nothing to do with ethics or anything else. That' s just me. And I' m sure a lot of people just do it and don' t even think twice about it, but I don't. I think twice about it. You know, when my kid needs, comes to me with questions, and I say, well, sorry, I'm doing my paperwork, move along, I mean, I know that in the long run he's going to forget that I said that, but to me as a mother, another guilt. Another notch on the guilt belt, you know. I'm just working. 
When pressed to discuss this, she agreed that it had to do with ethics because of job responsibility and her responsibility to her students and their families but she still did not view the needs of her own family as a legitimate aspect of the moral dilemma.

...to me, ethically you're going to do, you're going to do what they tell you to do and you are. So I guess it sort of does. It sort of does, but like when you're not supposed, I don't know. I don't know, I guess I'm confused at the whole thing, but I just know that sometimes I become frustrated when it's the paperwork requirements. And I understand you're supposed to justify what you're doing, so you have to have everything in paper, but it bothers me that way. And when I think of ethics, I think, I guess I'm just kind of, at least as far as ethics is concerned, I'm thinking about ethics as far as dealing with the kids, you know, and families. And the whole paperwork thing is sort of, I guess it's another ethics issue, but it's not what I'm focused on because it doesn't have to do with the kids, direct care of kids and families. No.

This suggests that for Darlene, the desire to be and to be seen as competently meeting the needs of her students overrides her discomfort with working at home unless it is something she views as not contributing to the needs of her students. Darlene still seems to be wrestling with the relationship between her own needs and her role as a professional.

Three of the scenarios clearly did not pose a moral dilemma for Darlene. The first of these was the scenario in which a mother was coming to class and encouraging her daughter to perform actions which the teacher felt she could not do. Darlene saw this as a positive action on the mother's part, encouraging the child to succeed rather than emphasizing what her delays. She also saw this as an opportunity to educate the parent in typical sequences of child development. The second was the scenario in which a child was evaluated for developmental delays, and was found to have some delays but nonetheless did not qualify for preschool services. The author of the scenario thought to find a way to qualify the child in spite of the results, but Darlene however, felt that the regulations were clear. She stated, "So I do not think that is really a dilemma, that's really just a matter of helping the family find the resources they do need if she doesn't qualify." The third was the scenario in which a father wanted his child in a school other than that which the teacher felt the 
child would be most safe. Darlene felt that this was a case in which the teacher could document her concerns yet still provide an opportunity to honor the parent's choice.

These scenarios are of great interest because they clearly have moral dimensions that involve the welfare of the child and the parents' role in their child's education. Perhaps they are not specifically identified as moral dilemmas by Darlene because she knows clearly what she would do under the circumstances. That is, the situations do not require any deliberation on her part to resolve the situation. This suggests that the perception of a dilemma is in part a function of the individual's familiarity with similar events. This is very different from the researcher's original formulation of the research questions in which moral dilemmas are distinguished from practical problems. For the researcher, events with moral dimensions were defined as moral dilemmas because there is always the option to act or not act, even when one has an opinion of the ideal course of action. For Darlene, the category of practical problems also appears to include those problems which have moral dimensions and for which she clearly knows the solution.

Two of the scenarios posed problems for Darlene but it was not clear if they posed any moral dilemma. Darlene's responses to these scenarios were different from her responses to the other scenarios in that she wanted more information before making a comment on the scenarios. The first of these was the scenario in which the parents of a child with autism did not believe their child could do the things documented by the teacher and staff, and accused the staff of physically abusing the child. This scenario caused Darlene to ask several questions about the parents' perceptions, and to speculate on how to defend herself against these accusations. Here again there did not seem to be a dilemma in that she did not specifically feel called upon to take an action. Darlene did not discuss this directly in terms of moral issues but did discuss it as affecting her reputation. This contrasts somewhat with the Delphi results in which potential harm to an individual's reputation was ranked high as an indicator of a moral dilemma. It is possible here again that the word "dilemma" is confounding the question. In cases of reputation it is clear that one should defend oneself, therefore there may be no dilemma per se. 
The second scenario involved the mother who could not make up her mind between the preschool special needs program and the Headstart program. In this case, Darlene chose to view this more as a practical problem that required some investigation to understand what was happening in the mother's mind. She wondered if there were real issues affecting the child that resulted in his behavior change. Darlene chose to take the mother's perception at face value. This is in contrast to the author of the scenario who felt that the mother was trying to find an arrangement that would maximize the amount of child-care for her child. Whether this is true or not, clearly Darlene had access to less information than the author and this affected how she approached the question.

This tendency of some events to generate many questions for Darlene suggests that the specific details of events are as important to the identification of a problem as they are to reasoning related to choosing an appropriate solution. This points out one of the difficulties with posing hypothetical dilemmas to subjects. There is not always agreement about what details are relevant to a dilemma, consequently, the individual's responses will always remain hypothetical to some extent. Darlene summed it up by saying,

And it's hard too because you mention that you have a scenario and I'm thinking of one in my head that might be a little the same, but it might be different, so I might come up with an answer from my experience as opposed to...

In response to another scenario where the author was asked to evaluate her own nephew for developmental delays, Darlene's first comment was, "I do not have a nephew, I have a niece...,' further suggesting that to Darlene moral dilemmas are highly dependent on context. Darlene later discussed this directly when talking about the differences in values between her husband and herself,

Like he works in sort of like a business, and school related, you know, he sees this definite, you know, ladder to where he's going, a definite road, and with some of the things that I'm doing, with the people that I'm working with, they're, we don't see, it's fuzzier. I think it's fuzzier for me than for him. So there might be more of a, I have to guess, kind of thing than for him. This is what's next. And B comes after A. And C comes after B, whereas for me it's like, yeah, 
I don' t think that, so with this family I'm not so sure that's what's next for them, but I'm also dealing with such a younger population it might be different.

This suggests a belief that how a person's values develop, the type of dilemmas one might encounter, and the procedures for resolving dilemmas are very dependent upon the context in which the individual functions.

Throughout the first interview, in the context of the question of whether a scenario would pose a moral dilemma, Darlene frequently made statements such as "I'm not comfortable doing this at all," "I wouldn't be comfortable with that," and "I would feel some major discomfort with that." This raised a question about whether the emotion of discomfort was actually a signal of a moral dilemma that preceded the specific identification of the nature of the dilemma, or whether the emotion was simply an accompaniment to the recognition of the dilemma. When asked about this idea, the following exchange occurred:

Researcher: ...it suggests the possibility that the initial identification of the problem might start with an emotion and then later on the reasoning part of it. You know, the logical explanation of why it's a moral dilemma might come afterwards. And I was wondering if you had thought about that, as far as your own experience. When things happen, do you immediately know why it is that you're uncomfortable?

Darlene: I think sometimes I do. Sometimes I do, like if it's a neglect type thing where a certain someone comes in with an injury or just looking really bad, that's a quick, that' s not really emotional, you just look at it and say that's right in my face I kind of know it really well. But if it's something that's subtle, more subtle, that makes me uncomfortable first, and it's not like until you like research and look further into it that you understand why you' re uncomfortable, it's because it's something that should be taken care of. Something that's making, it's making you uncomfortable because it's not ethical or moral or, or, you, you're looking at the kid and the kid's not healthy or happy.

For Darlene, there are some situations where the nature of the dilemma and the knowledge of what to do are almost automatic. In other cases, the emotion of discomfort is the first signal that 
something is wrong and further deliberation is required to understand the specific nature of a moral issue.

3. What process do these preschool special needs teachers use to determine the proper action to take under the presenting circumstances of a dilemma that they have identified as being in the $\underline{\text { moral domain? }}$

Darlene made reference, directly and indirectly to a variety of processes she would use in trying to resolve a dilemma. In terms of the processes which appeared in the Delphi study, she mentioned gathering documentation, providing information to persuade other parties, seeking advice from supervisor, seeking advice from colleagues, requiring a team decision, seeking help from other agencies, and deciding without consultation with others.

When discussing the hypothetical scenarios, Darlene often stated that the issue needed to be resolved by the IEP team. For example, in the case where the teacher was asked to sign an IEP even though there had been no meeting of the team, her preferred solution would have been to call a meeting and eliminate the dilemma by following appropriate procedures. Her action would be in keeping with the legal requirement that decisions about the provision of services must be made by a team. Although unstated, Darlene gave the impression that there was also the issue of legal repercussion against herself.

In another scenario, a mother kept switching her child from one program and back to another. Here Darlene felt that a team meeting was necessary to gather as much information as possible to understand the specific nature of the problem. In a third scenario where a teacher and a classroom aide who had physical limitations of their own were assigned to work with a highly aggressive child, Darlene again felt that a team meeting was necessary to resolve the situation. In these three cases the dilemma was not about what action to take so much as it was about who was actually responsible for resolving the issue. For Darlene reasoning about an issue is sometimes affected by who is involved in the situation

When discussing dilemmas that she had actually faced in her career, Darlene raised the issue of procedural requirements of different employers: 
What's interesting is I've worked with several organizations and they all have different philosophies with how I'm supposed to follow through on protocol. And when I was working with the county it was a lot different than when I was working with Head Start. Head Start I'm more independent. I can do kind of go to the end and then get my supervisor's approval at the end. With the town system, you get very strict guidelines. So depending, I mean sometimes when you're working with the school system you've got to follow through on every little thing and they're telling whether you can or can't follow through. It's a little more difficult than if you're having a gut-wrenching situation and you can kind of follow through with yourself, and at the end kind of just inform your supervisor of what you did.

Darlene expressed a preference for the situation where she could follow through and then report back to her supervisors about the outcome. She later qualified this preference by explaining that in her current position there is no actual building principal and the staff share responsibility. So it is not that she simply prefers to act on her own but rather that she prefers to be in a situation where her judgment is valued.

In the case which she submitted for the Delphi procedure, Darlene was working with a child who she felt was being put at risk medically by his family. She felt that she had done everything she could to influence the child's parents and was required by law to make a referral to CPS. However, she was told that she could not make the call because school protocol said she had to inform her principal and then he would decide about making the call. In her current position she is free to follow through on decisions. She only calls her supervisor after the situation has been resolved or if she is uncertain how to resolve it. In the context of the discussion of being told to lie about working at home, Darlene expressed the opinion that ethics required her to follow the protocol of her employer even if she disagreed with their decisions. She stated, "...ethically you are going to do, you're going to do what they tell you to do, and you are." This apparently absolute statement was tempered in the second interview, when she said,

...years ago I'll do it because that's what the boss says I have to do. I' m not going to hurt anybody or go against laws, but I' $m$ not going to just lay back and do it now. 
In the first interview, during a discussion of definitions, Darlene expressed her understanding of the meaning of the words "ethics" and "morality". She said,

Ethics somehow I see as coming from a book. The ethics say this is what you have to do whereas the morals I see coming from the inside, that's what you have learned, that's how you've interpreted, that's how you're going to use it.

In answer to a follow-up question, Darlene made an interesting observation regarding how some people make decisions. To illustrate what she meant, she said,

I think that's kind of what I'm trying to point, do you understand what I'm saying. Like I, morals I feel like you're brought up with, like some people in this world have no morals because they were brought up and their parents didn't teach them right from wrong and what should be done. Now when they go and they work in an office, they kind of learn at least office-wise, what the ethics are there, but they don't have any morals to bring in to that. But I think that when you have morals growing up, then you get to a certain place, like what we're doing, and if it's ethics, you have to follow, you use those morals to follow it, you use your morals so you can follow the ethics and be comfortable with what you're doing. Now, if you haven't grown up with morals, I believe that you may get into a position where it doesn't matter what you do as long as ethically you're following the right line, you're not going to have the turmoil in you, you know, you're just going to follow ethically what you're supposed to do and then, which, you don't have any beliefs about it. You know. You know. Which I think there's a lot of people out there that don't have morals, you know, they just do what they've got to do, they don't care how they make other people feel, and they don't have it inside of them to feel bad about what they're doing. They're like, 'Why is it, why is it wrong to, you know, call this person all these names, because, you know, I call it like I see it,' whereas the rest of us are going to use, I'm not going to call, I'm going to tip toe around to get what I think is needed and in the best interest for the kid, you know.

This illustrates her emphasis on "being nice" as a central value. It further suggests that she believes there are practical reasons as well as moral reasons for acting in a manner that respects the feelings 
of others. For Darlene, there is no point to "calling it like I see it" if it prevents her from getting what she needs.

Darlene's example also suggests an image of the self as representing one's heritage and upbringing. As she says, "you use your morals so you can follow the ethics and be comfortable with what you're doing." Moral reasoning is successful when it results in an outcome the individual can live with. What the individual can live with is related, at least in part, to the family history of moral education. Responsibility lies in the concrete and individual application of general rules of conduct. Thus, responsibility is called into play because each person has to apply the rules but each person will have inherited a different interpretation of the rules. What emerges for Darlene is an interesting and highly relativistic view of moral perception and reasoning.

Later in the interview, during a discussion of the categorization of various dilemmas, Darlene expanded upon this individual source of values:

...you know, assign them, put them in categories, you know, and everybody depending on their background is going to maybe put it in a different category, you know, depending on what they believe it is. I know my husband is a very moralistic person and a very ethical person might come in and say something totally different from what I say, you know. Yeah, yeah, cause his belief system is, you know, pretty much the same as mine, but sometimes he'll say something like well you believe that, and I'll say yeah, so I mean, even, we live together, we've been together for, forever, it seems like, and, but we do have different belief systems when it comes to certain things. And it might be just because I had my mother or my father, and he had his mother and his father, and I chose where I'm going with it, and he's you know, your whole life is many, many choices, and even though you've chosen to be together, what you're doing outside of, might be a little different, and require a different, have different requirements.

This clearly suggests her belief that an individual's moral development is not simply an ontogenetic response to the environment as conceived by Kohlberg but involves a measure of inheritance, individual choice, individual perception, and serendipity. Several times in the interviews, Darlene mentioned the different "roads" that were taken in her life or could have been taken. 
4. When preschool special needs teachers make a judgment regarding a moral dilemma, what other factors do they consider when deciding whether or not to act on that judgment?

5. When moral judgments compete with other values, goals, and concerns, how do these preschool special needs teachers prioritize these factors in order to determine the action which they will actually take?

In the discussion with Darlene, there was no clear distinction between the process of deciding what the appropriate action is and the subsequent process of considering factors that might affect whether an action is actually taken. In the instances where she almost made a distinction, Darlene mentioned several factors which she might consider. These were loyalty to her employer, job protocol, trust of her administrator, consequences to self of acting or not acting, and the welfare of the child. In terms of priorities, the welfare of the child almost always took precedence.

In most cases, the factors which Darlene took to mitigate either for or against action were considered as a part of the process of identifying the specific nature of the dilemma and the process of reasoning about the dilemma. An example that illustrates how mitigating circumstances are intertwined with the process of identifying and reasoning about a dilemma was Dawn's discussion of the scenario about being asked to sign an IEP as if a meeting had been held. The position could have been taken that it was illegal to sign the IEP and her employer's attitude toward her might be the mitigating circumstance, and in fact this may be how Darlene thought about it. However, her statements suggested that considerations of who was involved was a clear part of identifying the nature of the dilemma and reasoning about the dilemma.

Oh my gosh. I wouldn't sign it. If you knew, it depends too, if you have a trustworthy team member, that you know is professional and is doing everything appropriately and you know that they wouldn't compromise professionalism, I might have a tendency to sign it. Now if it was somebody I didn't know very well, or I question their professionalism, I might say, but if I knew that the parent was an attorney, I would definitely say, I'm not comfortable doing this at all. Is there any way we can meet to have an IEP. And if it had something to do with the date, like they had to have it signed because the date was passing, maybe have the IEP and talk to the parent 
and talk to them and see if you can back date it or make some kind of note saying we couldn't meet because of. But I do not think I would feel comfortable signing it if the father of the child was an attorney. Especially if he was an attorney and he knew his special ed. laws. Then you're in deep trouble.

Such intermingling of considerations may be an artifact of asking hypothetical questions. Darlene frequently asked about and speculated about details of these scenarios during the discussion. The real life scenarios that Darlene presented did not involve any considerations beyond deciding what the appropriate course of action was, therefore no comparison is possible between her responses in real and hypothetical situations.

\section{$\underline{6 .}$ Do these special needs teachers feel that they live up to their own standards of moral} behavior? If not, how do they resolve the resulting tension and plan for future development?

Darlene did not directly address the issue of how she is able to maintain her sense of moral dignity. However, she did talk about how her ability to act independently had changed as she matured and gained more experience:

Researcher: I can't imagine that you would feel comfortable with just doing what you were told to do.

Darlene: No, um, now I think I've come a long ways in that, because there was a time when I would do, if that's what you wanted me to do I'm going to do it just because I didn't have a really good sense of who I was, let alone, I'll do it because you tell me to do it. Now, I knew that hurting someone was wrong and I knew that, so that as far as that goes, but as far as speaking out for not only what I thought was right, and my rights, but speaking up for kid's rights, that's come with age, I think. That's come within the 10, 15 years with, and it gets more and more, some people say you get bitter when you get old, and I don't think it's bitter, I think, it's, you become more aware of the injustices and then you decide to make a decision to make it a verbal statement that this is not right and I don't like it. 
Shortly after, she expanded this by saying,

I've come to the point where I can within the last 10 years, even with that feeling inside me, I don't care what I feel inside, it's going to come out because I think it needs to come out. Because years ago I'll do it because that's what the boss says I have to do. I' m not going to hurt anybody or go against laws, but I' m not going to just lay back and do it now, now.

At another point in the discussion, Darlene talked about both the will to act and the knowledge of how to act to be effective in an intervention,

So I think you come a long way in your tenure, working with these families. You know what you should say, what you shouldn't say and how you read people, and the things you need to do as far as feeling comfortable with yourself. You, you come a long way. Now when I get to the point where I'm telling everybody what to do, I think it's probably time to leave. You know. You're not doing right by your kid! It's probably time to step down, but.......

During this part of the conversation, Darlene again made reference to her internal state with regard to actually acting upon her beliefs. She expressed an extreme discomfort when advocating for what she believes is right:

And it's, even when you're sticking up for your own rights, like my kid's rights, um, I'm still uncomfortable about it but I know that it's right. Deep down in my gut I hate doing this, I hate doing this, I hate fighting for this because I know it's right, but I hate having to do it, I don't believe, I can't believe they just don't see it and make it right, I have to actually voice my opinion on this, I don't like to do this. So even those there's some turmoil inside of me because I don' t actually want to speak it, I want them to just know it.

This statement seems to express some resentment against those involved for having forced her to act to intervene in a situation, repeating the theme of responsibility discussed before. She feels that those responsible for the situation or perhaps those in a position of authority (it was not clear to whom she was referring) are also responsible for understanding and being aware of the problem.

Darlene did make one statement that gives a sense of how she might act when her values conflicted with those of her employer. During the discussion of being told not to tell reviewers that 
she worked at home or spent her own money on supplies, Darlene was asked what she would do if she were ever actually asked to do this. She stated,

I don' t know exactly what I'd do unless I was actually in those shoes, but I think I have a problem being honest, I would want to be honest, and I might even say, this week I didn't take work home, or make the comment like that. You know this week I could say and feel good about what I said was right because it's honest, without breaking, you know this week, I didn't take work home, or, or, or, this week I didn't borrow any, you know, toys from my son or this week I didn't take stuff home. But I don't know unless I was, I have not been in those shoes, and I know teachers who have said they have been in those shoes and I'm just lucky I haven't. And I hope I don't. And maybe if you work in this profession long enough you get to the point where you're so good at this stuff that you don't have to take the work home, but I just can't see it happening. I just can't see it happening, like if you've got a bucket load of lesson plans from year's past you can, you don't have to, but being creative and being spontaneous is part of the writing the lesson plans, so to use the same lesson plan last year that you used this year, it might work, but chances are it won't work. Or I can't, I don't know, I suppose some teachers do do that to save time...

Clearly, Darlene would attempt to find a way to meet both her values of loyalty to her employer and her sense of the importance of honesty. It is interesting that this scenario raised another question with Darlene wondering if it was even possible to do her job and not work at home and spend her own money. The implication is that perhaps her inexperience had led to the situation, or maybe there would be no harm in lying if she would eventually reach a point where she could do the job without working at home.

7. What do these preschool special needs teachers identify as the origins of their moral values and moral beliefs?

When asked if she had a sense of whether these values came from a religious source or were a product of her parents' personalities, Darlene said: 
Um, the sense of where they come from is my family. They come from my family, because I think they' re so important. My family is really important to me, and what they believe and what their parents believed is so important to them, that it was kind of handed down, sort of.

Following this train of thought, she added, ....I mean they both believed that there was a higher power and they both believed in the same, they were both very spiritual, and I believe every one in my family is very spiritual, and that comes from their families when they were growing up. My mother's grandfather was a minister and my father's family came from Scotland and Ireland where they were Catholic religion, so I mean it's always been there.

She then discussed her beliefs regarding church attendance and religion as a source of values: Now as far as going to church, people say, well, you're not religious and you're not Christian because you don't go to church, I, you know, this is me, and my beliefs, you can be spiritual and be a Christian and not go to church, that's just me. I have a lot of people that would say otherwise, but I also believe that I'm a good person and that regardless of whether I go to church or not I'm going to be the same person I am. I also believe there are people who go to church every week and consider themselves Christians and spiritual that are some of the nastiest people I've ever met.

Darlene did not express a belief that religion was the origin of values nor did she mention her education as an important contributing factor. The theme of family and upbringing was much stronger as a source of values. When asked specifically to identify where her own values ultimately came from, Darlene said,

Now, if you can detect where it actually came from other than your family. That would be hard for me to find. But, when you asked me the question and I think about the question, the only thing that keeps coming up is actually like a picture of my family, a picture of my Mom and a picture of my Dad. You know, that's where it's coming from. But as far as pinpointing it, it would be very difficult. 
Darlene presented a complex picture of the origin of individual values. The theme of family as the source of values, the previously discussed sense that personal choice contribute to the individual's sense of self and responsibility, and the contribution of the specific context of action all blend to form Darlene's sense of herself as a moral agent.

Yet the image of family was the strongest image presented by Darlene. This was emphasized toward the end of the second interview when she discussed her adoptive son and the importance of maintaining contact with his biological family.

Because he's got a great story behind him, so, when he grows up, his social, he doesn't just have support from this side of his family, he has support of his biological side of his family, so he's got the best of all the worlds. So, he's lucky ...

This emphasis on family reaches into the future as well as coming from the past,

I think it's a heritage it's your, your lineage is going to be continued. Your, everything that your mother did to you, you have a chance to either do the same or do different to somebody else to make them better.

\section{Personal Story or Fable}

While Darlene did not express a personal story or fable per se during the interviews, it is tempting to see one in the themes of family and choice. An image developed of a life course that begins with the family, where values are imparted to children. These values are in turn interpreted by the individual child whose perceptions of those values may vary widely from those of other members of the family. For Darlene, this basic value received from her family is to be nice, which is something like the Golden Rule. Treat others as you would like to be treated.

Then the individual must struggle over the application of their values within the contextual structures which they encounter as they make life choices of career and family. Depending on the individual there will be different levels of independence in moral action which will change as the individual matures and increases their experience. This developmental process is seen by Darlene as also a process of coming to know herself; what she wants from life and where she is going. Having 
her own family is very important to Darlene and she used the image of 'fighting' to build a family several times. Darlene sees her life as representing the legacy of her forebears and building family through raising children gives her an opportunity to pass on the legacy of values. For Darlene this includes the possibility of correcting mistakes made by her own parents and also making mistakes of her own.

This image of family is not simply a self-centered desire for posterity. Here the value of being nice, treating others as you would like to be treated, expands her focus outside the family and extends her sense of responsibility to others in the community. Darlene has also extended the theme of family into her career where she works with young children and their families. Here, the theme of nice -ness seems to have undergone a transformation for Darlene. In her discussion of how she has faced moral challenges over the years, she expressed an understanding that being nice in the long term may mean standing up for her beliefs by being forceful in the short term. And she talked about having developed the will to act even when she would prefer not to act.

In the end, it seems that a morally satisfying action for Darlene is one that contributes to her sense of being helpful to others and of being a nice person. An action that fits well with her memory of family and the love and support she felt as a child. An action that fits with her struggle to build a family of her own and pass on values that will support her own children

\section{Case \#2: Judith}

Judith is a 49 year old native of West Virginia. She has two adult children from her first marriage, and now lives with her second husband in a rural portion of the state. Judith works in a small rural elementary school and has been a preschool special needs teacher for 15 years.

Judith grew up in a small coal mining town in West Virginia. She is the next to the last child of four children; three girls and one boy. All of the children have names beginning with the letter J. The three girls are only a few years apart in age and there are 11 years between Judith and her brother. Judith's father was a coal miner and her mother was a homemaker until Judith was 6 years old. About her mother working, Judith said, 
Nobody's Mom worked back then, where I lived anyway. Nobody's Mom worked, and mine did and I hated it. But she worked several jobs. But the two she worked the longest were at the bank and she was a secretary for the United Mine Workers.

Judith's father worked in the coal mines until he was 58 , when he had a heart attack and had to retire.

Judith remembered her childhood with fondness and feels lucky to have grown up in a small town at the time that she did. She stated,

And yeah, a small town and basically, you know that's the one thing I think about some times how lucky I was because when we grew up we could play out after dark, there weren't any street lights and you were never afraid. There wasn't that fear. You didn't think people would break in the house and rob you or steal your bike if you left it down in the playground. Back then that didn't happen. It was a good time to grow up.

Judith went to a school so small that there were only 33 students in her graduating class. Most of those students had been together for the entire twelve years. After high school, Judith attended a small local college where she majored in Secondary Education and English Journalism. About her majors she said, "Loved journalism, hated teaching. Never did it other than student teaching practicum, never did it." Both of Judith's sisters are teachers, and when asked if her family's values contributed to the decision to go into education she jokingly said, "I started out in sociology/psychology. Didn't want to do French, so I went into education." Later she said, ...they raised all 3 of us girls with this, it was never, we were never pushed to grow up and get married, you know, and find the right person to take care of you deal, it was, go to college, go to college, go to college. And all 3 graduated with education degrees. And my oldest sister has a masters. Jessica didn't get a masters. John didn't go to college.

There was no emphasis on being teachers as a suitable career for a woman but when she thought about it, Judith acknowledged that there had been many teachers in her family. Judith and her sisters all came to education after pursuing other interests in college. 
Judith was married immediately after graduation from college and did not work as an educator until she was in her thirties. At this time she worked a substitute teacher "in a place that would call me. It was ------- School in ------- which was all special ed, and that's how I got into it." About this experience, Judith said,

I never really wanted to teach until I got into special ed. I did not, I didn't teach. I'd never taught regular ed. I didn't like it. I didn't want to do that.

When the interviewer asked about her childhood thoughts about the future the following exchange occurred,

Researcher: ...when you were younger, high school or college, did you have a vision of a trajectory of your life, you know, where it was going to go and how it was going to be.

Judith: No, I thought I was going to be a writer.

Researcher: Well you did have some.....

Judith: I had that dream that overwhelming urge to show dogs and write books. Um.....I never thought I wanted to be a teacher. I fell into that when the sociology didn't work out. Because of French.

Researcher: Right.

Judith: And I never thought I'd be a housewife. Never, just never thought about it. That was not an emphasis at home, and I ended up staying home 10 years with the kids until I thought they were, well, when Abby was 5, back then, '85, yeah, I got married at 20 because I had Megan at 23 so from 23 to from ' 75 to ' 85 I stayed home with the kids, and I still don't have any trajectory goin', I just float along day to day, I'm here. And I, no, I don't know. I never planned on getting married at 20. I think that was the whole crux of the problem right there, got married too young. And it just threw everything else out of kilter. Always wanted to live by myself, always wanted to try that. Never got to.

After 24 years of marriage, Judith divorced her husband. She expressed that she wanted to leave the marriage after her first daughter was born but stayed because, 
And couldn't do it. Couldn't bring myself to do it because I felt that it was wrong. I didn't have the scriptural ground for divorce, and you know, I just, yeah. So I was pretty unhappy for 24 years.

Judith tried to wait until her daughters were both out of high school but in the end she divorced her husband when her youngest daughter was a senior in high school. She expressed some continuing guilt over the divorce. She also stated that this was a time of self examination,

I think my, honestly I don't remember having a strong kind of feel about where my life was going. I don't remember that ever being..., but I think seriously that when I got divorced and set my whole....., everything about myself was just kind of laid out on the table. It's like you said this would never be an option you would never do this, you would never do this, you would never do this, and it would turn out awful, I'm just telling you a little bit more. You know, there were things that happened at that time...

After the divorce, Judith sought help for her depression. This depression she felt had been with her through out her life but she had felt guilty about seeking therapy and medical help; feeling that it was not something a Christian person would do. Judith had been active in her church for many years. When several members of the church told her that, "God doesn't give you depression, ...that's the result of sin," Judith left the church and eventually attended the church of her second husband.

In addition to her job as a preschool special needs teacher, Judith is pursuing a doctoral degree in education at a regional university. She states that one of her unmet lifelong dreams is to finish her degree and move out to the western United States and work with Native Americans. She also still dreams of showing dogs. 
$\underline{\text { Judith and the research questions }}$

1. What events, occurring in the course of their professional duties, do some preschool special needs teachers consider to be moral dilemmas?

During the first interview, Judith was asked to comment on 15 of the scenarios which were submitted by the Delphi participants. She was not asked about all of the scenarios received because one was Judith's own scenario, and one scenario was from a time when the participant was working as an early intervention specialist and the details of the events were not meaningful to the preschool special needs teachers. A third scenario was left out of the interview phase because the researcher was unable to get important clarifying information from the participant who submitted the scenario.

Of the 15 scenarios discussed, 11 clearly posed a moral dilemma for Judith, 3 scenarios did not pose a problem for her, and 1 scenario posed a problem of a different nature. When discussing the scenarios, Judith had a strong tendency to reference similar events from her own experience. Of the 11 scenarios which posed a dilemma, Judith referenced her own experience in discussing 8 of the hypothetical dilemmas. In her discussion of the scenarios that did not pose a dilemma, Judith referenced her own experience in 2 of the hypothetical scenarios. The scenarios where Judith did not make reference to past experience tended to be scenarios for which her answers were short and where she showed no hesitation regarding what should be done. Overall, this suggests that for Judith, the identification of a dilemma (as well as the reasoning about the dilemma) is closely bound with past experience

2. From the perspective of these preschool special needs teachers, what specific characteristics of these dilemmas signal that they are moral in nature?

When Judith responded to the hypothetical scenarios, she rarely mentioned any characteristics that indicated that a moral dilemma was present. She tended to make an emotional statement about the scenario and then go directly to possible solutions for the problem as if the identification of the problem posed no difficulties for her. For example, in the scenario where the child routinely came to school sick, she began the discussion by saying, 
I do not know, that's the same thing as the abuse. And I do not know what you do. I've been tempted to call Human Services a few times, and I might in that case, if the child was sick.

In the case of being required to do a developmental test on her own nephew, her first response was, "I would let someone else do that testing." In the case of the child left home alone, "Wouldn't that be awful. I mean that would be, that would be awful. What would I do, I'd probably let my jaw hit the floor." In the case of the student who was placed back into preschool even though he was too old, she said, "I don't think I'd let them do it. I mean, I don't even think I would have the meeting about that." Her certainty regarding dilemmas, combined with her tendency to relate the hypotheticals to real experience, suggests that her years of experience have led to an almost automatic identification of the nature of a dilemma. Consequently, the next logical step would be to find a solution to the problem.

In spite of this tendency to discuss possible solutions, Judith did sometimes go on to discuss the nature of the dilemma. In the case of the teacher who was asked to sign an IEP as if there had been a meeting, it is possible to ascertain what is at issue for Judith. She stated,

That would really be a big, big issue. I hate when people use their power over you, like the principal to make you do things that you don't want to do that you really know in your heart are really wrong and they just get this, you know where you're stuck. You know, not this, you have to work, you have to do what you have do, you have to work. You know don't make waves and all this kind of stuff.

Clearly there is a conflict between her knowledge of the legal requirements for writing an IEP, her loyalty to her employer, and her own need to remain employed and not create an unpleasant work environment. She strongly states that the imbalance of power makes this a moral dilemma.

In another scenario which involved a parent who came to class and loudly encouraged her daughter to demonstrate skills that the teacher felt the child could not perform, Judith intermingled the possible solutions with statements about what was at stake in an otherwise trivial seeming event. Here again, she begins with an emotional expression and then begins by relating this to past experience by making an assumption regarding the events, 
I don't know. I wouldn't want to be faced with that. That's hard because I know what they've done is they've tried to explain what the child can't do, those skills and what harm it might be, and I don't know.

Here Judith talks about the harm that may be done to the child if parental expectations are too high. She follows this with a discussion of the mother's motives and the potential good the actions may have,

I mean, that would not be a good situation because 10 to 1 you're not going to be able to tackle that Mom, she's going to keep on doing that same thing for that child. And I don't have any problem with a Mom telling me how smart their kid is, because I want to say that's right, don't ever limit them. You know what I mean, that I would encourage, the positive image of the child because we get the opposite too often, but that's a tough one, it's hard for parents, with mental impairments, you know, that's, I don't know that would be a tough one.

Judith then goes on to discuss how to provide the parent with developmental information which would help her to better understand her child's need. Another aspect of the dilemma is how to value the parent's contribution to her daughter's development on the one hand and to combat a tendency to feel that she, Judith, knows better about the child's needs,

And you don't want, you know, that's fine, working with the parents, and always saying to them, well you know your child better than anyone else does, you know, I want your input, you know, you know your child better than anybody else does, it's really important to get, and then sometimes it's like I don't think I hear myself, you know what I mean, it's like I'm saying, no, no I know better, and that, that is real moral dilemma, you know what I mean, so I mean, you're looking at Mom like that and thinking oh, she doesn't have any understanding of her kid and you've got that judgmental thing going on, and you know, that's hard, that's a hard place to work with this as parents. And you want them to love that child, you know they do love that child, but you want them to be proud and everything, proud of their part in helping the child, and nurture all of that, and it's hard. That's hard. That's all. That's a hard one. 
The dilemma here is to decide how the child would best be served, how to best promote the child's relationship with the parent, and how to balance parental and teacher input. For Judith, the event, which for others might simply be annoying, requires a very delicate balancing act.

In the second interview, Judith described an interesting real life dilemma that will also illustrate her thinking about what constitutes a moral dilemma. Judith described a recent event where she planned to show a dog at a regional dog show. She had a strong desire to win,

Abby, my daughter, is very precious, she's very pretty. And there is a show I'd like to go to in January. We have a dog named Eve who has four points, she has a questionable bite and it's going to be hard to finish her. The judge is D.B, ...and he loves pretty girls. And he'll put them up. I'll say, Abby will you come with me to the show in January? Oh, Mom. She hates to. So I talk her into it. We show Eve, because Eve's her dog. Oh yeah, she'll show Eve. Okay. Out front I say, okay, it's D.B., She says, "What's that mean?" I want you to go sit outside the ring before...the setters go in. And make eye contact a couple of times and one smile. "No, I'm not doing it." Please do it for your Mom. Seriously, do you play those games, you know, to win, or not?

This example is interesting because the dilemma results from a conflict in her own values rather than from outside actions. There is a conflict between her desire to win and her desire to win fairly, knowing that she can influence the outcome of the dog show by asking her daughter to act in a way that she wouldn't normally behave. It is hard to tell though how strong a dilemma this would have been since her daughter declined. If the daughter had agreed, would Judith have actually allowed the deception to occur?

Three of the hypothetical scenarios did not pose a moral dilemma for Judith. There is no immediately apparent commonality between these scenarios so they each will be briefly discussed. In the case of the student with autism, whose parents questioned the teachers progress reports and accused the teacher and staff of physical abuse, Judith began with her characteristic response, "Oh, that's awful. What do you want me to tell you? What would I do to clarify it?" and then she asked, "Is that a moral dilemma?" These comments were followed by a lengthy discussion of how 
to get the parents to understand that children often perform different skills in different settings. Judith seemed to view this as a practical problem rather than a moral one.

The second scenario involved a student who was in both a preschool special needs program and the Headstart Program. The boy's mother kept pulling him out of and returning him to each of these programs, giving various reasons for the changes. Judith laughed after hearing this story and asked, "Everybody has one of those every year, what's the problem?" She continued and gave the impression that this was a common problem, then brainstormed how to approach the issue, and suggested that the problem was really with the parent,

Yeah, yeah, until they work it out themselves what they want. And then you say no, we don't have that program, sorry. That's not a, I'm sorry that's not a big deal. Yeah they don't like preschool. See I'm not going to say brush it off, you'd just say why, can you tell me why he doesn't like it or he's happy when he's here. You know. And what do you think the difference is, it seems like you could ask some questions like that, but if the child is happy in the program I wouldn't get too concerned about the mom saying she likes Head Start better. Now if he was miserable every day, in my program, I'd try to find out what I could do to ........ but that to me isn't a dilemma.

The third scenario dealt with a mother with mental retardation who had two boys with developmental delays and was unable to care for these children without the help of her own parents. This mother had told the teacher that she intended to have another child because she wanted to have a daughter. Judith responded to this by saying, "I'm already rolling my eyes. I wouldn't say anything 'cause that's her business." Judith continued by stating that if the mother asked her opinion, that she would give it but otherwise it was not her place to act to prevent the mother from having more children.

The characteristic that may be common to these scenarios is that they involve conflicting perceptions of circumstances rather than any conflict of values, or the absence of any real threat to anyone from the participants' actions. In each of these scenarios, Judith emphasized her role to either educate others or to help in the effort to uncover information which would eliminate the 
differing perceptions. Judith did feel some need to act under each of these circumstances.

However, the actions were educational. Judith may have felt a human sense of responsibility to help the families of these children but perhaps because her job role is defined in terms of the welfare of the child, she felt no moral imperative to do so. At one point she expressed this idea, You know and you're going to spend some time with the parent, even if it's just that meeting you're going to spending some time with that parent. Where you can go a whole year and never meet a regular ed kid's parents. And I think special educators tend to get more involved in the lives of the kids. And two I mean it's like medical things, I mean you're, you know, you're like a nurse, you're like a teacher, you know, it's like you can do so many things that you don't just stand up there with a text book and a state IGO and go over stuff. That's stuff that, ___ you' ve given birth to that IEP. You know, you and a whole bunch of people, it's a part of you and you're going to do it to the best of your ability and it gives it a real personal feeling to it. I think we agonize more over our kids because it's like, oh, it's just, just I always tie it back to the family thing. I feel like it's this whole family I've got to help. You know, and I want to, it's not that I have to, but I want to.

There is also the suggestion that the teaching profession, special education in particular, is like the medical profession where professionals can have a large influence on people's lives. It is tempting to also see here a reference to the higher moral standards that medical professionals are expected to maintain.

At another point Judith commented on the nature of her feelings of responsibility (as opposed to the responsibilities spelled out by her job),

The other thing is, for all our fuss about parents, but I do try, I honestly have to say I do try my best. It's one thing I'm not ashamed of. I really do try my best to get along with the parents. And to try to help them. And I'm getting to the point where I've got parents that are younger than my daughters, and I feel like their Mom. So it, it sounds like, I feel like I should have my own degree in counseling, what's this job that I have to take care of everything, it's like you're, 
you know it's like dealing with children and grandchildren, where the Mom's and kids feel like.

These thoughts about the nature of her moral obligation as teacher, were echoed in another portion of the discussion where she stated,

I'm generally faced with, I generally agonize over moral issues. And sometimes my husband says "That's not a moral issue, what are you worried about?" you know that kind of thing. This actually raises the question of how one does identify a moral dilemma. Judith does not answer the question but she raised the issue several times again during the second interview. There she talked about guilt and how it gave the appearance of a moral dilemma when perhaps there really was not one. When asked how often she felt she encountered moral dilemmas on the job, she first said they occurred weekly, then she said, "At least every other week. But then again I have a friend who is a psychologist who tells me I live my guilt." At another time, she said,

But I went through this yesterday, I was telling Kathy, I said, okay, Kathy, I even used the term, I have a moral dilemma. And I said, I can do this or I can do this. And she looked at me and said, I know what you're going to do, you're going to feel guilty and you're going to do this. And she was right. You'll feel guilty and you'll feel like you're lying and you won't do it. You won't take the easy way, you're going to drive yourself crazy worrying about it and that's okay. That's right. That's what I did. Guilt rules my life.

This suggest a possible split between reasoned assessments of moral responsibility and an emotional response to situations. It also suggests that for Judith, as her friend suggests, there is some confusion about the boundary lines of responsibility. It raises questions about the role of identifying responsibility in the process of identifying moral dilemmas.

One hypothetical scenario gives a somewhat different insight into Judith's view of her responsibility. This was the scenario in which a child qualified for preschool special needs services and the teacher recommended placement in a rural setting because the child tended to run off and therefor would be safer. The father preferred a different school. Judith did not feel that there was any moral dilemma here. Her first reaction was to suggest what needed to be done for the child to succeed in the father's choice of placement, 
Well, I guess put in a lot of support team and make sure everything's covered, the bases are covered and everybody knows what's going on when he comes in.

She followed this by clarifying that this was not a real dilemma for her because she honored the parent's right to choose,

I mean, we don't our parents don't very often get a choice in schools, you know what I mean, it's like I take these kids, you know, or we take their kids or somebody takes their kids, you know it's pretty much outlined who goes where. I know there's exceptions, but I don't have a problem with the Dad wanting the kid in the other program, and I understand. I took my daughter out of high school and moved her to another high school because of trouble. I mean, I'm not against that. It's not a personal thing, you now what I mean, it's like okay, I don't have a problem with that.

She then talked about the child's safety and her own comfort level. She describes steps to implement a plan to ensure the child's safety, and to make sure the father knew the real meaning of his choice,

They don't take my recommendation, but I would want to make sure I felt comfortable with the kid being in that setting. You know, take him to the classroom, the Dad, you know, and make sure the Dad's fully aware, you know, are there any outside doors, that, you know, who's going to be responsible for him in the hallway, is he allowed to go to the bathroom by himself and you know, just make everything real, real clear. And put down on paper everything the way you want it to go.

It is not clear if there is also a motive to protect herself in this way by documenting the choice. There may also be a suggestion that Judith is shifting the responsibility to the father. This would further explain why this did not pose a moral dilemma for her.

Judith's response to another real life dilemma, gives further insight into her sense of what poses a moral dilemma. She was talking about her first job in special education where the principal refused to attend any of her IEP meetings. In regard to the IEP's themselves she said, 
So yes, they were all illegal. I got used to that. That did not bother me. That was not a moral dilemma there. That didn't bother me. You know, everything was legal, on the paper, other than him not being in there, I felt like everything was okay, we weren't going to have a problem with the parents, it just prolonged the meeting.

These comments suggest that for Judith, identifying moral dilemmas is not a simple process of comparison of the circumstances with existing rules. If it did, then the principal's refusal to attend the meetings would have posed a dilemma for Judith. In this instance the criteria are whether the child will be well served without the principal's input and whether the child's parents will be upset about the procedural impropriety. Thus the outcome of the events contributes to the determination of the exact nature of the dilemma.

$\underline{3 .}$ What processes do these preschool special needs teachers use to determine the proper action to take under the presenting circumstances of a dilemma that they have identified as being in the moral domain?

As with the characteristics of moral dilemmas, when discussing the hypothetical dilemmas, Judith made few direct references to the processes for determining the proper action to take. She did however directly state some of the processes. Others were inferred from the context. These processes were: seek advice from colleagues, seek advice from supervisor, consider consequences of alternate choices/weigh the risks and benefits of various actions, provide information to persuade others, gather documentation, seek help from other service agencies, and base the decision solely on the welfare of the child.

It was often difficult to separate the reasoning portion of the dilemma (processes for determining the proper action) from the solution portion of the dilemma and the other values portion of the dilemma. In these cases it was possible to identify Judith's reasoning based on the outcome desired by the solution suggested. Even though Judith did not consider this to pose a moral dilemma, the scenario where the teacher and the father differed about the child's placement is a good example of 
this blending of solution and reasoning. Looking at the text of her comments, it can be seen that Judith wants to ensure the child's safety in the placement,

Well, I guess put in a lot of support team and make sure everything's covered, the bases are covered and everybody knows what's going on when he comes in. I mean, we don't, our parents don't very often get a choice in schools, you know what I mean, it's like I take these kids, you know, or we take their kids or somebody takes their kids, you know it's pretty much outlined who goes where.

The text also suggests that she honors the father's right to choice and wishes to promote that. This is seen in the discussion and the reference to her own experience,

I know there's exceptions, but I don't have a problem with the Dad wanting the kid in the other program, and I understand. I took my daughter out of high school and moved her to another high school because of trouble. I mean, I'm not against that. It's not a personal thing, you now what I mean, it's like okay, I don't have a problem with that.

Here, as discussed before, Judith mentions her own feeling of comfort of the father's choice of placement is accepted. That is, she again expresses a concern for the child's safety,

They don't take my recommendation, but I would want to make sure I felt comfortable with the kid being in that setting.

This is the point at which Judith begins to shift the responsibility to the father and ensuring that he takes the responsibility with full knowledge of the outcome of his choice,

You know, take him to the classroom, the Dad, you know, and make sure the Dad's fully aware, you know, are there any outside doors, that, you know, who's going to be responsible for him in the hallway, is he allowed to go to the bathroom by himself and you know, just make everything real, real clear. And put down on paper everything the way you want it to go.

In this instance, Judith's reasoning process is a mixture of weighing the consequences of the choices and balancing that with considerations of the father's right to chose. 
When discussing the hypothetical scenarios Judith frequently suggested either providing information to persuade the other parties in a conflict or suggested gathering information to clarify the situation. When either of these processes was suggested, Judith's comments hinted at the possibility that the precipitating events would disappear, eliminating the need for further action. This shifting of responsibility did not seem an attempt to evade responsibility but a sincere attempt to identify who exactly was responsible for resolving the issues.

One other process which Judith mentioned was prayer. At other portions of the discussion, Judith's religious beliefs were discussed extensively, the choice of prayer only came up once in terms of a dilemma. This was in the case of the teacher who was assigned to work collaboratively with a Headstart teacher who refused to allow students with developmental delays to work along side the regular Headstart students. Judith viewed this as a complex and difficult dilemma,

That's a tough one. That would be really tough, because I wouldn't want to go to the supervisor, and cause a permanent rift when I thought I could butter her up or win her over, with Hershey bars or I don't know. I don't know, that would be a terrible spot to be in and would be very difficult and I really don't know what I would do on that one other than, pray. Pray a whole lot. I don't know. Honestly, ... I don't know. That would be, that to me is a very big moral dilemma, because I would be okay with going to the back of the room and teaching the kids, you know. That's not worth it, not worth getting fired over because they want to be cranky. I don't know what I would do but I would try real hard to win her over. And I'd say well, okay, okay, just let me teach two things to whole group. You know, something like that. And just work on it, but that, it would be hard.

If she were to go to her supervisor, she risks harming her relationship with the Headstart teacher and ending up with an integrated class that doesn't work well because of the poor relationship between the teachers. If she doesn't go to her supervisor and she agrees to teach her own students at the back of the room, she risks the displeasure of her supervisor. A third possibility is to accept the situation and slowly try to win the teacher over to including her students. Here, Judith has considered all of the possible outcomes and seems to reach an impasse. Perhaps this is the reason 
that she looks to prayer for guidance. It is tempting to discuss Judith's religious beliefs and their role in moral reasoning and to link that role with the issue of guilt. After all, Judith herself says, half jokingly, that her guilt came from her Baptist upbringing. However, Judith does not make direct reference to Christian principles when discussing the dilemmas either real or hypothetical. This will be better discussed in the section dealing with the sources of Judith's moral values.

Nonetheless, Judith does directly state that guilt plays a frequent role in her thinking about solutions to a problem. The role of guilt in identifying a moral dilemma was discussed earlier. When asked to expand on her comments about guilt, Judith said,

I can't, I'm not much help. But I went through this yesterday, I was telling Kathy, I said, okay, Kathy, I even used the term, I have a moral dilemma. And I said, I can do this or I can do this. And she looked at me and said, I know what you're going to do, you're going to feel guilty and you're going to do this. And she was right. You'll feel guilty and you'll feel like you're lying and you won't do it. You won't take the easy way, you're going to drive yourself crazy worrying about it and that's okay. That's right. That's what I did. Guilt rules my life.

In keeping with the role of guilt in identifying a moral dilemma, for Judith there seem to be occasions where, even though the situation is arguably not her responsibility, guilt over rules and leads her to chose one course of action over another. Or perhaps it leads her to act rather than not act. This will be discussed again in the section on the prioritizing of values. For the moment it is important to point out that the process of reasoning about actions to take to resolve a moral dilemma are strongly influenced other values and other factors that may conflict with each other. That is to say that for Judith, these two processes are sometimes coextensive rather than sequential.

This overlapping is again demonstrated in one of the few passages in which Judith mentions her religious beliefs in regard to moral responsibility,

Um, a little bit of compassion and I don't know. I don't know. I don't know. My, what I come from is God didn't put me here to not help somebody else along the way and that's kind of my basic belief, is we're all here to help somebody in some way. We all have different jobs and 
they're all important. And that's....that's something that I can do and that I like to do and that's what I do. That was my calling.

More concrete examples of this altruism occurred in a discussion about what role special education plays in society,

but even if I had a little boy who was, uh, a SIDS baby that they resuscitated and was cortically blind and just tons and tons of problems from, the doctor estimated 30-minutes without oxygen, so you can imagine how impaired that child was. The only sense that I knew that he would use of his 5 senses was smell, oh, and hear, he knew your voice he, he couldn't even turn. I mean, he was so drawn up, so tight like this, you know, we'd spend a day, and the people would say you don't do anything but babysit him. You know, we'd spend the day trying to straighten out, you know range of motion and just tons and tons of those kinds of things with him. And I said, well, his Mom has 4 or 5 children, I forget, and she's a nice, nice lady. She wasn't stupid by any stretch of the imagination, but and I said, so what. If I take him 2 days a week or 3 days a week for 6 hours, that gives her a break and that helps her be a better Mom to the other kids. I mean, she still had one at home, younger than this one was, and you know, what's the big deal? You know, if we're, if we're a support that helps her keep her sanity and get through the day and take care of the kids in the evening when they all come home from school and get the housework done and, what's it hurting anybody. To me it's still, you know that was enough of a reason to work with this little boy.

This passage demonstrates a broader sense of her responsibility and her ability to affect the lives of individuals beyond the life of the child she is specifically employed to help. Judith has a strong sense of her role in society as almost a vocation in the religious sense. Referring to the theme of responsibility in Judith's life, this sense of vocation, combined with guilt, have led Judith to broaden the realm of responsibility.

One last statement will demonstrate the limits of Judith's willingness to follow what might be termed conventional rules and follow higher moral principles. Here again she expresses her beliefs in biblical terms, 
...this maybe sound a little strange, Sometimes I think I can break the rules because I think the greater good is for the child and not the rules. You know what I mean? Cause I know that even in the Bible that we are called to be under the laws of the land. You know God said that's how you live in peace as long as it doesn't break the moral law of God, that you know you should be as subject to kings or whatever, kings and princes or principles. So I think I sometimes look at that like the greater good is gonna be down this route.

4. When preschool special needs teachers make a judgment regarding a moral dilemma, what other factors do they consider when deciding whether or not to act on that judgment? 5. When moral judgments compete with other values, goals, and concerns, how do these preschool special needs teachers prioritize these factors in order to determine the action which they will actually take?

Judith mentioned a number of factors which she would consider which might affect whether she actually took an action which she had determined to be the most appropriate action under the circumstances. The factors which could be identified included the best interest of the child (if in conflict with responsibility, law, etc.), consequences to oneself of acting or not acting, her relationship with her colleagues, consequences to others of acting or not acting, her relationship with the individuals involved, responsibility to her employer, and personal responsibility vs. professional responsibility.

However, these considerations were not made in a clear sequential fashion as had been predicted by the researcher. Judith tended to make all of these considerations nearly simultaneously. This can be illustrated by a real life example that Judith gave. She was talking about having students whose IEP's required them to be included in the kindergarten class for 2 hours a day and how teachers frequently worked against their inclusion,

I constantly have IEPs written up for inclusion and it's 2 hours a day and they say, I'm not going to take them 2 hours a day, you know and they dragging them back in my room. You 
know, they're supposed to have them 2 hours a day. I don't want them two hours a day. It's all the time. And you try to work it so that everybody's happy. You know. It's like, got to work with this teacher next year, too. So you try to ease that kid in there a little more and a little more and do what you can you try. I think the bottom line comes down to the child, if that were my child, what would I want for that child, you know. You look at him and say, I want him in that classroom 2 hours. So you may just keep trying to stretch it out and stretch it out and get him in there. Sometimes I send my aide to get them in there, you know. Whatever we can do.

Without stating it explicitly, the morally appropriate action would be to require those teachers to keep the students for the two hours a day as stated in their IEP's. This would in theory maximize the welfare of the students. However, Judith expresses concern that it would ruin her relationship with the kindergarten teacher. Consequently, she decides that the best approach would be not to force the issue but to slowly alter the circumstances until the child is successfully (from the kindergarten teacher's perspective) included for the full two hours. This seems to be an effort to balance the benefits for all of the parties involved.

Judith talked about another even more disturbing real life dilemma which represents an instance where Judith did clearly distinguish between the morally appropriate action and the other considerations which affected her actions. In this case, the classroom aide slapped a child, ...I had an aide who slapped a child in the face. That was a pretty big moral dilemma. I went to the principal, I told him what happened. ...I'll be honest I was scared to death of her. She was known to hurt people. And he said, you know, this happened once before several years ago. And I said yeah, I do know, because I had, I didn't have her, but the little boy she hit several years ago, I had his brother in my program and the Mom told me what had happened. And she promised never to do this and he said well I'll talk to her. I said, no we're way past talking, this woman has bruised one kid and slapped another one and left her hand print on her face, and I didn't actually see it, I had my back turned, I was in the file cabinet. I heard it and turned around the little girl was standing there like this with her eyes great big. The 
planning period teacher saw it. And the aide got up and walked out of the room, you know. And I said, to the planning period teacher, did she slap her. And she said yeah, and I said well, we got to do something because she was always doing little things to hurt the kids, little things, a pinch or a hair pull or something like that. You know, and this has got to stop. And I think every teacher who's ever had her has reported her. I know at least five different times that same name has been turned in and he says, well, I'll talk to her about it. And I said if you're only going to talk to her about it just forget it. I'll just watch the kids. Cause that's not going to do anything but cause more trouble between she and I. You know, if we're not going to do something serious like move her away from special ed kids, and with kids who can talk and tell, you know, but those kinds of things, yeah all the time.

This is a complex response to the realities of her circumstances. Judith clearly knew what the appropriate action was, ie. report the incident to her principal. Unfortunately the principal declined to take any decisive action. This would not have improved the safety of the children and would have, in Judith's mind, resulted in an even worse working relationship with the aide.

While these considerations did not prevent her from taking the appropriate action, the fact that the action did not result in the aide being removed from the class had much the same effect. Because nothing would really be changed by the principal simply talking to the aide, Judith chose not to pursue the issue, to take the responsibility herself, and to resolve to be more vigilant when the aide was with the children.

As mentioned in the previous section, guilt seems to play a prominent role in Judith's decisions whether to act or not to act on what she considers the most appropriate solution to a moral dilemma. However, it is difficult to determine just how much of a role because each time Judith mentioned guilt she laughed and seemed to make light of it. It is also difficult to determine how much of a role it plays in this particular context because when Judith does mention it, it appears to influence every aspect of the process of identifying a problem, reasoning about the problem, and finally acting upon the problem. 
The previously discussed comments about guilt can be included here too. Even though we do not know the exact nature of the example, it is suggested that a reasoned approach to it suggests one action (this could be considered the appropriate action to take) and Judith's feelings of guilt could be taken as the mitigating consideration,

I can't, I'm not much help. But I went through this yesterday, I was telling Kathy, I said, okay, Kathy, I even used the term, I have a moral dilemma. And I said, I can do this or I can do this. And she looked at me and said, "I know what you're going to do, you're going to feel guilty and you're going to do this." And she was right. You'll feel guilty and you'll feel like you're lying and you won't do it. You won't take the easy way, you're going to drive yourself crazy worrying about it and that's okay. That's right. That's what I did. Guilt rules my life.

It is suggested here that solving the problem is not her responsibility, but guilt leads her to act as if it were.

In this context, Judith gives the sense, without actually stating it, that she feels a sense of spiritual obligation to act for the greater good,

...what I come from is God didn't put me here to not help somebody else along the way and that's kind of my basic belief, is we're all here to help somebody in some way. We all have different jobs and they're all important.

This can be seen as in keeping with her own definition of obligation as something that you do not necessarily want to do. However, she goes on to add,

And that's....that's something that I can do and that I like to do and that's what I do. That was my calling.

This statement makes it clear that her desire to help is not simply the result of a moral injunction but rather something that she knows she able to do and something that gives her life meaning. This is reflected in another comment where she states,

I love what I do. And iI think the bottom line, the reason that I've always liked this is that I feel like we have that opportunity to help a child and help a family. And that to me has always been 
the draw for the special education preschool. You get to help a family. And I think more the younger ones than the older ones.

Her again her words present helping others as a privilege rather than a burden.

This interest and the moral injunction to help others, relate to the idea, discussed above, that Judith sometimes feels comfortable breaking the rules if there is a higher good to be served. In the context of deciding whether to act or not, there are times when Judith's calling would clearly override any legal or policy decision about how to resolve a dilemma.

\section{$\underline{6 .}$ Do these special needs teachers feel that they live up to their own standards of moral} behavior? If not, how do they resolve the resulting tension and plan for future development?

During the interviews, there were a number of times when Judith addressed the question of whether she lived up to her own standards, or rather what she believes are God's standards. She did not directly talk about how she resolved the tension in those situations where she felt she did not live up to her moral standards but there were hints at how she felt about such lapses.

The moral dilemma which Judith submitted in response to the first Delphi questionnaire is a good example of a case where she did not live up to her own standards. At this time, Judith had been in a serious automobile accident. Her doctor had given her permission to return to work but she was still weak and experiencing considerable back and leg pain. Judith's classroom aide at that time had severe arthritis and greatly restricted mobility. When a new student with severe aggressive behaviors was assigned to her classroom, Judith objected. She did not feel that she and her aide would be able to control him and protect the other children from harm. Judith tacitly accepted the situation but was unable to get the paperwork completed and the bus scheduled because the father did not have a telephone and did not respond to her letters. In the Delphi questionnaire, Judith stated that she did not do what she should have because she did not advocate strongly enough for extra supports in her classroom. When she was asked for details during the first interview, she stated that she did not do what she should have because she did not go to the family home to make the arrangements for the child. This situation caused Judith a great deal of heartache and in her 
mind there really didn't seem to be a solution that was satisfactory. Judith did not state it directly but she gave the impression that she didn't actually make a choice but dragged her feet until the situation resolved itself in another manner.

When she was asked what she would do if she had it to do over again, she stated, I'd like to say I'd take the kid, I would have the kid before Christmas, but given the circumstances, I probably would have jumped and shouted a whole lot harder to get someone in the room trained in restraints and someone strong enough to restrain him and willing to do it.

But then she found a reason why this arrangement would not work. You know, that was the other thing I kept thinking, I know it's going to happen, somebody's going to fill the job because they going to say oh this is easy, three grownups in the classroom and it's only preschool and they're not going to do it and I'm going to end up doing it anyway. I'm still going to end up being hurt. You know.

This was followed by,

But if I had it to do over again, I think I'd put him in, I think I'd put him in and just say well we'll just do what we can do.

Finally, when asked what she meant by "put him in," she said,

I would have, I would have called the bus garage, asked for the driver of the bus, talked to him and said what time do you want to pick him up, gone to the house and said, Mr.

the bus will be here Monday at this time and it will pick him up and bring him home at this time. Which is what I should have done, or at least I would have done that and gone through Headstart. You know, I could have called Headstart and said tell, call his Dad, this is the day this is the bus.

Judith seemed quite disappointed with how she had handled this situation but did not give the impression of certainty about how she would act in similar circumstances if they arose. This suggests that Judith was uncertain how she would plan for future development in maintaining her own values. 
When talking about why she left the school in which she worked for 8 years, she began by talking about structure and fairness,

I am so happy here. I am so happy. My room is too small. And I don't even care. I've got a kid coming in and I have to have adaptive equipment, bring her in, we'll find a place. You know? I don't care. We can move the cots outside. I'm just ...I'm just so much happier. There's support. You know. Consistency in the rules. They go to everybody and to every child. There's not that, you know, he tells you that you have to do and tells somebody else they don't have to do it. That kind of thing. It's straight across the board. I need structure in my life.

When Judith was asked what she meant specifically about structure she began to talked about the atmosphere of the previous school as a whole and how it affected her morale. It also affected her resolve to do what she felt was right for the students,

Well, part of the reason that I left [school] and went to [school] is because I was becoming the worst teacher on the face of the earth. Why was that? I didn't have the moral fortitude to do my job under such lax conditions. And every year I was getting a little sloppier and little sloppier, doing a little less, and a little less, and a little less. And I thought, I'll get in there and I'll get with someone who's going to watch and walk up and down the halls and make sure that everybody's working, and I'll be working again, and I'll be a teacher again, and that's what's happened. And it was a moral thing. I could not. And it was easy. __ was the easiest school in the world to be at if you didn't want to do anything. You know, I mean, I turned in lesson plans, if I felt like it. You know. I did. Steve it was awful. I was awful. That was not a good setting for me at all. It just, it was not. We didn't, if we didn't want to work we didn't work. If we wanted to have art day all day today, if we wanted to have art day all week. We would have art day all week long. It was awful. It was. And it was like......the....I was going to base my there were three kindergarten classes, speech therapy, preschool and bathrooms. That's what was down there. Well kindergarten kids ran the hall all day long. Nobody cared if they were in a room learning. They were out. That's what I mean, it was like, well what building 
works like that. And I was just getting sloppier and sloppier with that stuff. I had to get out of it. I can't live with....my guilt was ruling my life. So I had to get out of it. I went where I would work again. Basically I'm lazy. I needed an overseer.

It is difficult to judge just how important the structure or supervision are really necessary for Judith. When she talked about this, while making it clear that the facts were true, she tended to be somewhat light hearted. It is not certain whether this was intended to mask her disappointment with herself or whether this was amusement at an interesting explanation for the events. Neither is it certain that the conditions in the old school were really affecting her performance as a teacher.

During the discussion about her struggle with depression and the response of some members of her church, Judith talked about her response to those members who felt that she was depressed because of some secret $\sin$. She said,

People are never perfect, and God's way is perfect. So, just because there were some men in the church who screwed up, I think I got it right, I wouldn't turn my back on God.

This statement may give a hint to Judith's response to any of her own failings. On the one hand she may torment herself and feel guilty over what she views as a moral lapse. On the other hand, she seems to accept that man is by nature imperfect. This suggests that on some level she can be kind to herself because she is struggling to follow God.

In a discussion about her divorce and the effect it had on her and changed her conception of who she was, she stated,

Well there were things that happened at that time that I thought would never ever happen to me. Things that I thought I would never ever do, and I had to take a whole new look at myself and say, you're not who you thought you were at all. I'm still in transition.

Later, she talked about how it altered her perception of others,

Well, I thought I was a lot better than I found out I am. Laugh. And I used to be extremely more severe in the way I judged others. And I think and I know all about judging and not judging but I think we all have a tendency to do it anyway. It's one of the things that you try to get out of. 
You know yourself, you try to rid yourself of that. And I think I was a little much more severe judge than I am now. Than I think I ....

This reduction of judgment may also apply to herself and may be related to the idea that only God's way is perfect. When she was asked,

Do you think that when you face a moral challenge, ... do you activate that image of a Christian person ....of working to be a Christian person and that what ever decision you make has to fit into that?

she agreed. This conception of the need to work at being a good person may help to reduce the stress of any particular "failure" on her part because the nature of existence is conceived as an effort to meet God's standards. These standards are conceived to be unattainable without God's intervention and support.

7. What do these preschool special needs teachers identify as the origins of their moral values and moral beliefs?

It is difficult to grasp where Judith feels her values come from because of her tendency to laugh or to speak ironically about details of her personality and the course of her life. However, it is reasonable to assume that her life as a Christian is the primary influence on her beliefs and convictions. Her spiritual life was mentioned during the discussion of many difficult times in her life, particularly her early married life, the divorce, and her struggle with depression.

This discussion will begin with the earliest date of influence Judith mentioned. In one of the discussions about guilt, she was asked about the origins of her guilt and she responded, "Oh, that good Christian upbringing. That was the Baptist upbringing I had." Here again Judith said this with a laugh so it is not clear if this is really her belief. When asked if this was a theme in her family, Judith said that neither of her parents was guilt laden. It was not clear if her parents used guilt as a disciplinary tool or not. She also stated that one of her sisters feels guilt even more than she. As was discussed above, it is not clear to what extent the feeling of guilt interacts with other values in Judith's life. I is safe to say that it is certainly a recurring them in Judith's conversation. 
When Judith was 16, she began attending the Church of the Nazarene. She joined the congregation when she was 20 .

...I thought, well nobody made me join, and if I'm going to join then I need to do the best I can. You know, to be a member and not embarrass them too badly, but, (laugh) so you know, I didn't go to dances and for a long time didn't go to the movies. I can remember one time, I thought God would strike me dead, it was at Christmas time, remember the movie, Santa Claus: The Movie came out?... what I did, I took my girls. We missed church on Sunday morning to go.....ohhhhh....that's it. I'm going to fry for this one!

These particular prohibitions seemed less like values that she held but rather values she needed to maintain to remain in the congregation.

The value that she does seem to gotten from her religion is a need to help others, ...what I come from is God didn't put me here to not help somebody else along the way and that's kind of my basic belief, is we're all here to help somebody in some way. We all have different jobs and they're all important.

This desire to be helpful is a consistent theme throughout the interviews. Judith talks about it almost as a privilege to be in a position to work with families and to have an opportunity to help them with their lives.

When Judith was asked about mentors or role models in her life, she mentioned a teacher she had in junior high school. This particular teacher stood as a person of high moral character. Judith mentioned him in her characteristically ironic way by contrasting his character with his interest as a human being,

I had a teacher from the 7 th through the 12 th grade. He was our homeroom advisor, L.H., was his name. And he also taught English, 7th, 8th and 9th grade, I think. I think those were the years I had him. And he to me was a very ethical man. And he had.... boring .......very boring....... 
When she was asked about this contrast, Judith said,

...I hope not, but I have an enormous amount of respect for him and I just felt that he treated kids fairly, that he was just a moral person, an upright person, and I kind of remember him, didn't particularly care for his class, but I had a lot of, a ton of respect for him, probably more than any other teacher in my life. Yeah, Old Mr. H. I wonder if he's still alive. He walked real slow and talked real slow, and every Christmas he'd go through the halls singing Christmas Carols in Latin. ..... But I loved him.

Much of Judith's view of the role of religion in her moral life has been discussed under the previous headings. This includes her response to the congregation members who felt her depression resulted from sin, and her response to her divorce. In the first she expressed her belief that humans are flawed and only God's way is perfect. This is a principle which Judith seems to try to apply to herself as well as to others. The second, her divorce, seems to have resulted in what might be termed greater humility, although Judith didn't label it as such. She talked about becoming less judgmental as a result of the events that followed the divorce. In the end it also seems to have resulted in greater certainty about her own beliefs,

...I think I have more of a sense of if I can live with it, do you know what I mean. It's like if she felt offense at something and I didn't feel like it was wrong...it was her problem she could deal with it. And I think I'm a little more that way than I used to be. Maybe not a lot but a little more that way.

This was followed by a humorous discussion of her development, Jack keeps saying, "Is there any more evolving that I should know about? Anything you should tell me...you're gonna hit 50 soon and another big change. Cause I said to him one time, he said, "Judith you need to be more understanding or you need to be more something." And I said, "Hey, I hit 40 and I figured I'd listened to 'em [her family] all my life, I didn't need to listen to 'em any more." He said, "Oh, you're gonna be 50, is there anything I should know your about to change?" I said, "No. That was my teenage rebellion that came out at 40." 
What emerges from the discussions with Judith is a picture of the development of morality as a process that results perhaps from both effort and accident. The effort is to live as a Christian, following Christian principles, and the accidents are the circumstances of life ranging from working with unsupportive principles to divorce and depression.

\section{Personal Story or Fable}

Any attempt to construct a personal story or fable from the interviews would probably look much the same as a chronology of Judith's life. Judith did not identify a story as such that she tells herself, but she does view herself as a Christian person trying to make her way through life. Clearly, when faced with a moral dilemma she activates that image when deciding how to respond. Other themes that emerged from the interviews were depression, change, a desire to help others, and serendipity.

Because of her Christian orientation, it is tempting to see her life in terms of the Christian mythology of wandering/laboring in the wilderness, and working to help others. Whether Judith views her life as such is another question. Some insight might be gained from a discussion of her unfulfilled dreams. When the interviewer explained to her the area of research called narrative psychology, Judith responded by saying,

I have unfulfilled dreams that I'm still holding on to. I want to go work on an Indian Reservation. I want to do that so bad. I always wanted to do that. That's not, and that might happen. Like I tell my husband, we could do this Jack, because you know, his background's in business and he worked for the small business development center, you know, doing the business plan and setting up, you know, getting the bank loans, he could help. I can work with the kids. You know, you can work with the people selling the turquoise jewelry. You know, we could do something here. 
When the interviewer asked where she thought this dream came from, she repeated the theme of helping,

I just think that it was just that there's a need out there and ... that thing about helping people comes back. And it's bizarre because what you always read about is all the fetal alcohol and that's the stuff that scares me. I keep thinking, I wonder if I could do that. But yeah, that's one thing, and we may do that some day. I don't want to be 65 when I retire, I want to be 50 .

In light of this recurrence of the theme of helping, it seems likely that for Judith any internal story she has must include the struggle to make a difference in the lives of others.

\section{$\underline{\text { Case \#3: Beth }}$}

Beth is a 30 year old preschool special needs teacher who lives and works in a rural part of West Virginia. She has two children from her first marriage and is currently married to a man who owns a pawn shop.

Beth was born in Maryland and at the age of 5 the family moved back to the small coal mining town in southern West Virginia where her parents grew up and live to this day. Beth grew up and lived in the same house until she got married. She has two sisters who are considerably older than she. About their relationship, Beth said,

...I was the youngest and my sisters are a year apart. And they're eight years older than me, so they're really close and, which I see us all as being close, but by the time, my Dad was so strict on them, but by the time I was there he was mellowed out, ......and, so it's kind of like he raised two separate groups.

When she was asked about her family's values, Beth talked more about her relationship with her sisters. She stated,

My sisters, we're, nah, I don't know if it's just because we're women or what, but it's just, constantly taking the knife out of your back, the back stabbing...it's, one sister will call and talk about the other one, and then the other one will call, and ... I used to really get into that, but now 
that I'm, I'm in church, I try not to do that. And I let them know. I'm not going to talk about my sister. But they're not in church still, none of them are. Not even my Dad which bothers me. At the time of the interview, Beth's parents had been married for 40 years. Her father worked for the municipal water treatment plant and her mother was a nurses aide. It is interesting that when talking about her childhood, Beth never mentioned the role her mother played and state that she thought her mother had attention deficit hyperactivity disorder. In the first interview, when Beth was asked about mentors, she talked about her father and the role he played in clarifying situations for her.

Beth attended small public schools. Her high school graduating class had only 85 students, most of whom had been in school together since kindergarten. When Beth was in junior high school, even though her own family didn't attend church, Beth began attending with friends. She described it,

Here's the way, we have the little church close to my house. My Mom and Dad never went to church. And my sisters didn't go to church. But it just happened to be the time I was growing up, I guess, I walked to church every Sunday. And walked to it every Wednesday night to prayer meeting. But it was just a short walk and every kid that I went to Junior High with, we all did. We had a little youth fellowship.

When she was asked about the motivation for attending church, Beth said, It was kind of like opposite or good peer pressure. There were about 12 of us in the community and we all went. You know, youth fellowship, Methodist Youth Fellowship. Later she stated,

Okay, I guess it was more of a social...I always had so many questions and I would question things and if I didn't get an answer I kind of felt, well, is this all a fairy tale or is it real?

The discussion of church naturally flowed into a conversation about dating and getting married. Beth stated that when she started dating, she stopped going to church. She talked about dating as almost a scripted activity, 
But then, afterward I got, I didn't go. After you get a boyfriend and all that. I didn't go. And then you married your boyfriend.

She followed this by saying,

I wasn't allowed to date until I was sixteen. When I did, I dated the first boy who came along.

We dated for six years, so I went to college and finished my elementary ed degree.

Being a teacher had been a life long goal for Beth. She said,

...I told my parents that I wanted to be a teacher from my first day of kindergarten but no one in my family had ever went to college. Or anything. If I hadn't gotten a scholarship I wouldn't have went, but I got a scholarship. Yeah, I always wanted to be a teacher.

Beth attended a small college in southern West Virginia and majored in elementary education and received certification in multi-subjects, $\mathrm{K}$ through 8.

Beth and her first husband were married after Beth finished her elementary education degree.

Her own words best describe their marriage,

Then, after I finished college we were married. He had no work ethic. His family didn't either. Anything like that. So I worked. And .... and he.....developed, an alcohol and drug problem. He was gone all the time, so I had my first child. Now, I know we really planned for and everything and my first boy, and then the drug problem with him got a lot worse and right when I really wanted to get out, like I found out I was, we had had a really big fight and I went to the hospital because he had abused me really bad, and I found out I was pregnant. One month pregnant. So do you stay together or do you not. So we moved in with my parents. Cause my Dad was like, if you're going to be with him I need to, you know he wanted to keep an eye on me. And finally it was Christmas, the Christmas of '97. At Christmas Eve we always have a big thing at my Mom's and he came in, a big party, and he came in, with gifts for everybody. We had a party with gifts for everybody, he didn't come in with gifts, he came in completely out of it. I was like, go that's it, forget it. And then a month later he flagged me down beside the side of the road and messed up my car really bad, and my arm. And I got a restraining order. And that was over. 
Beth was acutely aware of the irony of her situation,

And this whole time I'm working at FMRS trying to tell these other women why they should go to a family resource center, why they should put their children first, and I'm not doing it myself. And I had a real problem with that. I would come home and cry every day. Telling these women what to do and telling them to take care of their children, and here mine are suffering from it. So, .... He ... I put him out then.

Beth held several positions before her employment as a preschool special needs teacher with the public schools. While she worked at FMRS as an early intervention specialist, Beth developed an interest in special education and began working toward a degree and certification in early childhood special education. When talking about her present job, Beth is adamant that this is the job she wants and that she will retire from.

At present, Beth describes her life as a Cinderella story. She is happily married and both she and her husband have accepted Jesus in their lives. Beth described the change in her life,

And then I met about 8 months later I met my husband now, who's my husband now. And you probably noticed he's quite a bit older than me. He's 25-years older than me. But we've been, we've got along good and we're happy and we started church last Christmas. We both got saved July the 1st. And baptized together. And it's made a tremendous difference. And now it's, my whole life's just so different. And Jesus plays a big part in my life.

Talking specifically about the change religion has made in her life, Beth said, It's given me a confidence and peace that I never knew before. I kind of don't sweat the small stuff outlook. And I want to, like, one day I would love to go to the women's resource center and I want to say, to me it's kind of like, I want to say a Cinderella story, but I'm not quite Cinderella, but I came from nothing, and lived in this trailer and was so abused, and now my husband, I can find no fault in him, and now that we're together in Christ it's totally different. I didn't know life could be this good. And I would like to give that hope to others. That's probably the way I see myself, as, as a Cinderella story. 
When the interviewer asked her what her long-term goals are now, she stated,

That would most likely be with my children, the way I want to raise my children. That's my big personal goal. Is children. I battle over sending my children....I have one in Christian school right now and one in public school. Next year I'm trying to decide whether to put them both in public school, because my 5-year-old, he'll be able to go to kindergarten, where he's in preschool ed at a Christian Academy now. To put both of them in the Christian Academy. And to make sure that they have their values intact. Um, my personal goals are to raise healthy, Christian children with good morals, and ethics, that aren't scarred from my mistakes. That's, I don't know. ....that's it.

\section{Beth and the Research Questions}

1. What events, occurring in the course of their professional duties, do some preschool special needs teachers consider to be moral dilemmas?

As with the previous interviewees, Beth was asked to comment on 15 of the scenarios from the Delphi. When discussing the hypothetical scenarios, Beth made reference to a variety of characteristics that seemed to indicate a moral dilemma. In terms of the Delphi items, these were, a violation of law, regulation, or policy, a risk of damage to an individual's reputation, a risk of damage to an individual's self respect, a risk of harm to others, a risk to relationship between individuals, an individual's rights are ignored, a conflict between two or more responsibilities, and a conflict between responsibilities and self interest.

Beth's responses to the scenarios were much more difficult to categorize than in the previous case studies. They did not divide clearly into the categories of moral dilemmas, no moral dilemma, and dilemmas that were not clearly moral in nature. Beth's responses were more complex regarding whether they posed a moral dilemma. In several cases, Beth stated that there was no moral dilemma and in these cases there really did not appear to be a dilemma for her because there simply was no issue in her mind. In several other cases which Beth stated posed no moral dilemma, it was not always clear whether they still had moral implications in Beth's mind. The confusion here seemed to 
stem from the use of the word 'dilemma.' In these cases, Beth stated that she knew exactly what she would do. Consequently, there was no moral dilemma. However, when pressed to explain, it seemed that there were moral implications that she perceived surrounding the scenario.

2. From the perspective of these preschool special needs teachers, what specific characteristics of these dilemmas signal that they are moral in nature?

Before beginning the discussion of the scenarios, it should be noted that Beth expressed some reservation about the validity of responding to hypotheticals. At the end of the discussion of one scenario, she was asked if there were no dilemma since she knew what the answer was. Beth laughed and jokingly said,

I have the right answer for all those, right? Just kidding. In my mind, the right answer. And of course it's easy to answer these questions and it doesn't really say anything. ..if I were in that spot, how would I...?

This gives an impression that Beth has some humility about her ability to solve problems but also gives an impression that if it were a real dilemma, there would be other aspects of consideration that are not present in the hypothetical scenario. She was talking here more about the process of making decisions but it seems reasonable to extrapolate this also to the consideration of whether there is in fact a moral dilemma. This presents some weak evidence that the context of events are relevant to the identification of a dilemma. Beth frequently described similar events that she had experienced when talking about the hypotheticals which would provide some further support for the importance of context.

In the scenario about the child with autism whose parents accused the teacher of lying about his progress, Beth viewed this as more of a practical problem than a moral dilemma. Her response concentrated on helping the parents understand that children perform differently in different settings,

...I would say I would just go on to explain how the child functioned well in a group setting and that maybe there was structure there and this is offending sometimes but I always say there is 
structure there, that they need at home, maybe if the home was a structured environment they would behave as they do at school...

As for the charges of abuse, Beth first stated, and the abuse, that's where I just, flash your degree and say, no, not me, I've been through all this training and I know not.

She also stated that she would not feel threatened by the situation because, ...Right, because I know for example, Mark, if there were anything happened to him at school that, I mean, I document everything, and maybe he hit his head on the table and got a knot, I would have that documentation there to show anything, and if he came in with bruises that were visible of course, if that, if I could see, if I had to take him to the bathroom, those would be documented as well, and I might suggest getting CPS involved to see just exactly what was going on there.

It is clear from her words that this doesn't present a moral dilemma because there is not really any issue other than to provide documentation to support her position. This presents a conflict of perceptions rather than any conflict of values. When asked, Beth agreed that this was a practical problem and not a moral one.

In the scenario where the teacher was required to assess her own nephew, Beth clearly felt there was no issue for her in this situation. She stated that she "...would do the testing accurately in that, because I would be looking out for the child, what's best for the child in that situation." Here again there was no issue. Beth did state that she could see how there might be an issue for someone else. Unfortunately, the interviewer did not ask a follow-up question to clarify what that dilemma would be.

In the scenario where the mother wanted to have another child so she could have a daughter, even though she was unable to take care of her sons, Beth's response gave an impression that she felt it was none of her business. On the other hand her words suggest that perhaps it was also not a 
dilemma because there was no avenue for affecting the situation,

Really there's nothing you can say and nothing you can do. Other than not encourage it.

There's nothing you can say or do except worry.

When she was asked directly if it posed a moral dilemma she responded,

There's nothing I can do about it. Do you see alternatives? I mean, what can you do? I can't

say, oh, you can't have another child. What can you do.?

This suggests the idea that there is no moral dilemma if you feel that you do not have the capacity to affect a situation or if there are no available options to affect it. However, there is not enough evidence from the transcripts to support the idea that this is how Beth feels.

In the case of the scenario where a 6 year old child was transitioned into kindergarten with a mental impairments teacher and then was returned to the preschool program, Beth stated that there was not really a dilemma because it would never happen in the county for which she works. She then said, that if for some reason it did happen, then she would have to accept the situation. She gave the impression that this would be out of deference to her supervisors by saying, "No, at his age level he couldn't come back to preschool, or if they said he had to, then he has to." However, later she stated more strongly that it was not a dilemma because it wouldn't happen in her school district.

In the 4 previous scenarios, there was no moral dilemma for Beth for a variety of reasons but all having to do with the nature of the circumstances as Beth defined them. The following scenarios represent cases where Beth stated there was no moral dilemma because she knew what she would do. In these cases it was clear that Beth understood the moral issues raised by the events. This makes them different for Beth than the previous scenarios.

In the scenario where a child was assessed for developmental delays and did not quite qualify for preschool services, there was again no dilemma for Beth. Here, the procedural requirements outweighed any feelings of a desire to help the child professionally. However, Beth did refer the family to other service agencies who would be more able to help. This topic was pursued in a later interview when Beth was asked if she made the referral because it was her job duty or if she took 
the responsibility on herself. Beth had no trouble distinguishing between the two and stated that she was taking on the responsibility. She stated

Right, right. No it's definitely not part of my job responsibility. All I have to do is cut and dried say, we're sorry we're having this eligibility meeting and you aren't eligible, that's all I have to say, but if I know that the parents want to get them involved with something, want to see the child involved in something like personal social skills, being around other children, or I see they really do need something there, I take it upon myself to refer them. Or to hand out phone numbers or brochures or something to get, so that they're not just stranded.

There were two actions to take based on different realms of responsibility but in this particular case they did not conflict with each other. therefore there was no dilemma. When asked again if there was no dilemma because she knew the answer, Beth expanded this idea further

It's probably a moral dilemma the first couple of times I ran up against it and didn't realize that I should, oh, I couldn't refer them here or here. When I was beginning, I didn't know that, and that's why I developed that little list of people they could contact if they weren't eligible. So, that's not a job responsibility, that's a personal responsibility. Well, it was a moral dilemma before I knew what to do, that's why, that's how the little list got created, because one night I thought, they don't have anything to do.

These comments raise the idea that the identification of a moral dilemma is greatly affected by the individual's experience with similar dilemmas. Consequently, how an individual defines a moral dilemma will change over time.

In the case of a child who described having been sexually abused and whose father was known to hold a grudge, Beth stated emphatically that she would call child protective services without hesitation. The potential dilemma here being between acting to protect the child and acting to protect herself. In this discussion Beth made it clear that past experience helped her to feel confident that there was only one real choice,

That probably has something to do with my ex-husband. We had a, he was the stalker type. So I've been around it and that kind of thing doesn't scare me. I don't worry about that. I just say, 
if you're not going to stand up for your child, we will. The child has to be protected. And I'm not here for you, I'm sorry I'm not here for the family, I'm here for Charlie. And that's where it stops.

This statement also makes it clear that Beth feels no conflict because the child's interests take precedence over those of the parent.

The examples above, while not exhaustive, make it clear that for Beth, it was more frequent that there was no dilemma because of the nature of the events, than it was that there was no dilemma because she knew what she would do. Beth's responses to the first 4 cases have to do with the identification of dilemmas (moral sensitivity in Rest's terminology) and the other 2 have more to do with Beth's internal sense of conflict.

During the discussion of the hypotheticals, Beth pointed out that the interview was making her aware of a pattern of behavior in dealing with some moral issues. These were scenarios where the dilemma was to call child protective services or warn families in order to maintain the relationship with them. This was the pattern of response for the scenario in which the teacher became aware that a child was home alone and also for the scenario in which a child was being injured by his brother. In the first case, Beth was asked why she wouldn't automatically call child protective services. She responded with more detail regarding the circumstances,

Because of the rapport I have with the family. If I know that previously everything was fine, and maybe this was an oversight on her behalf, I'd offer to help out like, if he needs to come to school just give me a call and I'll arrange something, but never, or put the other smaller kid in the car with you, do not leave your child alone.

This suggests that in reality this is not a pattern but an indication of her sensitivity to particular relationships. It suggests that if she did not have a relationship established with the family, she would view the dilemma differently. The outer limit of her response to a threat to a child's welfare is established by the case of sexual abuse. For Beth, there was no question that she would call child protective services. This example also suggests that sometimes the facts of an event and the possible outcomes of actions are intertwined in the definition of the nature of the dilemma. 
Beth was asked about this again in the second interview. The exchange is worth quoting at length because it gives more insight into Beth's thinking about dilemmas indicates an interaction between Beth's self image and reasoning about dilemmas,

Interviewer: ...this is one of the things I wanted to talk about is you had said that, something to the effect that I was making you see that you have a problem with not calling CPS. And .... Beth: A pattern.

Interviewer: Did you get the feeling that there was something wrong with that. The way that you were handling those issues?

Beth: Yes.

Interviewer: In what way was it wrong.

Beth: Because I don't jump to call in CPS right away....I don't, I don't follow those guidelines like I should about calling CPS.

Interviewer: Why would you say you don't.

Beth: Because I usually warn the parent first instead of going ahead and doing it and saying... Interviewer: No, I meant what's your, motivation? You know, what makes you decide .... Beth: Oh, I want to keep that family, I want to keep the relationship, I don't want them to not like me and pull the child out.

Interviewer: See I'm seeing that as a conflict between head and heart.

Beth: Right.

Interviewer So, you know, the regulations say that you should do this, but you're trying to maintain a family relationship, is that what you're saying?

Beth: Right. It's so hard to maintain a family relationship and follow those regulations and do everything perfectly. It's hard. It's hard. To know when to do which one.

Interviewer: I think it is hard. Do you have a feeling ..... you know that maybe you'd be more professional if you called? You know, used your head more than your heart ... 
Beth: I think it is more professional, if I called, and...there's another teacher in our school, in fact there are several. But there's one who, she's really calm and she's really like, I mean her voice is like, I want to be like this, her voice is like monitone.

This question of professionalism will be discussed further in the sections on the processes of determining the proper action and the prioritization of values. Here it is important to point out that Beth expresses the value of maintaining effective relationships with parents and simultaneously feels that it makes her feel less professional. This again implicates the question of experience. At other points, Beth describes her confidence level as a matter of being a new teacher and suggests that she is not yet comfortable in her professional identity.

Further evidence that Beth's professional self image is still developing, is evident in Beth's response to the scenario where a child consistently came to school sick and the parent did not take him to the doctor in spite of repeated contacts from the teacher and the school nurse. In this case, rather than discuss the scenario, Beth talked about procedures she had developed and a specific case that she had experienced. In this case the child had head lice. Repeated contacts with the parent had no success, so Beth contacted the bus garage and told them not to pick the child up until further notice. She then contacted the parent and told her of these arrangements. Beth's supervisor found out she was told not to involve the bus garage again in similar circumstances. If these events were to occur again, the dilemma for Beth would be to either act to protect herself and others from head lice by involving the garage, or to follow her supervisor's directive.

I just wanted transportation not to pick him up, I didn't say he had lice, because I knew that would be going too far, but I said don't pick him up until I let you know, and that caused a lot of trouble. And that's what I would do again, I would say, he's not well, bring in the doctor's excuse, and the bus will pick him up. But then, if he had a doctor's excuse the next day, which happens, that says he's fine, doesn't have anything, I would just deal with it and say, okay, they say he has nothing wrong then, I would wipe nose, and forget about it.

This scenario is mentioned here because in an earlier scenario, Beth stated that she would be obligated to follow her supervisor's decision. These responses would seem to contradict each other 
but perhaps it is simply a matter of what is at stake. In the first, a child is placed in a program that would be beneficial to him but is not age appropriate and does not meet state guidelines. In this scenario the health of the child and many other individuals is at stake. This greater risk may account for her willingness to ignore the chain of command.

The role of empathy in identifying moral dilemmas also came up in the interviews. In the first interview Beth talked about having baby-sat a child with autism and how the experience gave her greater empathy for the child's parents. In a follow-up question, Beth was asked if she thought this empathy helped or hindered her ability to recognize a moral dilemma. At first, her reaction to this question was to explain her motives for having taken care of the child with autism. In this case her motives were practical in nature. She wanted the child to see her in a different light and she wanted to get some insight into methods for working with him in school. The interviewer then pressed her to think about empathy in a more general sense,

Beth: Yeah, I think it is a fault. I don't think it's.....I think it's a fault, definitely. Being too empathetic.

Interviewer: And why would you say that that's a fault. Can you be more specific?

Beth: Because of my relationship with my families at school, I tend to let, I look for, for example, there's one kid, his mom and dad, his mom said, I put his dad out, he's not coming back, he's on drugs, and all that. And I said, well good for you, and I should have stayed out of that. I said good for you. And then the next week she's like, he's doing good he's in a church, and I said, I'm so glad to hear you're in church. And........and....I was having a bit of a behavior problem with the child, he has a behavior intervention plan, and I thought, that's not mine. I thought, I didn't, I didn't tell the parents as I usually would, like hey, Carl's really having a behavior problem here, because I knew, you're having problems at home, this is stemming from that. Um. I didn't want to add to the fire, fuel to the fire. And I tried to still...to this day...I mean I see that dad on the street corner when I leave school....and I still think, you know, he's doing good. But he's probably not. Anything they tell me I believe. It's a big fault. I don't want to think that. I'm very naive. 
Interviewer: So you think your empathy keeps you from being objective and maybe, it make you less helpful in a situation.

Beth: Right, you can get run over with, where they probably need somebody to say, well listen this is causing a problem for your child, and I'm like, I don't deal with it as harshly as I should, I just, go with the flow, I guess. Like you're making it sound like a good thing, but it's not. You get run over really easy.

The relationship of these comments to the question of identifying a moral dilemma may not be immediately apparent. While Beth is talking primarily about her responses, the real issue seems to be the recognition or lack of recognition that there are competing values at work. She seems to be saying that she will respond to support the person she is speaking to rather than seeing that the main issue is the welfare of the child, or the individual's need for objective advice.

Beth gave a concrete real life example of a time when she felt that her emotions interfered with her judgment. Beth told of a little girl who was sent home on the bus and regularly her mother would not be home to get her. Beth's administrators wanted to take the child directly to child protective services but Beth had the child brought back to school and stayed with her until her mother was contacted. In the end the mother was reported to child protective services anyway and as a result, the mother hired someone to be there when her daughter got home from school. Beth's last comments were,

So, that really was a case where I shouldn't have, I should have just let them take her to CPS at the start, I guess. But I couldn't stand to think about her sitting around waiting for her Mom to come. With strangers.

3. What process do these preschool special needs teachers use to determine the proper action to take under the presenting circumstances of a dilemma that they have identified as being in the $\underline{\text { moral domain? }}$

Beth made reference, directly and indirectly, to a variety of processes she would use in trying to resolve a dilemma. Putting them in terms of the processes which appeared in the Delphi, she 
mentioned request further information, weigh the risks and benefits of various actions, seek help from other agencies, provide information to persuade other parties, gather documentation, and decide without consultation with others. As with the identification of moral dilemmas, what seemed most striking about Beth's responses were the things Beth did not do to help think about the problem.

The process of decision making and the role of authority came up several times during the interviews and began with the discussion of the scenario which Beth submitted for the Delphi. In this case, the parent of a child kept saying that Mikey didn't like this program then he didn't like that program, and the mother seemed confused about her son's needs. Beth had discussed the situation with her aide and the speech pathologist, and they decided to make a home visit to try to find out what was really going on with Mikey, The interviewer asked Beth if she had approached her supervisor about the situation and Beth said,

Interviewer: So you didn't talk to your supervisor about the situation?

Beth: My super, my preschool facilitator, who's my supervisor?

Interviewer: Right.

Beth: I didn't mention it to my supervisor.

Interviewer: Do you mind if I ask why not?

Beth: Because it's cut and dry, and she's often told me, follow your head and not your heart. She just comes right out and says that.

Interviewer: Okay, so it wasn't something that you, it wasn't that you didn't think she would be supportive, but more that you pretty much, or at least thought you knew how she would react. Beth: I knew how she would react and it's totally, here are these two areas, do your tests, see what your score is, ... and no leeway on what you've seen. What's the whole purpose in doing the home visit, if there's, if I can't base anything on what I see?

When she was asked if her supervisor meant follow the regulations when she said follow your 
head, Beth said,

Right, and she's tells me you're used to the medical model from FMRS. You know, she was 'scratch that' she said that I wanted to bring families into it, make it more family and it wasn't. She said I was just there for the child now. And what she means was if he qualified cognitively and personal social, in those areas, fine, he's in preschool. The personal social area wasn't there and I just happened to be witnessing an occasion that on the test scores he did not have delays in personal social, tough luck, he didn't have two areas. But what I saw was, the cognitive area,...was there on the test, the personal social, he didn't test, as having a problem there, when I saw the home visit, went on the home visit, I saw the potential, which potential means nothing written down, you know, and that was more what she meant about following my heart. But I just knew that this was going to be terrible if he's not out of the home, personal social skills are going to really go down hill, and if she's telling me to rely on data, and I didn't I was going on instincts.

This was followed by the discussion of the little girl whose mother was never home when she got off the bus and the role head and heart played in her decisions about this scenario. This discussion blended into the discussion about professionalism mentioned previously. Beth felt that calling child protective services (following her head) would be more professional.

Her relationship with colleagues seemed to be a sore point for Beth. She is the only preschool special needs teacher in the school where she is employed, she works in the poorest area of the school district and she has a larger case load than the other teachers. Beth felt that the other teachers did not understand her experience and therefore could not give her advice when she needed it. When talking about a new instructional program she was required to use, Beth said,

I'm doing this with my group, well the other group is obviously going to be interrupted and I'm trying to get my point across and everybody else just thinks, new girl, she's got to get used to it. That's how I feel. That's how I feel there. That's how I feel with my colleagues. I feel like they have all this experience, yes, in a regular setting, but they can't help me with my overload problem I have right now. And they can't help me with the kid who's integrated in kindergarten 
because they've never had that. They can't help me with the fact that I have a nurse in my classroom in the morning session because I have a child who needs to be tube fed and suctioned. Who's made it clear that all she does is tube feed and suction, she doesn't wipe noses or change diapers or lift. So there's another body. And, there are a lot of people in my classroom.

Beth did say that her principal was supportive of her and her ability to make decisions. But here again, she did not indicate that she would go to him for advice, My principal however, is one of those men where I feel like, he's got my back, all the time, that's what I feel like. He thinks that, if I think it's important enough to stand up for, he's behind me. He may not know all the facts, because he doesn't know all the fact about special ed and preschool special ed, no, he knows it's a different world, but I like the fact that he trusts me enough to know that I researched something before I'm going to say anything about it.

Beth also gave the impression that her colleagues in the building were not of much help to her, and that she was isolated even in the school,

For example, Faculty Senate meetings are a waste of my time, but I have to go. I mean I could get my folders ready or my lesson plans or something, but yeah, it's kind of like we're separated from the rest of the world. Or they come in and, because of the way my room is set up, I told you. the second grade teacher who's new this year would say, it's so loud in here. Is this a regular preschool? Define regular. I just answer her questions, what is the norm? But, I've said no there are some children in here with different diagnosis, for example the one that's squealing right now, there could be a diagnosis of autism, I don't know if you're familiar with that, but...... At another point in the interviews, Beth had mentioned this isolation in terms of the issue of confidentiality. Beth had stated that her job duties kept her from having time in the faculty lounge and she felt that was a good thing because the faculty lounge was "the root of all evil." when she was asked about this she said,

Because I think that's where confidentiality goes down the drain. I think that's where bad attitudes come into play. ...I don't think that this year's teacher and next year's teacher should 
sit, and talk...I know it would be good if it were, here's what he can do, he can do this, this and this going in, but she's going to do some pretesting when he goes into that class. She'll find out on her own more objectively because you hear, boy, you're getting him next year and I'm so glad, he does this, this and this. And you've already made up your mind about a child before he's in your classroom. You already know what the parents do for a living, what they do, how they react to the teacher and you need to form your own opinions. And I just don't think that's a good thing.......basically I think there's complaining in there. Really, I don't have time for that. I'd like to complain, but I don't have time to do that and I don't want to label my kids before they're out of my room.

This gives the strong impression that contact with her colleagues would tend to make it more difficult for Beth to make objective decisions.

After these comments, Beth stated, And sometimes I feel like I'd rather go with my instincts and be wrong than talk to somebody else and have them say no you can not do this even though it might work.

When asked a follow-up question, Beth raised the issue of emotions and how they affect decision making for her,

Yes, that's again when my emotions govern my life. When my response, if I feel really strongly about something, going with my instincts and thinking, what's the worse that could happen to me? Other than asking for my supervisor's, who will give me, what I should be doing, it might not be what I should be doing. I mean, she'll tell me what I should do by the book, but, she doesn't have that ... rapport with the families that I do and I can't, that's something that I really don't like to jeopardize. I think once I get to that level where I want to be with them, that can make life so much easier. If you know these families so that when you call them at home they don't one, hang up the phone or two, know you're coming and don't answer the door. Because I've had those, but then if you can kind of talk to them, and they can see that you are on the same level. I'm not worried about how your house looks or anything like that. All I want to know is what does your child do at home and what do you think about it. Then they're more 
willing to let you in and they see you more as a friend. And I think that rapport is be very important. And I don't want what my supervisor says to kind of, for me to come down with a hammer and just shatter the whole thing.

This makes it clear that Beth feels there are some values which are more important than procedural propriety. However, she did seem conflicted, as was seen earlier, between those values and a direct order to do something:

If my supervisor told me to do it I would do it. But it's like, in your heart, when you know, for example, like if it was calling CPS or talking with the family about hey, this has got to stop. And I want to do, hey this has got to stop. Of course if it's nothing severe, but at the back of my mind I know, .... you know, this is straight from the book, this should be a CPS call. ... and I know that's what she's going to tell me to do. Do I go ahead and say, okay, this is the last straw. And give them a harsh talking to, but it's better coming from me than from coming from somebody who can actually take the child.

There was at least one instance where Beth said she would ignore what her supervisor told her to do. Here again it may be a matter of the seriousness of the threat to the child's welfare whether she would listen to those orders or act to maintain her relationship with the family.

Beth paints a picture of herself working in virtual isolation and forced to make choices on her own. This is not entirely by choice but she does express some sense that no one understands her circumstances and therefore their advice may actually be a hindrance. Comparing the processes that Beth said she would use to resolve a dilemma with the rankings, she mentioned several processes that the group ranked high in importance, These are weigh the risks and benefits of various actions, gather documentation, and request further information. She also mentioned several processes from the lower end of the rankings. These processes were seek help from other agencies, provide information to persuade other parties, and decide without consultation with others. This difference in responses may be a reflection of the isolation Beth feels on the job. 
4. When preschool special needs teachers make a judgment regarding a moral dilemma, what other factors do they consider when deciding whether or not to act on that judgment? 5. When moral judgments compete with other values, goals, and concerns, how do these preschool special needs teachers prioritize these factors in order to determine the action which they will actually take?

Beth mentioned very few factors which she would consider which might affect whether she actually took an action which she had determined to be the most appropriate action under the circumstances. The factors which could be identified included the best interest of the child (if in conflict with responsibility, law, etc.), consequences to others of acting or not acting, her relationship with the individuals involved, responsibility to her employer. Beth did not really discuss the process of reasoning about the dilemma in these terms. In most cases the conflict was actually between these values and it would be a mis-characterization to separate them from the process of thinking about the best action to take.

The examples of this conflict were discussed earlier under the discussion of 'head versus heart.' In this context it is important to point out that the conflict was between doing what seemed best for the child and following procedures. Beth did at one point say that she thought it was best to call child protective services. In this characterization, the child's welfare would be the mitigating circumstance that would prevent her from taking the "right" action. Rather than being a moral position, this view seem to be related to her desire to be seen as professional by her colleagues. However, in most of the discussions surrounding these conflicts, Beth viewed them as the actual cause of the conflict. In each of the scenarios, the welfare of the child or the maintenance of a relationship with the family were values which took precedence over procedural issues.

In one scenario only did Beth make a clear distinction between the right thing to do and other considerations. This was the scenario where the Hispanic child was evaluated without an interpreter and was qualified for preschool special needs services. Beth responded to this as if the child were assigned to her classroom, and as if she were assigned to another teachers room: 
Okay, I know that there should have been an interpreter there, but if that child's coming to my classroom, frankly I think that a child in this area who would be speaking a different language would benefit from my classroom. Would be around it, but honestly Miss Beth needs to buff up on her Spanish. I would need to know how to address that because I can see that happening. They would say, oh she needs speech, she needs, she has personal social issues, even if she did, it would kind of help her adapt to our culture. I think we would all benefit from each other in that situation. Even though that's not the right thing to do. I think they should have an interpreter to see how she would function in her setting, but she's not going to be in her setting all her life, it would be good to expose her to the type of children that are in my classroom. We'd all benefit.

Beth knows that legally, the schools were required to assess her in her native language but she tries to see the benefits, for both the child and her class, of having a Hispanic child in her classroom. However, later, it became apparent that her position on this was confounded with the issue of authority. Assessments in Beth's county are the responsibility of her supervisor and thus the implications of the assessment would be even more serious. While Beth did not say it specifically, she gave the impression that the consequences to herself of acting to correct the situation would be too serious.

When the scenario involved the child being placed in another teachers room, the nature of the dilemma changed. Here the motive would be more to protect the child in question because she really believed the child would benefit from being in the preschool classroom.

Oh. And it wasn't someone who was going to say, buff up on her Spanish. I would probably tell them, well technically you know, she doesn't have to be in your room. But think about it. She's going to benefit from your classroom. And the other teacher would probably say, but she's taking somebody else's slot. And I would, this is one of those where I would say, okay, administrator, cut and dried, what is it? I would go to the administrator with that.

Beth saw that interceding with the other teacher would create a conflict she did not want to deal with. If she explained the legalities of the situation, then the other teacher might move to have the 
child removed from the program. If she didn't act to intercede, then the teacher might assume the child really was developmentally delayed and not provide what the child needed. Under these circumstances, Beth would let her administrator make the decision.

The concept of CYA or "cover your ass" came up several times during the interviews with Beth. It was tempting to see this concept as an alternate consideration but it came up in the context of scenarios in which Beth felt there was no dilemma. She did give the impression however that the concept might also arise in situations in which she felt powerless to act,

Well, of course there's all the legal stuff but you always want to have documentation if someone comes back. Well, why didn't you say so. I did, here it is, see, you chose not to follow it. Law suits and things like that so that at any given time, well, maybe I can put it this way, at any given time in the back of my mind I know that at least I wanted to do the right thing. That kind of makes me feel better.

Beth did not seem to see this as a matter of maintaining job security in a difficult situation. If she had, this would have clearly made this an alternate consideration to the most appropriate action. For Beth, CYA had more to do with her inner sense of well being and being able to live with her actions or inactions.

\section{$\underline{6 .}$ Do these special needs teachers feel that they live up to their own standards of moral} behavior? If not, how do they resolve the resulting tension and plan for future development? When Beth was asked if she felt she could maintain her sense of moral dignity on the job, she made an interesting comment about the challenges she faced,

I definitely think it's a challenge. And sometimes you just feel like your morality is like, like a general's, stripes on a sleeve, and they like, swipe. You know they just want to take them away all the time, or they want to push you all the time. People, like supervisors who, especially when it comes to calling CPS, when I have a rapport with the family, and that, this is one thing my supervisor has told me, you're not, you don't do IFSPs any more, it's not family related, it's IEP and it's just, an education model. 
This theme of conflict with supervisors was apparent throughout the interviews. Even though Beth had made major changes in her life, and looked forward to a time when she would have years of experience to fall back on, she made it clear that this conflict with authorities would probably not change.

Beth did not directly state how she would plan for future development but she was very clear about changes that had recently occurred in her own life that affected her sense of morality, Moral, there are a lot of examples that have moral dimensions in that I thought if you were to interview me this time last year, before I, before I was a Christian, there are things that would have been a moral dilemma that aren't now. For example when you asked about, when you asked about signing an IEP or IFSP now, before, that would have been, I would have thought that would have been a moral dilemma in that I thought, oh I really shouldn't do this but I will, I'll do it for you, for another teacher who needed it signed. When I worked at FMRS. And now, I just wouldn't do it because it's wrong, and, I wouldn't want anybody to think I would ever do anything like that. I mean, I wouldn't do it, number one because I try not to lie or do anything like that. Because of you know my religion, but, before, I mean, I can't say I haven't done it, I've done that, on an IFSP, after the parent had left and hadn't signed a review and I signed it. Which was so wrong. But I was so wrong at that time anyway,...

Beth's faith has made it possible for her to stand up for what she believes in the face of authority who are pressuring her to do otherwise.

At various points in the interviews, Beth explained things about herself that she would like to change over time. Her relationship to these aspects of her personality was very complex and somewhat difficult to interpret. The first of these issues was the concept of professionalism. Beth stated that she wanted to be more professional and this seemed to involve controlling her emotions,

Beth:...there's another teacher in our school, in fact there are several. But there's one who, she's really calm and she's really like, I mean her voice is like, I want to be like this, her voice is like monitone. She's like, no matter what, she can say, she's a kindergarten teacher and she can say, 
okay, Justin, pull a card. You know, I'm not like that. I'm like, Justin! Look at! It's your turn now! Do you want to pull, pull a card! Now do you want to have it, pull a card!

Interviewer: Why do you think that's a good thing?

Beth: I do. And I just think it's, she's competent, she knows what she's doing, and she'll, I've heard her on the phone and she'll call the parent and you need to come and pick up Ryan, he's misbehaving today. I don't think he's had his medication. Well, his father may say he's given him his medication, but he's not behaving appropriately today. Could you come, like come and get him within 20-minutes. Good bye. And I want to be like that but I'm not. I'll call and say, I would never, I don't call about behavior, I handle behavior on my own. I don't call about behavior. If they're sick, I try to do what I can do because if they're there $21 / 2$ hours, I call and let the Mom know, but I guess I see myself as a pushover. Because I call and say, Micky's not feeling very well, could you, I know we only have about an hour left in class so would you want to come and get him or do you want me to put him on the bus, it's up to you. But I'll take care of him until then. I'm like that.

Beth seems to feel that "being more professional" by controlling her emotions more, would prevent her from being taken advantage of. She also later on stated that "being more professional" would not make her a more effective teacher but would alter the perceptions of others,

Interviewer: Can I ask you, do you, when you say professional, do you mean, do you think that professional and effective are the same?

Beth: No. No. No. Uh huh.

Interviewer: So you think the lady with the monotone is not necessarily more effective?

Beth: ...........No. I think that's more for the benefit of her peers, like me and the other teachers just say, oh, look how she does that. No I don't think it's necessarily more beneficial with the child.

Interviewer: Okay, so what you're saying is that you want to be the professional, not because it benefits the children, but more because it would benefit you in the eyes of.......am I pushing too hard. 
Beth: No, there it is. This is very therapeutic. Yes, you're right. You're right.

Interviewer: Well, do you think that's a function of being a new, a new....uh....beginning professional?

Beth: Uh huh. Part of the confidence thing.

Interviewer: Yeah.

Beth: Because I'm sure in 5 years with this same job I'll probably be acting, I'll probably act the same way but I won't care....that..... monotone sees it......

Interviewer: The same way you are now? Or...

Beth: yeah. Yeah. Because my aide talks with me about it, oh we've had other teachers who were really not good with the kids, and you're good with the kids, and I think, am I good with kids because, why does she think that, because I'm playing or and I think it's that I'm not monotone. I don't know, I keep going, I keep, going against myself here don't I?

Beth seems torn between her desire to be a good teacher and her desire to be perceived as a competent professional. It is interesting that she doesn't see these goals as being in conflict.

She raised this issue of perceptions again in the context of a discussion about how we present ourselves to others,

Beth: I think that I would have answered these questions differently if it were someone that I knew were asking them. Yeah.

Interviewer: You seem to strike me as being very open. I don't.....

Beth: Yeah, but if it was somebody I knew asking these questions, then I wouldn't....

Interviewer: Then you wouldn't be.

Beth: I'd never let them know I wanted to be the monotone... What I mean is I want to be more professional, less animated.

This again seems to be a point of conflict. On one hand Beth wants to be perceived as a competent professional (defined as the "monotone") and on the other, if asked, she would not want others to know that she thinks her emotionalism makes her feel she is less professional. 
The interviewer pointed out that she was talking about two different types of emotionalism. There was her emotionalism with the children that she sometimes felt makes her a good teacher, and there is the emotional reaction to situations that affects her outside the job. When she was asked directly which of these she wanted to change, she said,

That my emotions didn't rule my life. Yeah, because I don't think my idea of moral dilemmas is every going to change. It may. But, in a way I'm glad that I notice the smaller things. Before it gets out of hand. Get it taken care of before it gets blown up out of proportion. If I could deal with it better, control my emotions better. I'd pick that.

7. What do these preschool special needs teachers identify as the origins of their moral values and moral beliefs?

the subject of the origin of her values came up at many points throughout the interviews. Beth mentioned her father 's influence, and the changes in her values that resulted from her recent acceptance of Christ into her life. She hinted that these origins might be related even though the religious origins of his values might not be direct immediately apparent. Beth described his influence and his background,

Because, my values, I've never talked to anyone about this, but like my values, I feel like come a lot from my Dad, other than the church. But my Dad, he never went to church but, there's a whole other story in itself too, his grandmother made him sit at 7:00 every evening for an hour and a half while she prayed out loud really hard and really pounding the Bible, and when he got older he wouldn't go to church but he, he has that, and he gets that, if you can live with it, ......if, like, if I say, oh I can't sleep, if you'd treat people right during the day, you'd sleep at night. I mean, he's just, like that. He has instilled a lot of values in me. And.......and I don't see that from my mom and sisters. I think my Mom has ADHD, she's ........ and my Dad, I don't know, he's just calm. And he's given me a lot of my values and when I met my husband now, Dave, when I met him, like he had those same values that I loved, ...... 
Beth's words give the impression of a broad standard for treating other people and for finding ways to live with one's own actions.

While Beth's father's advice may have given her a lesson in character, Beth seems to feel that her understanding of specific events was shaped more by her religion,

Moral, there are a lot of examples that have moral dimensions in that I thought if you were to interview me this time last year, before I, before I was a Christian, there are things that would have been a moral dilemma that aren't now. For example when you asked about, when you asked about signing an IEP or IFSP now, before, that would have been, I would have thought that would have been a moral dilemma in that I thought, oh I really shouldn't do this but I will, I'll do it for you, for another teacher who needed it signed. When I worked at FMRS. And now, I just wouldn't do it because it's wrong, and, I wouldn't want anybody to think I would ever do anything like that. I mean, I wouldn't do it, number one because I try not to lie or do anything like that. Because of you know my religion, but, before, I mean, I can't say I haven't done it, I've done that, on an IFSP, after the parent had left and hadn't signed a review and I signed it. Which was so wrong. But I was so wrong at that time anyway,...

For Beth, a total transformation was required for her to achieve her present standards of behavior and understanding of the moral implications of events.

The events which brought about this transformation were the abuse she experienced in her marriage, and the experience of working to become independent financially and personally after the divorce. The subject arose when Beth was asked to describe the worst moral dilemma she had faced. Beth describes how the events of her life forced her to take a close and sometimes painful look at herself.

\section{$\underline{\text { Personal Story or Fable }}$}

Any attempt to construct a personal story or fable from the interviews would probably look much the same as a chronology of Beth's life. At one point, Beth described her life as a Cinderella story, 
..I want to say a Cinderella story, but I'm not quite Cinderella, but I came from nothing, and lived in this trailer and was so abused, and now my husband, I can find no fault in him, and now that we're together in Christ it's totally different. I didn't know life could be this good. And I would like to give that hope to others. That's probably the way I see myself, as, as a Cinderella story.

It is not clear whether Beth activates this image or the image of herself as a religious person when faced with a moral dilemma. It is clear, however, that these images have helped to shape who she is as a moral agent. The story of her conversion is worth quoting in full and in her own words. This section of the interview began when Beth was asked about the worst moral dilemma she had face:

Beth: Divorce because even though my family didn't go to church, at that time no one else was divorced in my family. Now they are, but except for my Mom and Dad, but my sisters are now. At that time no one else was, and there's my big, crackhead husband, who's beating me up in front of our kids, and there's still something in me that's saying divorce is wrong. It's really something. To hear me saying, divorce is wrong, but then to do this to try to help him try to get through this, I put him through re-hab three times, and it kept getting worse, but then part of me says, your children are seeing this and if you wait any longer they're really going to be messed up. But what it actually took, and this is terrible, what it actually took was the second time I got a restraining order, I got a call from Children's Protective Services, who said, if you don't take, if you don't stay away from this man, because I would have went back to him again, you're not protecting your children. You're not protecting yourself but you're not protecting your children, and if you don't protect your children, we will protect your children. So I have been through that in my life. I don't want anybody to know that. I mean, I've never actually saw a CPS worker or anything, but...but it was like, they had to slap me in the face so I could realize, you know, you're not taking care of your own children. Which my kids, the youngest never saw anything. The oldest, he says, I remember he poked you in the eye, but he doesn't, he was like 2 $1 / 2$. So... 
Interviewer: How did CPS become aware of it?

Beth: Well, I had to, when I filed for divorce and I like tried to get benefits because at that time I was unemployed, that was before, no that was when I worked at the car dealership, when I was expecting, after I had the baby I didn't go back to work. I was going to substitute, but then for like 3 years I wouldn't go out of my house because I was so, it was like I was so ugly or so, all that, and my confidence level was ziltch. I wouldn't go to a gas station. I wouldn't go to a store. I just felt so terrible about myself. My self-esteem was really low, and um, man I was convinced that this was the only man in the world who would ever have anything to do with me. Who else would. And, it took that and I realized, well, my kids are way more important that this, and I wanted to give my kids what I had from my Mom and Dad. So, that wasn't going to happen. So I ended up getting a divorce, but it was a real struggle. I mean, like I told you, that's when I, I would smoke. And I had to live with my Mom and Dad. And I had nothing. And like 2 o'clock in the morning and there I would be, sitting, in the dark, smoking and crying, and it was terrible. It was terrible. That was the worst part of my life. So....but it's always darkest before the dawn. I'm in the dawn now, I feel like I can ...... That time if I would have been in church things would have been so different. But, it could have been that I would have been even more against divorce. I don't know. Things happen for a reason and they all happen right on time. At FMRS, um, my aide, was, she goes to the church that I go to now, and she's like a, I don't know, she's kind of a like a minister or a missionary, but I don't know what they call it. But she's, she knows a lot about the Bible and she could preach on things, but I mean, but she didn't preach to me that time. I mean like, I came in and she'd say, you need to put a little more makeup on that because I see that you have a black eye, which was really embarrassing, but she could have really preached to me at that time but she didn't. And I saw the little angel up there that she gave me, and, she was like, oh, come to my church. But I was like, oh, no, I couldn't, I'm so bad, there's no way. And I had, so she left, and I had a little girl from down that way who was in my classroom and she went to that same church. Even though Becky was gone she went to that same church, and her Mom was like, come and see her in the Christmas play, and I said, 
okay I will. And then somebody said, don't go to that church, they're a bunch of Bible beaters. And the longer your skirt the closer to the front you can sit, I mean it was just like they were making fun of it. And I said, oh, I'm not going, and I wouldn't go. And now, when I started this pre-school job, my aide goes to that church. She's Apostolic and um, she wanted me to come to the Christmas Play last year, and I went to the Christmas play and I really like that church and I saw all those people and I thought, you know, there he was all along. And he's kind of like the prints in the sand thing, like, there was God in my life, all along, he was there, and I was smoking and I was crying and things like that and all I had to do was reach out and he was there all along. Things could have been so different. I mean, I was, I don't know. I was just a nervous wreck in my mind. And it was terrible. And to think he was there all along.

\section{Case \#4: Rebecca}

Rebecca is a 55 year old native of West Virginia. She has two adult children, and has been single since 1993, when her husband passed away. Rebecca has been teaching for 15 years, eight of those years have been in a preschool special needs classroom.

Rebecca grew up in a middle class family in the same small northern West Virginia community in which she now lives. Rebecca had one younger brother. They both graduated from the local high school. Rebecca and her brother both enrolled in a small Church of Christ Bible college in Tennessee but Rebecca soon became homesick and returned to West Virginia where she finished her undergraduate education in a small private college near her home.

Growing up, Rebecca and her family were active in the local Church of Christ. Rebecca feels that the church and her family were the primary influences on her values:

Rebecca: $100 \%$. All of them. That is when your values are shaped as a child and definitely that is how mine were shaped. My parents started the church, they were chartered members of the church up the hill. I should have been too because I was there and from the moment of conception so to speak so I always thought I should have been a charter member and I was brought up in a church and it was a church school, a Bible school, Church of Christ college... 
When Rebecca was asked about mentors in her life, she talked again about family and church, and added the influence of one teacher in high school:

Rebecca: Of course when I was younger, my mother and my father too. But my mother was a very big influence in my life. She was a really, really, nice great person. Dad was like complete opposite but that is OK. People that I can remember in church because we were there on Sunday morning, Sunday evening, Wednesday evening for all the activities. We were always in church so there were several people there in church. My Sunday School teacher, I remember with great fondness that really was a learning influence in my life. I always called him the Peters.

Interviewer: Peters?

Rebecca: Yes they led people to Christ. Then in high school I had a Latin teacher. That was my first choice. I wanted to be a Latin teacher....and she was a great influence in my life as far as teaching is concerned. I had some great teachers in high school.

Interviewer: But no one stands out more than others who shaped your values?

Rebecca: It would have to be my mother who shaped my values the most.

Interviewer: What do you think her primary value was? If you had to sum it up?

Rebecca: My mother's? My mother's would be the spiritual aspect of life. The believing of the greater power, whatever that might be, to whoever you are and always doing the right thing.

Growing up, Rebecca wanted to be either a teacher or a nurse. When discussing this, she took a slightly humorous view of those goals:

Rebecca: I either wanted to be a teacher or a nurse. What else do children want to be at that age, back in the 50's or early 60's? Get married, have a family or be a teacher or nurse. This gives an impression that her choices were somewhat unconscious and that she didn't give serious thought to her options. On the other hand, she described majoring in a subject that clearly interested her:

No. I never did. I always figured teaching or nursing. I really liked literature, English and all that so I went into that and that is how I ended up being an English major. My Social Studies 
major, I stood in the wrong line at registration in college and I got up to the desk and he said this is for History majors only. I said that's mine. So I have a double major. I wasn't going back to the end of the other line. That is one way to pick your majors.

This last story was told in a somewhat ironic tone, so may or may not accurately reflect her state of mind when choosing her major.

After college Rebecca married and briefly moved to San Diego, California. Her husband was in the Navy at that time and was stationed there. They soon moved back to their home town where they remained. Rebecca's two daughters were born and raised in the same community.

When Rebecca was asked if she had an image of the structure of her life, she stated, "Obviously not.... just drift along in life and whatever happens, happens and I, hopefully I can keep going on." This may be a reflection of her history of employment in education, which she described as filled with happenstance:

My degree was in high school, secondary education, English and Social Studies were my majors and I worked for them for a while and then got a job teaching high school English and from there I became pregnant. Stopped and had the kids and went back to work subbing. Took me eight years to get back on in __ County. How far is this going? This interview. It is all confidential? One of the criteria to be hired, as a teacher is that you must coach. Not knowing, is the football the round ball or the one with points on the end? I had a very difficult time getting back into the system and especially with my, English teachers and Social Studies teachers were all coaches. So I didn't get in. I went into Special Ed because of the high degree of turnover. Any time there was a job opening I would say I am getting my master's in that. Isn't that a coincidence? So I finally ended up in early childhood. There was an opening and they said would you go back to school to get your degree? I said I would love to. So I went into early intervention and I got my master's in that.

Rebecca received her master's degree through the extension program of a regional university. 
Rebecca's husband passed away in 1993, and when her father passed away in 1999, she moved her mother into her own home to care for her. When the interview turned toward family relations for older individuals, Rebecca said rather forthrightly,

Rebecca: Yes at this stage, you don't have to be as concerned with family issues as when your children were young and growing up but neither does that mean that your job becomes your life. My job is strictly a means to an end, like giving me money so I can live my life.

Dedication for special ed, ach, give me my paycheck...I've always had that distinction. I never felt, even when my husband worked and I didn't get all shook up about some things. That is not your life. That just gives you the means to enjoy your life. To me your life is your family, your friends. The activities you choose outside of work. That type of thing.

It is hard to know how serious Rebecca was when she made this comment. It contrasts sharply with the care and concern she expresses for her students.

In keeping with these comments, however, Rebecca makes the most of her spare time by dancing five nights a week:

I started out with line dancing, country dancing. I love it. I love to jitter bug. I go Tuesday, Wednesday, Friday, Saturday and Sunday. I cut it down. It used to be on Monday and Thursday too but I cut out a couple nights.

As for future goals, Rebecca stated,

To live my life as I so choose. My immediate end is to make it to retirement which I wish it was tomorrow and whatever your goals happen to be. I want to travel. To see it all and do it all. 
$\underline{\text { Rebecca and the research questions }}$

1. What events, occurring in the course of their professional duties, do some preschool special needs teachers consider to be moral dilemmas?

During the first interview, Rebecca was asked to comment on 15 of the 18 scenarios which were submitted by the Delphi participants. She was not asked about all of the scenarios received because one was Rebecca's own scenario, and one scenario was from a time when the participant was working as an early intervention specialist and the details of the events were not meaningful to the preschool special needs teachers. A third scenario was left out of the interview phase because the researcher was unable to get important clarifying information from the participant who submitted the scenario.

Rebecca's responses to these scenarios do not divide easily into categories of those which posed a moral dilemma, and hose that did not pose a moral dilemma. Rebecca's responses tended to be brief and generally consisted of a statement of what she would do. When she was questioned further, it was apparent that she understood the moral aspects of the events. However, it soon became clear that the use of the word 'dilemma' was confusing the discussion. For Rebecca, there is clearly no dilemma if you know what you would do under the circumstances. The discussion of the definition of a moral dilemma occurred during Rebecca's response to a particular scenario and is reported in full:

Interviewer: Okay. Two of your students are half brothers. Sam is four years old and Davey is three. Over the year Davey has periodically come to school with many scratches on his face. Davey says Sam did it and Sam does not deny it. The boys mother has made light of the scratches. One morning Davey arrives with many severe and painful looking scratches on his face. They are worse than they usually are.

Rebecca: I would probably talk with the mother. Yeah, I would see... again you are looking... I would talk with the mother and explain to her my concerns and tell her that if this happens again I would be compelled to report it because that is not acceptable. She is going to have to supervise those kids better. Cut the other ones fingernails or something. Yeah, that is what I 
would do. I see a moral... no, I would just tell her, hey this is the way it is. Got to watch those kids better or we are going to have to report you to Children's Services.

Interviewer: Okay. But that does pose a moral...raises a moral question?

Rebecca: No, you can't let one beat the crap out of the other one. You've got to do something about it if she is too stupid to. I would.

Interviewer: Okay. So without trying to prejudice anything, several people have said that... have indicated that they thought there was only a moral dilemma if there is a question about what you need to do.

Rebecca: Well then there is no moral dilemma in what I would do.

Interviewer: I am just wondering if that is the case for you or just in this particular instance.

Rebecca: Oh, is that how I would define a moral dilemma?

Interviewer: Yeah.

Rebecca: No. To me a moral dilemma is when what I basically believe to be right and true goes against what I am told to do. Because basically I only do what I believe is right and true. Its when someone in a higher position tells me I have to do something else that I then face a moral dilemma. So like these... a lot of these are hey here is what I would do. To me there is... Interviewer: It's not... I mean I guess the word dilemma might be somewhat misleading. You know it is not a dilemma if you know exactly what you would do but it does still have moral dimensions I guess is the distinction I am trying to make. Does that sound....

Rebecca: Yeah, I understand what you are saying but see you have someone... I am not very often in a dilemma because I have no problem making decisions.

Interviewer: Okay.

Rebecca: So, hey if you are going to judge a dilemma on that... Interviewer: But it has moral dimensions...

Rebecca: It has moral dimensions but I would not require...

Interviewer: because it is the welfare of the child....

Rebecca: I would not classify it as a dilemma. 
Using her own definition, Rebecca almost never encounters a moral dilemma.

It is tempting to relate this definition to a moral dilemma Rebecca described related to her sexuality. She had been asked to describe the biggest moral dilemma in her life:

OK. It was after my husband died and I began going out with others of the opposite sex. Now don't forget I was brought up in a church. You know what the Bible says and I had a really difficult time dealing with that. The sex outside of marriage aspect of it. It was something very difficult for anyone brought up in a church to deal with. So that was the biggest moral issue I had to deal with in my life. I solved it by never having sex on Saturday and going to church on Sunday. You asked and you got it. I quit going to church on Sundays. That is probably the only moral issue that really bothered me that I can think of.

This dilemma appears to fit Rebecca's definition because it is a conflict between what she personally wants to do and what authority, in this case church or God, tells her she may do.

2. From the perspective of these preschool special needs teachers, what specific characteristics of these dilemmas signal that they are moral in nature?

Also in keeping with Rebecca's definition of a dilemma is an issue that she described from her professional experience. This is another instance where Rebecca's sense of what is right conflicts with the position of those in authority:

... I would like to see the records, I don't know if this is what you are referring to, but like when my kids leave this program, I would like to see their records just erased, just as if they were coming in off the street as any other child going to kindergarten. But no, this follows them. I had a... there was a... Before the school psychologist and I talked and we agreed that we would make all the files inactive. I would send her the psych's banded together, they were inactive, no one had access to them. Now he has decided, he who shall remain nameless, has decided that every child leaving the program shall be tested to determine proper placement. Now, if a child is obviously severe profound we meet as an eligibility team in the spring, discuss the options with the parent and give our recommendations which they normally follow. Other than that, I think 
every child deserves a shot at kindergarten regardless. Because that is how it is in the world. Why should they have to go into a special ed program because they were in here? Why should they automatically have to go to an MI program, a mild-moderate program? Now 'he' has decided, and again this is an instance that relates back to his sister teaches kindergarten, they had a child in there who should go into special ed, the parents won't agree to placement. Now, I have his brother in here, I didn't have that child. I have his brother so right away we are going to test him before he leaves our program to see what his placement should be. Why? To me that is a moral dilemma. Why should you? But I only work here. I don't make the decisions. Another example of this conflict with authority is the example Rebecca submitted for the Delphi procedure. In this case, she had been asked to sign an IEP for a student, as if an IEP meeting had been held. In the Delphi, Rebecca wrote, "The moral dilemma occurred because I was told to do it but I knew it was wrong." Although she did not state it directly, she was aware of the state and federal regulations applicable to the circumstances. Rebecca later described how her administrator had agreed to pay for a very costly outside therapeutic services in order to appease the student's father who is a lawyer. Rebecca was aware of the effect this had on her own program stating that it is probably why there is no money for her students. However, this did not play a role in the identification of the dilemma.

It is difficult to identify other characteristics of a moral dilemma (if in fact there are any) because Rebecca so clearly knew how she would respond under all of the hypothetical circumstances. In light of this it will be more instructive to discuss the two scenarios for which Rebecca stated there was no dilemma for reasons other than that she knew what to do.

The first of these scenarios is that in which the mother of a child with severe developmental delays routinely comes to class and loudly tries to get the child to perform skills that she is not capable of performing. Rebecca responded,

Rebecca: Get her out of the room. Oh, God. Yeah, I don't know that I see a moral dilemma there, I would probably encourage the mother to wait outside if she couldn't leave, if she needed to have transportation or something or was bringing the child in or whatever, I would definitely 
try to get her out of the room. We even encourage our children to come in on the bus and we don't even... don't even bring your child in because they do so much better without the parent. So I think I would probably point that out and give her some specific examples without using any names of children who performed better when the parent left them alone. It increases their independence and all that.

Interviewer: That is more of a practical problem for you than it is a moral problem?

Rebecca: Oh yeah. I don't see any...

Rebecca doesn't say, but there seems to be no dilemma because no one is being harmed and of course no one in authority is telling her what to do.

The second of these is the scenario in which the teacher believes a child will be safer if placed in a rural school but the father wants him to be placed in a different school. Regarding this, Rebecca stated, "Um, ultimately the choice of placement would be the parent's choice just as even enrolling him in the program is their choice. " Having said this, Rebecca goes on to give the impression that she feels some responsibility to ensure that the child is safe in the father's choice of school, and to do what will make sure the child receives services:

These are all preschool special needs. Well heck he shouldn't be unsupervised anyhow so control the kid so that he doesn't run out of your classroom and you won't have a problem with worrying about him running off from the building or whatever. And the father doesn't want him in the rural classroom, wants him in the other one. I would put him in the other one and alert the teacher and then... rather than have him not be in any program if that is the choice. Put him in the one the dad wants him in and tell the teacher and tell the administration he needs an aide, a one on one aide. Put it in the IEP.

If Rebecca's responses to the other scenarios are examined, it is possible to identify the issues involved and which would cause her to take action. It is important to remember that Rebecca is not suggesting that there are no moral issues in these events, only that they do not pose moral dilemmas. These issues include, her professional reputation, the rights of an individual, a violation 
of state procedures and policies, and a child's welfare. Regarding the issue of children's welfare, Rebecca stated that this was her primary value in her professional capacity:

I always tell them, to me the welfare of a child is the thing I am concerned with first and foremost and they should be glad that we are watching out for these kids. That's it.

One scenario that did not relate to the issue of authority, did actually present a dilemma for Rebecca even though she was sure how she would respond. This scenario dealt with a teacher who was asked to do a developmental testing of her nephew. Rebecca agreed that there would be issues that needed attention:

That would be difficult because of your closeness to the child and the child maybe not be performing as well for you. I would hope you wouldn't fudge the test results to get him in or to

keep him out. I would be able to do it but then maybe she can't. Maybe she should recommend someone else do it, the school psychologist or somebody. My problem would be if I did it and then had to meet with the parents. That would be very difficult, sitting across from your brother or sister or whatever and trying to...

However, when she was asked specifically if this posed a moral dilemma, she evaded the question and simply said, "I would have done the same thing because I wouldn't want to sit across from her and say the child needed early intervention." This suggests again that the word 'dilemma' posed problems for Rebecca, obscuring her understanding of the situation. She articulated the conflicts that would arise from the situation but then didn't see it as a dilemma.

3. What process do these preschool special needs teachers use to determine the proper action to take under the presenting circumstances of a dilemma that they have identified as being in the $\underline{\text { moral domain? }}$

Rebecca was very forthright about her solutions to the hypothetical dilemmas and did not often expand on her thought processes. As she said,

To me a moral dilemma is when what I basically believe to be right and true goes against what I am told to do. Because basically I only do what I believe is right and true. 
This characterization of her own values suggests a number of things. First it suggests a principled mode of reasoning as in Kohlberg's Stages Five and Six. It gives the impression that Rebecca's values supersede the details of events, that problems are less rooted in the context. This is further supported in the second interview when she said, "There is not a lot of gray in my life."

In contrast to this, when discussing the mother who couldn't decide what program she wanted her son to be in, she related this to a parent she knew who had the same difficulty:

Yeah. We had that. This one poor woman, her son is in here, her other son is the one that is having all the problems in kindergarten that's why he wants everybody to be tested. She goes to school. She works at a geriatric center, goes to college, they must take anybody now days, works at a geriatric center. Her husband is on disability, he has seizures and can not work and she has three kids and head start is pushing her to be a bus mom. The woman can barely cope as it is and I am thinking when is she supposed to do this and they are wanting to see her schedule. One of the kids is a baby. And we ran into that with her too, she wanted to put him in head start because they kept pushing her and I tried to talk to the head start people. Head start is... they do more active involvement.

Rebecca's line of thought had more to do with the identification of the mother's motives, which appeared to affect how Rebecca viewed the problem. In this one instance, at least, context did play a role for Rebecca.

Second, the quote also suggests that Rebecca is very certain of her values and is comfortable with them, and therefore, doesn't require a lot of deliberation when faced with a moral issue. When she was asked how she knew what was right and wrong she said,

If it is what you were brought up spiritually. Because of my upbringing in the church so I think that is what shaped mine - value system. Sometimes even that comes into question, cover all your options and get to the end and there is a God and I didn't believe and I should have. CYA. He is trying to figure out what to do with all this garbage I give him. Have you heard that, if you can't dazzle them with brilliance, do you know the end of that one? 
This statement was at the end of the second interview and Rebecca may have been joking a little when she mixed the concept of 'cover your ass' (CYA)with the statement about the origins of her values. There is at least a recognition there that humans are fallible in their judgments. She also at another point stated that her certainty came from age and experience. When she was asked if she had other dilemmas from work she said,

Rebecca: Just that one that I told you about where he wanted me to do something that was legally not kosher. Other than that, everything's pretty cut and dry in my life. It's either right or it's wrong.

Interviewer: Have you always been that way?

Rebecca: I guess so. I don't think so as a child. I think a lot of that comes with age too. Because when you are younger you are so worried about pleasing this one and not offending that one. When you get older it's I am not taking any more of your crap anymore. I hate to see when I get to my mother's age because she is even more stubborn. I guess I am getting to that point too.... You realize they don't know any more than I know.

Rebecca also expressed her impatience with people who have trouble making decisions when she was asked about an earlier statement that most things were black and white for her,

Rebecca: I acknowledge there is gray in the world. I realize that but it does seem I don't have trouble making a decision. I don't know if I ever had problems with that in most areas of my life.

Interviewer: I am not sure I know what you mean by have trouble making decisions. There is trouble making decisions because of the lack of will sometimes then there is also sometimes knowing which action to take. You seem to not have problems with either of those. Rebecca: Some people they have a difficult time making decision. They say, I don't know. I don't know. I am not asking for a life long commitment here. Are we going out for lunch tomorrow, yes or no? I have a hard time understanding, being patient with people who have such a difficult time making decisions. Especially on minor or trivial things. 
This suggests that Rebecca feels the repercussions of decisions are not nearly as great as one might think.

One last aspect of Rebecca's process of deliberation should be mentioned. Returning to the issue of sexuality that Rebecca discussed. It is interesting that she resolved the conflict with her spiritual beliefs by simply evading her conscience. She seemed unable to completely alter her own value system so avoided the feelings of guilt by "never having sex on Saturday and going to church on Sunday. " At another point she referred to this when she was talking about taking care of her mother,

I am earning my way to heaven. That is going to be my way in. I took care of my mother God. Remember that when you are looking at all the other things I did wrong. Rebecca was joking somewhat when she said this but it still seemed to be a genuine belief.

4. When preschool special needs teachers make a judgment regarding a moral dilemma, what other factors do they consider when deciding whether or not to act on that judgment?

5. When moral judgments compete with other values, goals, and concerns, how do these preschool special needs teachers prioritize these factors in order to determine the action which they will actually take?

In view of the discussion above, it should not be surprising that there is really very little to say regarding competing values. Rebecca did not at any time express a value that would be considered in contrast to what she considered the most appropriate action. Indeed there were very few conflicting values expressed at all. The only time Rebecca expressed a conflict was with the scenario about the teacher who was asked to do a developmental assessment of her nephew. Rebecca expressed the possibility of a conflict between doing an unbiased test on the one had and the tendency for a bias to enter into the testing based on her feelings for her relatives. Rebecca stated that she would have no trouble negotiating this issue but did express that she would not want to be the person who told her relative their son had developmental delays. As was fully discussed 
above, Rebecca considered this lack of conflicts a combined result of her personality and her experience.

\section{Do these special needs teachers feel that they live up to their own standards of moral} behavior? If not, how do they resolve the resulting tension and plan for future development? When Rebecca was asked specifically if she felt she was able to maintain her moral integrity on the job, she said,

Oh yes. I won't compromise that. I have to look at myself in the mirror every morning. Yes. Let the chips fall where they may. That is one nice thing about being here that long. I have been in the county long enough, what are they going to do - ground me? I don't think so. These comments, in the context of all that has been discussed, suggest that this is not a statement of bravado but rather a sincere statement of how Rebecca views herself and her relationship to her job and life in general. The question of planning for future development did not come up because Rebecca gives every impression of being satisfied with her ability to resolve problems.

7. What do these preschool special needs teachers identify as the origins of their moral values and moral beliefs?

Given Rebecca's forthright personality and character, it was unavoidable that this topic should have already been discussed in the sections about identifying moral dilemmas and reasoning about moral dilemmas. Rebecca had no doubt that her values were shaped by both her family and by the church and her ability to act on her values developed with age and experience. 


\section{Personal Story or Fable}

Rebecca was certain that she did not have a fable or story about herself and that she used as guide when making decisions about moral dilemmas:

Interviewer: Do you have an image I was talking about? ...Like a structure like a novel would have...Here's where I came from and these are the crisis that I went through and I overcame and came out the other end. That sort of an image.

Rebecca: Obviously not....I just drift along in life and whatever happens, happens and I, hopefully I can keep going on. I don't know. I never thought of it as a novel.

Interviewer: I don't know that you would have to necessarily think of it as a novel but kind of that way, kind of the way there is a beginning, middle and end.

Rebecca: I never had.

Naturally, this does not necessarily mean that Rebecca does not have some internal sense of her own life only that she may not identify that sense as a story. Or perhaps she really doesn't think of herself in that way at all.

Rebecca did make one statement that is reminiscent of a personal story or the desire for one.

Interviewer: Does that bother you as far as your self image?

Rebecca: What?

Interviewer: That people don't know what you do?

Rebecca: Heck no. I don't care. I couldn't care less. It is sickening too. It's like what do you do. I am a teacher. What do you teach? Preschool, special ed. Oh. What do you do in your spare time? I do Special Olympics. Oh. What do you want to drink? Diet Coke. Oh. My mother lives with me. She is 87 . Oh my God. How sickening can you get? That is ridiculous. I am going to go out and put an A on my forehead so they don't think I'm Pollyanna. Interviewer: A?

Rebecca: You didn't read the Scarlet Letter. Wasn't it an A? I was an English teacher so you have to agree with me. It wasn't an A for art either. Maybe we should delete some of this. 
Definitions of responsibility, obligation, and duty.

The words responsibility, obligation, and duty appeared rarely in the dilemma scenarios that were submitted for the Delphi procedure and there was some question about their use in the coding of Questionnaire 1. As a result, a specific question about the definitions of these words was added to the interview protocol to examine how the words are defined by the interview participants. The words did not appear in the interviews either, except in response to the specific question. The participants words will be given with little comment.

When defining the terms, Darlene took a hierarchic view:

Yeah, but I won't say it's really distinctly defined. Like I know, yeah, because I find duty is probably, I feel that that's less of something as responsibility and responsibility is a little less than obligation. I feel like obligation is like the highest. Like I am obligated to do this, I have to do this. My responsibility is saying I need to do it, and the duties are like it's part of my job, I've got to do it. So my levels are a little different just by the words, just the simple words. So those are how I look at it a little bit differently, and that's probably how I used it in my mind when I was filling out the questionnaires... Yeah, and my responsibility would be the overall, making sure that each one of those children are safe. So by taking care of all those duties, those kids are safe. That's my responsibility for those kids. And my obligation I would feel would be to make sure that these kids are doing what their IEP says. So it's kind of structured like, this is the IEP that's hanging over my head, as a huge umbrella, the IEP is the obligation, the responsibility is making sure that these kids are safe, and the duties are everything I do in between to get to that top part. That's kind of how I'm seeing it.

Judith defined the terms as having relative levels of compulsion attached to them and talked about personal choice:

...I always think of responsibility, I don't know that could be my. Didn't the other one, the responsibility and obligation have a different connotation to me. Not, I mean I realize that you could use those interchangeably but there's something when you say an obligation, you're obligated, it always makes it sound like something I don't want to do. You know what I mean, 
it's like, that's when I use that word, it's like I'm obligated to do it. You know, why are you doing it, it's not because it's my responsibility, I'm obligated to do it. So that to me gives a negative connotation with it. Responsibility doesn't, that would be something I choose to do, or just give it to me with, in conjunction with something else, but duty, I don't know, duty's what you get paid for, you report or something, I don't know, duty's not in there...Duty. I don't know, duty kind of goes back with obligation, I think. I don't know. It feels like it's something that's put on me whereas a responsibility is something I choose to take on. I don't know. Beth also mentioned relative levels of compulsion and choice that she attached to the terms: I do. I don't know why for some reason obligated, obligated makes me think I'm doing somebody a favor by doing that. Responsibility, is something that has to be done whether I want to or not, like a CPS call. And duties, a duty is something I would see as not my instinct or what I feel I have to do but what basically, what I'm required to do. What I can get by with doing that...Duty, obligation, responsibility. Responsibility first, obligation next, duty, basics. I don't know why I worry about that, but that's the way I feel about it.

Rebecca, like Judith and Beth, emphasized the different levels of compulsion and choice she attached to the words:

Responsibility and duty I don't. I think they are interchangeable. Responsibility and duty, obligation. I don't know, obligation I guess I think would be more subjective. Like okay maybe I have to do it, maybe I don't have to but responsibility I think you have to do it and duty you have to do it. Obligation is like you should do it but you've got more of an element of choice...That is how I view it. Yeah. A duty would be something I would have to do. Responsibility is something I have to do but an obligation would be, to me anyhow, something....It is something you should do but maybe you are not going to do. And it will be okay either way as long as you can live with yourself. 
From these quotations, it can be seen that there is general agreement among these four participants that the words responsibility, obligation, and duty are related to levels of personal choice. However, there is some variation in the levels of compulsion attached to each word. The levels of choice, from least to most, are displayed below:

Darlene: Obligation, responsibility, duty

Judith: Obligation, duty, responsibility

Beth: Responsibility, obligation, duty

Rebecca: Responsibility, duty, obligation

Darlene defined these as having a more hierarchical relationship than did the others. Duty consists of those actions she takes to meet her responsibility to ensure the students' safety. Keeping the children safe is a part of her obligation to implement the students' IEP's. 


\section{Chapter 5}

$\underline{\text { Discussion }}$

This chapter will begin with a brief restatement of the research problem and a description of the methodology. These will be followed by a discussion of the results, their relationship to the literature, and the limitations of this study. The chapter will conclude with a discussion of the implications of this study for the field of preschool special education and the implications for future research. The summaries of the findings will be organized in the same manner as the case studies, i.e. using the research questions as headings.

\section{$\underline{\text { Restatement of the problem and review of the methodology }}$}

For more than 30 years, the field of research on moral development has been dominated by the work of Lawrence Kohlberg and James Rest who have sought to construct and validate a universal model of moral development. The administration of either the Moral Judgment Inventory (MJI) or the Defining Issues Test (DIT) has been the primary, and frequently the only, methodology used to examine the moral reasoning abilities of various professions. Based on these tests, teachers have shown a disturbingly low level of moral reasoning. This study was designed on the assumption that moral development is a far more complex phenomenon than the MJI and the DIT are able to assess. It was also designed to test the hypothesis that teachers' low mean scores on these tests do not give an accurate picture of their moral development.

The methodology for this study was composed of two parts. First, a Delphi study was carried out to get a broad picture of the moral experience and moral perceptions of preschool special needs teachers as a group. The Delphi procedure consisted of three sequenced questionnaires. The first questionnaire asked participants to describe a moral dilemma they had faced on the job. The results of this were coded to create the second questionnaire which consisted of four sets of items to be ranked by the participants as to importance. The third questionnaire consisted of the ranking results and gave participants an opportunity to alter their rankings. 
This was followed by a series of interviews of four preschool special needs teachers in order to develop a more in depth picture of their individual perceptions of moral agency. The first interview consisted of detailed questions about the scenarios the interviewees had submitted for the Delphi and a request for comments on all of the scenarios which had been submitted by other Delphi participants. The second interview consisted of questions about the interviewees' backgrounds, their perceptions of their own moral development, and any questions which were raised during a review of the transcript of the first interviews. The interviewees were selected based on the setting they worked in and their years of experience in education. Two individuals each were selected from urban and rural settings. Within each setting, one participant had five or fewer years experience and one had 11 or more years experience. Based on the literature, these two variables were expected to show differences in reasoning about dilemmas.

In light of the evidence that hypothetical dilemmas do not always elicit responses that correspond to those from real life dilemmas, it is unfortunate that the interviews relied on them as heavily as they did. However, there is one difference from the use of hypotheticals in the MJI and the DIT. When responding to the MJI or the DIT, subjects are not able to ask for more detail and are limited to answering the questions of the examiner. In this study, the participants could ask for clarifying information and were not limited to the type of response they could make. As a result, important information was gained about how these teachers think about problems. The data show that teachers tend to view dilemmas as heavily contextual, as revealed by their tendency to either ask for detail or to respond by describing a situation from their own experience. In this case, contextual is meant to indicate the specific factual details surrounding the events. While the dilemmas in the MJI and the DIT were created by the researchers and bear little resemblance to the actual experience of the subjects, the dilemmas in this study have the virtue of being real dilemmas experienced by other preschool special needs teachers. It is believed that the responses to these hypothetical dilemmas are more representative of the subjects' responses to real life dilemmas because they are dilemmas they are likely to have experienced, and the interviewees had the opportunity to request further detail. 


\section{$\underline{\text { Summary and discussion of the findings }}$}

This section of the chapter is organized in the same manner as the case studies, i.e. using the research questions as headings. It is important to point out here that an underlying assumption of this study was that Rest's Four Component Model (Rest, 1984) provides an accurate representation of the process of negotiating a moral dilemma. According to this model, the individual first identifies that there is a moral dilemma and identifies the nature of the dilemma (Moral Sensitivity). Next he or she reasons about the circumstances, balancing different values, and decides upon the most appropriate action to take (Moral Reasoning). Third, the individual may consider whether there are any other issues that would mitigate for or against the appropriate action, and will access personal knowledge for implementing the appropriate action (Moral Motivation). Finally, the individual will take or not take the chosen action based on moral character, which either does or does not supply the courage to accept the consequences of taking the action (Moral Character). This model was implicit in the structure of the Delphi questionnaires and guided the development of the research questions.

Rest (1984) and Bebeau, Rest, \& Narvez (1998) have recognized that there is considerable overlap in these components. In the course of this study, particularly in the discussions with the interviewees, this overlap became apparent and it was often difficult to separate the considerations into the components of Rest's Model or the discussions of the research questions. In many cases, the four components were considered more or less simultaneously by the interviewees. In most cases, the considerations that might have fit the component of Moral Motivation, were actually at the heart of the moral dilemma and therefore inseparable from Moral Sensitivity and Moral Reasoning. Rest's Four Component Model is perhaps an important conceptual structure for guiding research and integrating research findings from disparate theoretical perspectives. However, if applied too rigidly, it can obscure the actual process of deliberation. 
1. What events, occurring in the course of their professional duties, do some preschool special needs teachers consider to be moral dilemmas?

The literature did not provide any basis for predicting the type of dilemmas that preschool special needs teachers encounter on the job. Examples of dilemmas that have been reported are limited to those issues which had made their way into the court system. The examples offered by the participants in the Delphi procedure provide a partial look at a more 'mundane' moral landscape encountered by preschool special needs teachers. However, existing literature (Howe \& Miramontes, 1992; IDEA, 1997; Strike \& Soltis, 1998; Bennet et al., 1992; Yonovitz \& Shipps, 1992: Gallagher, 1992; Bowe, 1995; Sokoly \& Dokecki, 1992; Katz \& Ward, 1989; Pugash, 1992; Bredekamp \& Copple, 1997; and CEC, 1995) did predict that teachers would encounter dilemmas from a wide variety of sources. The dilemmas included in the Delphi and new dilemmas discussed by the interview participants were precipitated by interactions with a wide variety of sources, i.e. children, the teachers themselves, parents, administrators, the law, other service providers, and colleagues. This finding confirms the prediction based on existing literature that preschool special needs teachers are expected to negotiate a complex moral environment in the course of their employment.

2. From the perspective of these preschool special needs teachers, what specific characteristics of these dilemmas signal that they are moral in nature?

The specific characteristics that participants cited as important to identifying a moral dilemma were also quite varied. These characteristics can be seen in Table 1, page 64. There were no statistically significant differences between adjacent items in the rankings. Those items which achieved a ranking of 'very important' (4.00 or above) are of note because they can be divided into violations of law and various forms of harm to others. These rankings suggest that the participants were familiar with the mandates of their job (legal procedures and advocacy for individuals) but should not necessarily be interpreted as indicative of their overall moral orientations. Rather it 
may reflect the fact that the design of the questionnaires limited their responses to the identification of professional dilemmas, as opposed to dilemmas from their private lives.

From a Kohlbergian perspective, this result might also be considered evidence of a Stage 5 level of moral reasoning on the part of these preschool teachers. The emphasis on legal issues is reminiscent of the "contractual legalistic orientation" of Stage 5 reasoning as defined by Rest (see Appendix A). The emphasis on protecting the safety and individual rights of others which characterizes all of the scenarios, is reminiscent of the tendency to define duty "in terms of contract, general avoidance of violation of the will or rights of others, and majority will and welfare."

However, the lack of direct discussion of these characteristics and the lack of moral language would probably be interpreted by a Kohlbergian as evidence of a preconventional level of moral reasoning. In addition, the respondents frequently discussed the possible consequences to self through out the negotiation of moral dilemmas, i.e.. law suits and loss of employment. This could be considered further evidence of a preconventional level of moral reasoning. However, it is difficult to determine from the scenarios if this awareness represents a pragmatic understanding of the preschool special needs teacher's job circumstances or if it represents an overall pattern of reasoning about morality.

Damon $(1983,1988)$ views moral development as an aspect of broader social awareness. Unfortunately, information about the social awareness of the Delphi participants is not available. However, the interview participants demonstrated a remarkable lack of understanding or interest in how their jobs affect and are affected by a wider social environment. When asked about these broader relationships, they seemed not to understand what the interviewer was talking about and became confused when pressed. There was also no evidence of a utilitarian mode of reasoning about dilemmas. Interview participants did seem to focus on the consequences of actions but did not seem to consider this in terms of maximizing the good beyond the individuals involved in the dilemma. The interviewees' considerations seemed confined to the specific context of the dilemma they faced. In the case of harm to a child, there did not seem to be any reflection upon the societal or structural causes of harm to children, or their own ability to affect those causes. 
Even though Kohlberg's (1984) research examined reasoning abilites and not the identification of moral dilemmas, this unawareness of broad social issues might provide some support for the finding that teachers reason at a conventional level or at least in a way that would be rated as conventional by the MJI or the DIT. Kohlberg's stages become problematic when viewed in strict accordance with the content of those stages which Kohlberg also claimed to be universal. However, if his stages are viewed in more general terms, the higher stages can be seen as the result of the individual's efforts to construct a consistent and defensible set of principles upon which they base their reasoning about dilemmas. These four subjects not only did not show any evidence of Stage 3 or 4 reasoning, they did not show any evidence of principled thought processes. Although, the principle that children should be protected at all times could perhpas be inferred from their responses. It should not be assumed however, that these individuals were making poor decisions. Rather, that they were basing their decisions on the immediate facts of situations and on past experience with similar events. As such, they do not seem to have developed the kind of consistent and defensible set of principles represented by Kohlberg's Stages 5 and 6. The interviewees seemed more focused on resolving the issue at hand rather than reflecting upon the moral implications of the events.

On the other hand it could reflect an ethic of care which emphasizes the well-being of specific individuals rather than abstract concepts of good or social welfare (Gilligan, 1993; Gilligan and Belenky, 1980; Noddings, 1984, 1994). All of the interviewees frequently talked about the importance of maintaining their relationship with families, another characteristic of the ethic of care. In contrast to this, however, is the fact that the Delphi participants rated 'a risk to a relationship' as relatively low in importance to identifying a moral dilemma.

Erickson (1963) and Gilligan (1983, 1993) talk of moral development as an aspect of identity formation. There is ample information from the interviews to support this view, since the participants were well aware of the relationship between their values and the developmental trajectory of their lives. Three of the interviewees talked about personal crises that had made them realize they were not the person they thought they were, and that the events had shaped who they are 
now, who they are with, and how they define moral dilemmas. This awareness of the role experience played in how they identify dilemmas was expressed by all of the interview participants. Their comments most frequently arose from questions about the use of the word 'dilemma.' On those occasions where the participant was asked specifically if a scenario posed a moral dilemma, all of the participants on at least one occasion, and usually more frequently, stated that there was no dilemma because they knew the right action to take. On several occasions participants stated that what they defined as a dilemma had changed over time and that experience with similar dilemmas also played a part. This also represents an instance where, using Rest's Model (1984) Moral Motivation (knowing how to resolve a situation) and Moral Character (having the courage to resolve the situation), as defined by Rest (1984) overlap with Moral Sensitivity.

Selman (1980) and Hoffman (1976) examined the role of perspective taking in the development of social awareness and, indirectly, its role in the development of moral judgment. From their work it is reasonable to predict that empathy (defined as a type of perspective taking) would play a role in the identification of moral dilemmas. There was evidence of such perspective taking by all of the interview participants, except except in cases where administrators were involved. Only one of the participants expressed even a limited understanding of how an administrator might view situations differently from teachers. However, one participant, Beth, expressed reservations about the role of empathy in identifying moral dilemmas. Beth believed that her empathy actually led her to be less objective about the circumstances of a dilemma, causing her to mis-identify the nature of the dilemma. Darlene's interview raised a more general question of the role emotion plays in the identification of a problem. When talking about the hypothetical dilemmas and her own experiences, Darlene frequently stated that some events made her uncomfortable. When asked about this she agreed that sometimes, but not always, the first signal that there is a problem is the emotion of discomfort and it then takes her some time to articulate to herself what the problem is. This appears to happen with issues that she has never faced before and may also reflect the notion of empathy to some extent. 
Research in the area of moral sensitivity (Nucci, 1981; Nucci \& Nucci, 1982; Nucci and Turiel, 9178; Smetana, 1981a, 1981b, 1993; Turiel, Hildebrandt, \& Wainryb, 1991; Turiel \& Smetana, 1984) predicts that individuals will distinguish between moral, social/conventional, and personal issues. Although there was no evidence in the interviews of such a distinction, it should not be assumed that the participants do not make the distinction. Rather this may be an artifact of the research design which emphasized moral issues.

When asked about how frequently they faced moral dilemmas on the job or in their personal life, interviewees tended to perceive them as occurring infrequently on the job and had difficulty identifying a moral dilemma in their personal life. When they did describe a moral dilemma from their personal life, it was always a major personal crisis such as abuse, divorce, or depression. Interview participants did make a distinction between moral issues and practical issues. This suggests that these teachers may have a very restricted definition of the word 'moral,' and perhaps social/conventional and personal issues may be included under the heading 'practical problems.' In the interview with Beth, there was also a suggestion that practical considerations (moral motivation) can overlap with the identification of a moral dilemma (moral sensitivity). When asked to discuss the case of a mother who wanted to have another child so she could have a daughter, Beth clearly stated that she had no right to intercede. However, she also stated that it was not really a dilemma because there were no options for interceding anyway.

Kohlberg (1984) and Rest (1984) have championed the use of hypotheticals in studying moral development and it presents serious limitations on the meaning of their results. During the testing conditions for the MJI or the DIT, subjects are not allowed to ask clarifying questions which may affect how they define the situation. During the discussion of the hypotheticals in the interviews of this study, participants frequently asked about details of the scenarios before responding to the dilemma. At times they declined to respond to the hypothetical at all and instead substituted a description of a similar dilemma they had actually faced at work. This suggests that, for these teachers, the identification of a dilemma is highly dependent upon the context and details of the events. Here again, this use of the word context should not be confused with a focus on the social 
context of events, which would indicate a Stage 3 or 4 mode of reasoning. Assuming that these teachers are not lacking in their ability to solve problems, this emphasis on context fits well with Perry's assertion (in Belenky et al., 1997) that the highest level of moral understanding is the knowledge that truth is relative and highly dependent upon context. This would further support the idea that the scores of teachers on the MJI and the DIT in earlier studies may be an artifact of the testing.

The interviewees' need for more information also gives another hint at why teachers may score at the conventional level of reasoning on the MJI and the DIT. If the dilemmas in the MJI and the DIT are seen as incomplete, then subjects may view them as a forced choice situation and perhaps feel it necessary to answer in a safe manner. There was some evidence of this in the Delphi when participants were asked to prioritize the possible competing values. In these cases, procedural propriety and legal issues took precedence over a desire to maximize the good for the parties involved, whereas, under ideal circumstances they expressed a preference for maximizing the good over procedural propriety.

3. What process do these preschool special needs teachers use to determine the proper action to take under the presenting circumstances of a dilemma that they have identified as being in the moral domain?

Because Kohlberg's influence has dominated the research on the development of moral reasoning (Kohlberg, 1984; Rest, 1994), the discussion of the findings regarding how preschool special needs teachers make a decision will be made in relation to his work. It is important to bear in mind that there are theoretical and methodological challenges to his theory (Gilligan, 1993; Krebs \& Denton, 1997; Krebs, Denton, Vermeulen, Carpendale \& Bush, 1991; Kurtines \& Grief, 1974). The author's intention therefore is not to take Kohlberg's Stage theory as fact and then to compare the performance of teachers to these stages. Rather, the intention is to look for evidence that would help explain why teachers score so poorly on the MJI and the DIT. This evidence may take the form of a critique of Kohlberg's work or it may point to some short comings on the part of the 
participants in this study. The ethic of care (Gilligan, 1993; Gilligan and Belenky, 1980; Noddings, 1984, 1994), which is in part a critique of Kohlberg's work, will also be brought into the discussion.

A graphic detailing Kohlberg's Stage Theory can be found in Appendix A. Since all of the studies in the literature (Chang, 1994; Holt, Kauchak, \& Peterson; Johnston \& Lubomudrov, 1987; Maccallum, 1993) indicated that teachers are able to reason on at least the conventional level, this discussion will not address Stages 1 and 2. Stage 3 represents an orientation to being helpful and maintaining the approval of others, and to conformity with stereotypical social roles, while Stage 4 represents an orientation to respect for authority, and emphasizes the importance of maintaining social order. Contrary to earlier findings based on the administration of the MJI and the DIT, no evidence of either of these stages of reasoning was found during either the Delphi or the interviews. Much the opposite perspective was presented by the interview participants, since all four individuals expressed a feeling of being isolated, misunderstood by their colleagues, and somewhat outside the traditional social role boundaries. They also described occasions where they had defied authority to defend a higher good or principle. The Delphi rankings of processes employed to resolve a dilemma (Table 2, p. 68) show that these preschool teachers as a group tend to employ a consequentialist mode of reasoning when faced with a dilemma. They also showed a preference for consideration of the concerns of everyone involved.

Unfortunately, these modes of thought are not addressed in Kohlberg's stage theory. However, concern for others and consideration of the outcomes of possible actions do have a place in feminist theory. Gilligan (1993) has proposed a view of morality which emphasizes the individual's perception, thought and action in real life situations. This view of morality can be labeled 'consequentialist' because the reason for moral deliberation and action is the desired outcome of maintaining relationship and respect for self and other. Gilligan sees this as a feminine approach to morality that contrasts starkly with Kohlberg's sense of dilemmas as either/or conflicts. The findings of this study provides support for Gilligan's claims of an ethic of care. The participants in this study showed an inclination to think of the consequences of actions when reasoning about a dilemma, and frequently emphasized the importance of maintaining relationships. 
Stage 5 represents an understanding of the social contract that binds all individuals and requires certain, sometimes, arbitrary constraints on behavior. The Delphi and the interviews did not produce any information, either pro or con, regarding this understanding of the moral landscape. As was discussed in the section above, the interview participants did not seem to understand questions about their relationship to society as a whole. This does not mean that they were not aware of that relationship, only that they did not discuss it. Participants may be lacking in language for discussing the nature of society and their roles in it, while being functionally aware of that nature and their roles. This would be consistant with the finding, from the Delphi questionnaires and the interviews, that participants almost never used moral language. This absence could indicate either a poor understanding of moral relationships or it could indicate simply that these teachers do not have words to apply to concepts which they operationally understand.

Stage 6 represents an orientation not only to socially created rules but also to principles of choice based on logical universality and consistency. There was some evidence of universalizable principles operating in the lives of the interview participants. Darlene expressed the Golden Rule as the actions of being nice, and the others expressed their sense of universal rules in the context of their religious principles. Judith even mentioned the Biblical concept of following the laws of the land as long as they do not violate any of God's laws. Judith also discussed this when she stated that there were times when she felt justified in breaking a rule to protect a higher principle. This sounds very much like Rest's definition of Stage 6 reasoning. However, during the interviews, the participants never made reference to these principles when discussing choices they had made in the past. It was shown that there was a discrepency between how often participants stated they felt morally challenged and the impression which was actually given to the interviewer. There also seems to be a discrepency between the interviewees' sense of the source of the their values, and their use of those values when deliberating about moral issues.

Some philosophers (Murdoch, 1956) and researchers (Day, 1991; Tappan \& Brown, 1991) have suggested that what an individual considers a moral choice is often a choice that fits well with an internal narrative that the individual has constructed about herself and where she is going in her life. 
None of the participants specifically stated that they access an internal image or story about themselves when making moral choices. This does not necessarily mean that they do not have such representations, only perhaps that the process is not immediately accessible to their consciousness. Some suggestion of this, however, is given by Darlene's emphasis on family and being nice, and Beth's mention of moral decisions being decisions she could live with. However, the discrepency between interview participants' statements about their values and their failure to mention them specifically during the interviews, suggests that these teachers are not in the habit of self reflection and may not be accurate reporters of their experience. This would appear to argue against the narative view of moral deliberation as a theory of how individuals actually deliberate. Its absence, coupled with the apparent absence of a consistent and defensible set of moral principles, may actually suggest the importance of self-reflection and internal narratives to mature moral deliberation.

Referring back to the Four Component Model, there was also some evidence of an overlap of Moral Motivation components with Moral Reasoning. It was often apparent that, for these participants, part of the process of reasoning about the dilemma and what action to take involved a consideration of other competing values, and moral and extra moral considerations cannot be separated from the identification of a moral dilemma as Rest has done in his model. As was stated in the discussion of Moral Sensitivity, the dilemma itself consisted of a conflict between these competing values. This was most apparent in the cases where the choice was to call CPS or to talk to the family member and warn them. All of the interviewees recognized that making the call was the most appropriate action to take. However, Darlene, Judith, and Beth expressed a desire to maintain the relationship with the family. This could have been interpreted as a competing value (moral motivation) but these teachers made it clear that this value was part of the dilemma and the reasoning took it into full consideration. This overlapping of the parts of the Four Component Model was so frequent, that it suggests that the division between Moral Sensitivity, Moral Reasoning, and Moral Motivation is overly artificial and may actually obscure the process of deliberation used by individuals. 
4. When preschool special needs teachers make a judgment regarding a moral dilemma, what other factors do they consider when deciding whether or not to act on that judgment?

These questions were designed to elicit information regarding Component 3 or Moral Motivation. Rest (1984) defines Moral Motivation as the process of examining competing values (including non-moral values), projecting the outcomes of each set of ideals, and selecting the value to act on. Further, this component includes the question of deciding whether or not to try to fulfill one's moral ideal. No directly related research was found to address this aspect of moral reasoning, consequently no predictions could be made about the findings of this study.

Looking at the definition, one could predict that there would be a blurring of the boundaries between moral reasoning and moral motivation because the dilemma itself is frequently the conflict between values. Some evidence supporting this prediction came from the interviews. The most common example of this overlap was described earlier in the cases of deciding whether to call CPS or talk to the family to maintain the relationship, where the conflict is between protecting the child and working to maintain the relationship with the family.

Looking at the rankings of factors that would be considered after the appropriate action had been identified (Table 3, page 71), eight of the items were ranked as 'very likely' to be considered. Of these, four were considerations of consequences, and four were considerations of principles. It is difficult to know how to interpret this sudden appearance of principles when they were generally absent in the rankings of processes of deliberation, where interviewees tended to concentrate on consequences. It would suggest that participants felt that their preferred mode of thinking (weighing the consequences of actions) belonged in the Moral Reasoning section of the Delphi and more principled considerations belonged in the Moral Motivation section of the Delphi. If this were the case, this would suggest that these teachers, while still aware of principled modes of reasoning, found considerations of consequences a more salient aspect of their deliberations. If this were found to be true of teachers as a group, this would also help to explain the low scores on the MJI and the DIT in earlier studies. It would further suggest that the distinction between Moral Reasoning and Moral Motivation is artificial. 
5. When moral judgments compete with other values, goals, and concerns, how do these preschool $\underline{\text { special needs teachers prioritize these factors in order to determine the action which they will }}$ actually take?

It seems reasonable to assume that using Rest's Four Component Model actually hindered this study. By artificially separating aspects of the process of deliberation, it may have been more difficult for participants to clearly describe the process and it made it more difficult to analyze the interview transcripts.

Looking at Table 4 (page 74), where these factors were prioritized, the picture is very similar to that of Table 3 (page 71). With the exception that considerations of individual welfare moved down in the rankings of importance and considerations of group welfare moved up in the rankings of importance. In some cases, the items actually traded place with each other. This may be further evidence that participants use a 'safe' mode of reasoning when put into a forced choice situation. Darley and Bateson (1973) in a study of helping behavior in seminary students found that individuals could not easily coordinate competing values when under pressure. If the individuals felt pressured by the forced choice situation, then the original rankings of the items may present a more accurate picture of the teachers' processes of reasoning.

$\underline{6 .}$ Do these special needs teachers feel that they live up to their own standards of moral behavior? If not, how do they resolve the resulting tension and plan for future development?

These research questions were included to seek information to support the position of narrative psychology (Murdoch, 1956; Day, 1991; Tappen \& Brown, 1991) and to get some sense of the moral character of the participants. Information to answer this question came primarily from the interviews. As was stated earlier, there was very little overt evidence of a story or fable that the participants use when faced with a moral dilemma. This does not mean that for these teachers moral choices do not have to fit into a coherent sense of self. It does suggest however that their senses of self or any stories or fables they may have are not readily accessible to them. When themes in their conversation were pointed out to them, they still did not identify them as stories per se. Beth at one 
point called her history a Cinderella story, but she did not give the impression that this story was seen as relevant to her moral choices.

It is tempting to see Christianity as an internal story for three of the participants because religion played such a prominent role in their lives. Beth stated that sometimes she would ask herself, "What would Jesus think if he were sitting right here?" However, when describing real life moral dilemmas, none of the participants actually described accessing that standard when faced with a dilemma. Janice did say that she would pray when talking about how she would resolve a particularly difficult challenge, but even here there was no religious standard that she mentioned.

The participants did not specifically discuss how they coped with the tension of having made a mistake. However, in another context, Judith talked about her belief that only God's way is perfect and man's is flawed. This is a common Christian view and seemed to provide her with a sense that mistakes were inevitable and therefore understandable. At other points she gave the impression that she would resolve to do better the next time she faced a challenge. The comments of all the participants suggest that planning for change was not required because time and experience would give them the ability to make better judgments.

Going back to the question of whether they lived up to their own standards of behavior, the unstated answer seemed to be, sometimes they do and sometimes they do not. All of the participants stated that overall they were able to maintain a sense of moral dignity on the job. As was stated before, since the interview participants had difficulty identifying moral challenges from their personal lives, it was not possible to assess their feelings away from work.

7. What do these preschool special needs teachers identify as the origins of their moral values and moral beliefs?

There was no literature base for this question but it was posed to get a more general sense of how the interview participants viewed moral issues. All of the participants mentioned religion, and the role of their families, but none mentioned education in the development of their values. Janice did not articulate a value per se but stated that her family always encouraged her to pursue her 
education. From her religious training she learned that humans are to serve others, which can be taken as a central value. Beth stated that from her father she gained a model of calm and treating others well, while from her religion she learned to focus on the important issues and not to worry about little things. Ruth stated that her family was the greatest influence on her values but she did not expand on this to explain how, yet she made more statements regarding the religious standards of moral behavior that she tried to meet. Darlene was able to articulate a primary value passed on from her family, describing it as 'being nice.' With further explanation making it clear that this value was very similar to the Golden Rule. She stated that all other values were subsumed by this one. Darlene gave a detailed picture of her understanding of how values develop. She talked about one generation passing on their values to the next, then each individual in that generation interpreting those values differently and changing them as a result of experience, and then, finally those individuals passing their values on to the next generation, who in turn interpret them differently.

One possibly significant similarity was noted between Beth and Ruth. Beth is a relatively new teacher and Ruth has been teaching for nearly 15 years. Of the four teachers interviewed, these two most frequently stated that a scenario did not present a dilemma because they knew what to do and they both tended to answer rather abruptly to those scenarios. Beth who is much younger than Ruth, had described having gone through a major life crisis. Ruth had stated that she had never had a major life crisis. This combined with the fact that all of the teachers interviewed had stated that experience can modify how you define and solve moral dilemmas, led to speculation that extreme hardship, and age or years of experience can independently lead individuals to a greater level of certainty about their values. It may also suggest that extreme hardship and years of experience can lead to less deliberation regarding the resolution of problems. Linder-Crow's finding (1995) that special education administrators showed a decline in moral reasoning, as measured by the DIT, with an increase in years of experience, would support this finding. 


\section{$\underline{\text { Limitations }}$}

This study has several limitations which restrict the application of its findings. One limitation is the limited sample. It was estimated that there are nearly 225 preschool special needs teachers in the state of West Virginia, but only 18 teachers chose to participate in the study. This is a very small sample and provides only limited generalizability, even within West Virginia. The existing literature (Maccallum, 1993) suggests that teachers form a heterogeneous group. However, the participants in this study appear to be more homogeneous. In light of this, the levels of agreement that were found in the Delphi phase of the research (Moral Sensitivity: Kendall's W $=.44$, chi-square $=106.18$ (df $=16, \mathrm{p}<.0001)$; Moral Reasoning: Kendall's $\mathrm{W}=.51$, chi-square $=129.39(\mathrm{df}=14, \mathrm{p}<0001)$; Moral motivation : Kendall's $\mathrm{W}=.22$, chi-square $=52.24(\mathrm{df}=13, \mathrm{p}<.0001)$; Moral Motivation prioritized: Kendall's $\mathrm{W}=.19$, chi-square $=44.70(\mathrm{df}=13, \mathrm{p}<.001))$ suggest that the participants were similar in some way that the researcher was not able to identify. It seems possible that these 18 individuals represent a small subset of teachers who are already quite sensitive to moral issues or have a strong interest in the subject or perhaps these participants all had some strong desire to unburden themselves in a relatively anonymous and safe manner. This possibility is suggested by the fact that three of the four interview participants strongly expressed their feelings of isolation on the job. Finally, West Virginia is a culturally unique portion of the United States, and it may be that the experience of teachers and how they view them may be very different from teachers in other portions of the country. Three of the four participants expressed a strong religious faith that shapes their view of themselves and events around them. The fourth participant, who came from another part of the U.S., expressed her faith but it did not dominate the conversation.

Another limitation comes from the selection of the interview participants. These subjects were selected in an attempt to contrast teachers from rural and urban areas, and new teachers with more experienced teachers. Unfortunately, the two teachers who correctly identified their setting based on the U.S. Census definition actually worked in towns that are adjacent to urban areas, making impossible a genuine comparison based on setting. A third limitation may actually represent an important finding of the study. This finding is that Rest's Four Component Model does not 
accurately reflect the process of deliberation of the participants in this study. In the course of the analysis of the Delphi and the transcripts of the interviews, it became apparent that it was difficult to isolate and discuss the individual components without discussing the other components. It became even more obvious that the component which Rest called Moral Motivation may not only reflect an artificial distinction from the other components of the model, but in fact may serve to misrepresent the content of the Moral Reasoning and Moral Sensitivity components. Rest (1984) and Bebeau, Rest, \& Narvez (1998) have acknowledged that there is some overlap in these components. However, in the case of Moral Motivation, the overlap may be large enough to render the concept meaningless.

While it is true that Rest's research on moral development and his Four Component Model (Rest, 1984, 1994) have greatly influenced the direction of recent research, basing this study on Rest's model may have been a less than ideal choice and only served to underscore the complexity of the subject. The assumption that the process of moral deliberation could be broken down into separate parts may have predetermined the kinds of responses participants could make and probably confused them as well. This suggests that interpretations of the material are more speculative than would be desired. There is no question that the model made analysis more difficult. The results of this study indicate that individuals do not deliberate moral dilemmas in a linear fashion but rather they make all of these considerations more or less simultaneously.

Another limitation arose from the use of the word "dilemma." The interview participants frequently stated that a scenario did not pose a moral dilemma because they knew what the right solution was. When they were questioned about this, they acknowledged that there were moral dimensions to those situations but there was no conflict in their minds. It is probable that the use of this word in the interviews accounts for the participants' inability to identify moral issues from their personal lives other than the major crises which they had experienced. As a result, this study undoubtedly gained only a partial sense of the individuals' sense of moral agency. 
$\underline{\text { Personal statement of limitations occurring from researcher bias }}$

In a study of this nature it is almost unavoidable that unintended researcher bias will affect the result (LeCompte, Millroy \& Preissle, 1992; LeCompte \& Preissle, 1993; Miles \& Huberman, 1994). It is therefore important that I acknowledge those biases of which I am aware. From the beginning of the development of this project, I have had difficulty with Kohlberg's theoretical perspective and what I perceive to be arrogance on his part. This arrogance is partly evident in the tone of his writing but more importantly, there is the arrogance in his statements that he has empirically resolved the philosophical debate between ethicists who hold a universalist perspective and those who hold a relativistic perspective. This debate has been on going for centuries and is unlikely to be subject to empirical proof. As a result of my feelings about Kohlberg, I may have unintentionally been more inclined to see evidence that contradicts his views. Through out the study I made attempts to look for evidence which support his position and which opened the possibility that somehow teachers as a group are morally deficient. I sincerely feel that there is no evidence that teachers are morally deficient nor was there strong supportive evidence of Kohlberg's theory.

There is also the possibility that my own cognitive style may have affected the case studies. I am strongly inclined to think about myself,others, and the events around me in terms of stories, be it novels, movies, or family histories. This led to my interest in the area of narrative psychology. Because I have this tendency, I may have seen more coherence in the text of the interviews than actually was there.

$\underline{\text { Implications for the field of preschool special needs }}$

This study has confirmed that preschool special needs teachers are required to face an unusual number of moral dilemmas which involve negotiation between a dizzying array of interests, concerns and values. This study has also confirmed that many preschool special needs teachers do not feel supported by their administrators, and are hesitant to approach those administrators for guidance when faced with a problem. It is a truism for all teachers that appropriate supports beyond material supports are needed to assist these teachers in their efforts to meet the needs of their 
students and to help them avoid burnout, but it is especially true for preschool special needs teachers. As Darlene pointed out, the issues faced by preschool special needs teachers are 'fuzzy' and do not allow for easy solution.

This study suggests that these teachers, who are no doubt quite moral people providing appropriate protections for their students, do not have the moral language to clearly communicate their thinking about the dilemmas they face. This seems to be true of their ability to clearly define the issues to themselves (this should not be confused with an ability to negotiate those issues). If they were given this language through education, it might help to ease some of the stress they feel surrounding the problems they encounter. It might also make them more effective advocates for change when communicating with administrators.

This study did not provide strong evidence to support the perspective of narrative psychology. There is the possibility that some type of narrative process is carried out by these individuals on a less conscious level. Beth at several points in the interviews expressed some dismay at what she was learning about herself from the conversation and also expressed the feeling that she was in therapy because of these realizations. This suggests that these individuals are not in the habit of self reflection. This is in keeping with the feminist writings of Gilligan (1993) and Noddings (1984) which state that women are not comfortable considering their own needs when deliberating about competing values. This may contribute to the sense of professional isolation described by the participants and the stress resulting from that isolation.

This study also suggests that these preschool special needs teachers are unaware of their role in society beyond the limits of their classroom. This is a rather disturbing finding in light of the large social debates that surround the fields of special education and disability services. Perhaps this is an artifact of the way the interviews were conducted. Here again the word 'dilemma' is implicated and the emphasis on professional issues may have prevented the participants from wanting to talk about other issues.

The implications of these findings are two fold. One, they suggest that the structure of school systems may in some way promote a pragmatic approach to problems and fails to encourage a 
principled basis for moral choice. While this was not stated directly, it was implied when the interview participants stated that they would avoid interaction with their supervisors when faced with a problem. Beth in particular stated that her supervisor always told her to use her head not her heart, meaning that she should resolve dilemmas based on procedures and policies rather than reflection upon the moral implications of the events. School systems, in their efforts to protect themselves from costly lawsuits, may be inadvertently stunting the moral development of their practitioners.

The second implication is that teacher preparation programs and administrative training programs need to focus more on questions of morality and ethics. An independent course in ethics, tailored specifically to special educators should be a mandatory part of Master's level programs. This course should discuss not only the landmark legal issues but should include a wide range of dilemmas faced by teachers in the field. A course of this nature could help to reduce the stress experienced by teachers and also begin to help them develop a basic set of principle on which to base their choices. A course of this nature is essential for administrators. The finding of this study that teachers are unwilling to approach their supervisors for assistance is deeply disturbing. Individual teachers cannot be expected to advocate for change if their administrators are not willing to support them or even aware of the issues faced by their emplyoees.

\section{$\underline{\text { Implications for moral development theory and research }}$}

This study has a number of important implications for research in the field of moral development of teachers. The primary implication is that it is extremely difficult to carry out research examining the processes of moral deliberation without imposing some values and definitions upon the individuals being studied. Perhaps it is inevitable that researchers will impose some degree of their own beliefs on their subject through their words and even through the design of the study. The use of Rest's Four Component Model is a good example of the way the design of a study can obscure the research results.

In a more general sense, this study raises the question of what exactly is being studied. The reliance on the implicit assumption that moral values are only brought into play when there is a 
conflict between values, may actually blind the researcher to other moral questions. The focus on dilemmas may also lead subjects to limit their comments to the most salient events in their lives rather than the pervasive daily issues. For example, why do people not always speak their minds when interacting with others? This example points to more general questions. Is it only important to know how people react in major situations or is a more inclusive picture of their views on ethics and morality needed? Do people strive for continuity in their values or do they simply apply them contextually as they have learned to apply them? How would an individual whose morality is religiously based respond to a course in ethics? These are questions which research has only begun to grapple with.

\section{$\underline{\text { Recommendations for further research }}$}

The most immediate research action that is necessary following this study is the need for further interviews with the same participants. First, there are a number of follow up questions that needed to be asked in the first and second interviews but were not asked from a desire not to guide the conversation, to provide consistency between the interviews, and in many cases, as simple oversights. The knowledge gained from this study would be used to probe more deeply into the participants' reasoning. Second, the research focus needs to be explained in greater detail to the interview participants. Participants in this study tended to focus on professional dilemmas, so it would be important to help them understand that their 'everyday' moral issues are of value as well. This would help gain an understanding of whether professional morality is distinguished from personal morality.

In light of the hesitation to approach administrators for advice expressed by the interview participants, another important area of research is to examine the differences between the moral perceptions of administrators and teachers. Such research could be conducted with the goal of understanding how various classes of individuals view moral issues. However, it might be better carried out as action research with the goal of creating better communication and trust between teachers and administrators. 
Courses in professional ethics would also greatly benefit from the collection of more scenarios than just the 18 scenarios collected in this study. The books that are available at this time concentrate on ethical theories and those dilemmas that ultimately made their way into the court system. These dilemmas, while important to the development of the field ofspecial education, are generally not the type of problem faced by preschool special needs teachers in daily practice.

The lack of moral language evident in this study suggests that research into the use of moral terms is much needed. Study participants defined terms rather idiosyncratically when asked to define moral terms such as responsibility, obligation, and duty. This research could be carried out as action research with the goal of providing teachers with more consciously applied strategies for solving moral questions. There is already a large body of research showing that educational interventions can alter the thinking of individuals. It would be of value to examine whether they actually affect the behavior of teachers in solving real life problems.

This research also suggests that there is a very weak relationship between assessed levels of moral reasoning and what might be termed moral competence or moral behavior. It would be of great interest to measure the level of success in resolving moral dilemmas or negotiating moral issues in a group of individuals who appear to have few formal structures or methods for thinking about those dilemmas or issues. This research would be difficult to carry out because first, some measure of success would need to be devised. As has been pointed out, however, any time external standards are applied to moral issues, there is great risk of imposing arbitrary standards and misunderstanding the experience of the individuals being studied. Perhaps a variety of measures, including self-reports could be devised to help avoid this bias in order to study teachers' success in solving moral dilemmas.

This study did not provide strong evidence to support the perspective of narrative psychology. This suggests that these individuals are not in the habit of self reflection. This is in keeping with the feminist writings of Gilligan (1993) and Noddings (1984) which state that women are not comfortable considering their own needs when deliberating about competeing values. A selfawareness intervention could be devised in cooperation with experts in counseling issues and 
Perceptions of Moral Agency

delivered to individuals to look for change in their perceptions of dilemmas, improved decision making abilities, and reduced stress. 


\section{References}

Angeles, P. A. (1981). Dictionary of philosophy. New York: Harper and Row.

Armon, C. (1998). Adult moral development, experience and education. Journal of Moral Education, 27(3), 345-371.

Armon, C. \& Dawson, T.L. (1997). Developmental trajectories in moral reasoning across the life span. Journal of Moral Education, 26(4), 433-454.

Aronfreed, J. (1969). The concept of internalization. In D.A. Goslin (Ed.), Handbook of socialization theory and research. Chicago: Rand McNally.

Aronfreed, J. (1976). Moral development from the standpoint of a general psychological theory. In T. Lickona (Ed.), Moral development and behavior: Theory, research, and social issues. New York: Holt, Rinehart and Winston.

Aurin, K. \& Maurer, M. (1993). Forms and dimensions of teachers' professional ethics - case studies in secondary schools. Journal of Moral Education, 22(3), 277-297.

Bandura, A. (1969). Social-learning theory of identificatory processes. In D.A. Goslin (Ed.), Handbook of socialization theory and research. Chicago: Rand McNally.

Bebeau, M.J. \& Brabeck, M. (1987). Integrating care and justice issues in professional moral education: A gender perspective. Journal of Moral Education, 16(3), 189-203.

Bebeau, M.J. \& Brabeck, M. (1989). Ethical sensitivity and moral reasoning among men and women in the professions. In M.M. Brabeck (Ed.), Who cares? Theory, research, and educational implications of the ethic of care. New York: Praeger.

Bebeau, M.J., Rest, J.R. \& Narvaez, D. (1999). Beyond the promise: A perspective on Research in Moral Education. Educational Researcher, 28(4), 18-26.

Belenky, M.F., Clinchy, B.M., Goldberger, N.R., \& Tarule, J.M. (1986). Women's ways of knowing: The development of self, voice, and mind. New York: Basic Books.

Bennet, T., Smith, P., et al. (1992). A comparison of professional codes of ethics in early intervention. Infant-Toddler Intervention, 2(3), 239-247. 
Benninga, J.S. \& Wynne, E.A. (1998). Keeping in Character: A time-tested solution. Phi Delta $\underline{\text { Kappan, 79}}(6), 439-445$.

Bergem, T. (1986). Teachers' thinking and behavior. An empirical study of the role of social sensitivity and moral reasoning in the teaching performance of student teachers. Scandinavian Journal of Educational Research, 30(4), 193-203.

Bergem, T. (1993). Examining aspects of professional morality. Journal of Moral Education, $\underline{22}(3), 297-313$.

Blasi, A. (1980). Bridging moral cognition and moral action: A critical review of the literature. Psychological Bulletin, 88(1), 1-45.

Blasi, A. (1984). Moral identity: Its role in moral functioning. In W.M. Kurtines \& J.L. Gewirtz (Eds.), Morality, moral behavior, and moral development. New York: John Wiley \& Sons.

Bowe, F.G. (1995). Ethics in early childhood special education. Infants and Young Children. 7(3), 28-37.

Bredekamp, S. \& Copple, C. (1997). Developmentally appropriate practice in early childhood programs. Washington, D.C.: NAEYC.

Brown, L.M., Tappan, M.B., Gilligan, C., Miller, B.A. \& Argyris, D.E. (1989). Reading for self and moral voice: A method for interpreting narratives of real-life moral conflict and choice. In M.J. Packer \& R.B. Addison (Eds), Entering the circle: Hermeneutic investigation in psychology (pp. 119-138). Albany, NY: State University of New York Press.

Canning, R.R. (1956). Does an honor system reduce classroom cheating? An experimental answer. The Journal of Experimental Education, 24(4), 291-296.

Chang, F. (1994). School teacher's moral reasoning. In J.R. Rest \& D. Narvaez (Eds.), Moral Development in the Professions: Psychology and Applied Ethics. Hillside, NJ: Lawrence Erlbaum Associates.

Clark, C.M. (1990). The teacher and the taught: Moral transactions in the classroom. In J.L. Goodlad, R.Soder, \& K.A. Sirotnik (Eds.), The moral dimensions of teaching (pp. 130-151). San Francisco: Jossey-Bass. 
Clayton, M.J. (1997). Delphi: A technique to harness expert opinion for critical decision-making tasks in education. Educational Psychology, 17(4), 373-387.

Council for Exceptional Children (1995). What every special educator must know: The international standards for the preparation and certification of special education teachers. Reston, VA: Council for Exceptional Children.

Damon, W. (1988). The Moral Child: Nurturing children's natural moral growth. New York: Free Press.

Damon, W. (1983). Social and personality development. New York: W.W. Norton \& Company.

Darley, J. \& Batson, C. (1973). From Jerusalem to Jericho: A study of situational and dispositional variables in helping behavior. Journal of Personality and Social Psychology, 27, 100108.

Day, J.M. (1991). Role-taking revisited: Narrative and cognitive-developmental interpretations of moral growth. Journal of Moral Education, 20(3), 305-316.

Delbecq, A.L., Van de Ven, A.H., \& Gustafson, D.H. (1975). Group techniques for program planning: A guide to nominal group and delphi processes. Glenview, Il: Scott, Foresman and Company.

Dienstbier, R.A. \& Munter, P.O. (1971). Cheating as a function of the labeling of natural arousal. Journal of Personality and Social Psychology, 17, 208-213.

Dillman, D.A. (1978). Mail and telephone surveys: The total design method. New York: Joh Wiley \& Sons.

Emerson, R.M., Fretz, R.I., \& Shaw, L.L. (1995). Writing ethnographic fieldnotes. Chicago: University of Chicago Press.

Erikson, E.H. (1963). Childhood and society (2nd ed.). New York: W.W. Norton.

Etzioni, A. (1998). How not to discuss character education. Phi Delta Kappan, 79(6), 446-448. 
Fenstermacher, G.D. (1990). Some moral considerations on teaching as a profession. In J.I. Goodlad, R. Soder, \& K.A. Sirotnik (Eds.), The moral dimensions of teaching (pp. 130-151). San Francisco: Jossey-Bass.

Feinberg, W. (1990). The moral responsibility of public schools. In J.I. Goodlad, R. Soder, \& K.A. Sirotnik (Eds.), The moral dimensions of teaching (pp. 130-151). San Francisco: JosseyBass.

Ferretti, R.P. (1993). Interactive multimedia research questions: results from the Delphi study. Journal of Special Education Technology, 12(2), 107-117.

Gallagher, J.J. (1992). The role of values and facts in policy development for infants and toddlers with disabilities and their families. Journal of Early Intervention, 16(1), 1-10.

Gerety, M.A. (1980). A study of the relationship between the moral judgment of the teacher and the moral atmosphere in the classroom. Dissertation Abstracts International, 41, 1952A.

Gilligan, J. (1976). Beyond morality: Psychoanalytic reflections on shame, guilt, and love. In T. Lickona (Ed.), Moral development and behavior: Theory, research, and social issues. New York: Holt, Rinehart and Winston.

Gilligan, C. (1981). Moral Development. In A.W. Chickering (Ed.), The modern American college. San Francisco: Jossey-Bass.

Gilligan, C. (1993). In a different voice: Psychological theory and women's development. Cambridge, MA: Harvard University Press.

Gilligan, C. \& Belenky, M.F. (1980). A naturalistic study of abortion decisions. In Selman, R.L., \& Yando, R. (Eds.), Clinical-developmental psychology. San Francisco: Jossey-Bass.

Gilligan, C. \& Murphy, J.M. (1979). Development from adolescence to adulthood: the philosopher and the dilemma of the fact. In D. Kuhn (Ed.), Intellectual development beyond childhood (pp. 85-99), San Francisco: Jossey-Bass.

Ginsburg, H.P. \& Opper, S. (1988). Piaget's theory of intellectual development (3rd ed.). Englewood Cliffs, NJ: Prentice Hall. 
Glanzer, P.L. (1998). The character to seek justice: Showing fairness to diverse visions of character education. Phi Delta Kappan, 79(6), 434-438.

Goodlad, J.I. (1990). The occupation of teaching in schools. In J.I. Goodlad, R. Soder, \& K.A. Sirotnik (Eds.), The moral dimensions of teaching (pp. 130-151). San Francisco: Jossey-Bass.

Haan, N., Smith, B., \& Block, J. (1971). Moral reasoning of young adults. Journal of Personality and Social Psychology, 10, 183-201.

Harrington, H. (1994). Teaching and knowing. Journal of Teacher Education, 45(3), 190-197.

Hartshorne, H. \& May M.A. (1928). Studies in deceit. New York: The MacMillan Company.

Hetherington, E.M. \& Feldman, S.E. (1964). College cheating as a function of subject and situational variables. Journal of Educational Psychology, 55(4), 212-218.

Hoffman, M.L. (1976). Empathy, role taking, guilt, and development of altruistic motives. In T. Lickona (Ed.), Moral development and behavior: Theory, research, and social issues. New York: Holt, Rinehart and Winston.

Holt, L., Kauchak, D., \& Peterson, K. (1980). Moral development, educational attitudes and selfconcept in beginning teacher education students. Educational Research Quarterly, 5(3), 50-56.

Howe, K.R., \& Miramontes, O.B. (1991). A framework for ethical deliberation in special education. Journal of Special Education, 25(1), 7-25.

Howells, T.H. (1938). Factors influencing honesty. The Journal of Social Psychology, 9, $97-$ 102.

Jackson, P.W., Boostrom, R.E., \& Hansen, D.T. (1993). The moral life of schools. San Francisco: Jossey-Bass.

Johnson, C.D. \& Gormly, J. (1972). Academic cheating: The contribution of sex, personality, and situational variables. Developmental Psychology, 6, 602-605.

Johnston, M. (1985). How elementary teachers understand the concept of "on-task": A developmental critique. Journal of Classroom Interaction, 21, 15-24.

Johnston, M. (1989). Moral reasoning and teachers' understanding of individualized instruction. Journal of Moral Education, 18(1), 45-59. 
Johnston, M. \& Lubomudrov, C. (1987). Teachers' level of moral reasoning and their understanding of classroom rules and roles. Elementary School Journal, 88, 65-78.

Joseph, P.B. \& Efron, S. (1993). Moral choices/moral conflicts: Teachers' self-perception. Journal of Moral Education, 22(3), 201-221.

Kagan, J. (1984). The nature of the child. New York: Basic Books.

Katz, L.G. \& Ward E.H. (1991). Ethical behavior in early childhood education. Washington, D.C.: NAEYC.

Keller, M. \& Edelstein, W. (1991). The development of socio-moral meaning making: Domains, categories, and perspective-taking. In W.M. Kurtines \& J.L. Gewirtz (Eds.), Handbook of moral behavior and development. Volume 2: Research. Hillsdale, N.J.: Lawrence Erlbaum Associates.

Klein, D.M. \& White, J.M. (1996). Family theories: An introduction. Thousand Oaks, CA: Sage.

Kohlberg, L. (1969). Stage and sequence: The cognitive-developmental approach to socialization. In D.A. Goslin (Ed.), Handbook of socialization theory and research. Chicago: Rand McNally.

Kohlberg, L. (1971). From is to ought: How to commit the naturalistic fallacy and get away with it in the study of moral development. In T. Mischel (Ed.), Cognitive development and epistemology. New York: Academic Press.

Kohlberg, L. (1984). The psychology of moral development. San Francisco: Harper and Row.

Kohlberg, L. \& Kramer, R. (1969). Continuities and discontinuities in childhood and adult moral development. Human Development, 12, 93-120.

Kohn, A. (1997). How not to teach values: A critical look at character education. Phi Delta

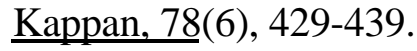

Kohn, A. (1998). Adventures in ethics versus behavior control: A reply to my critics. Phi Delta Kappan, 79(6), 455-460.

Krebs, D.L. \& Denton, K. (1997). The forms and functions of real-life moral decision-making. Journal of Moral Education, 26 (2), 131-146. 
Krebs, D.L., Denton, K., Vermeulen, S.C., Carpendale, J.I. \& Bush, A. (1991). The structural flexibility of moral judgment. Journal of Personality and Social Psychology, 61, 1012-1023.

Krebs, D.L., Vermeulen, S.C., Carpendale, J.I. \& Denton, K. (1991). Structural and situational influences on moral judgment: The interaction between stage and dilemma. In W. Kurtines \& J. Gewirtz (Eds), Handbook of moral behavior and development: Vol. 2 Research (pp. 139-169). Hillsdale, NJ: Erlbaum.

Krebs, D.L., Vermeulen, S.C. \& Denton, K. (1991). Competence and performance in moral judgment: From the ideal to the real. Moral Education Forum, 16, 7-22.

Krebs, D.L. \& Wark, G. (1995). Lessons from life: toward a functional model of morality. Moral Education Forum, 20, 22-29.

Kurtines, W.M. \& Gewirtz, J.L. (1984). Certainty and morality: Objectivistic versus relativistic approaches. In W.M. Kurtines \& J.L. Gewirtz (Eds.), Morality, moral behavior, and moral development. New York: John Wiley \& Sons.

Kurtines, W. \& Grief, E.B. (1974). The development of moral thought: Review and evaluation of Kohlberg's approach. Psychological Bulletin, 81, 453-470.

Le Compte, M.D., Millroy, W.L. \& Preissle, J. (1992). The handbook of qualitative research in education. San Diego: Academic Press.

Le Compte, M.D. \& Preissle, J. (1993). Ethnography and qualitative design in educational research (2nd ed.). San Diego: Academic Press.

Lessen, E. \& Frankiewicz, L.E. (1992). Personal attributes and characteristics of effective special education teachers: Considerations for teacher educators. Teacher Education and Special Education. $\underline{15}(2), 124-132$.

Lickona, T. (1998). A more complex analysis is needed. Phi Delta Kappan, 79(6), 449-454.

Linder-Crow, J.E. (1995). Moral reasoning and ethics among special education administrators: Dilemmas and strategies. Unpublished doctoral dissertation, Gallaudet University. 
Linger, B.T, (1998). What primary care physicians need to know about attention-deficit hyperactivity disorder: a Delphi of experts and a content analysis. Unpublished doctoral dissertation, West Virginia University at Morgantown.

MacCallum, J.A. (1993). Teacher reasoning and moral judgment in the context of student discipline situations. Journal of Moral Education, 22(1), 3-18.

MacIntyre, A. (1966). A short history of ethics. New York: MacMillan.

McNergney, R. \& Satterstrom, L. (1984). Teacher characteristics and teacher performance. Contemporary Educational Psychology, 9, 19-24.

Miles, M.B., \& Huberman, A.M. (1994). Qualitative data analysis: An expanded sourcebook. Thousand Oaks, CA: Sage.

Milgram, S. (1963). Behavioral study of obedience. Journal of Abnormal and Social Psychology, 67, 371-378.

Mischel, W. \& Mischel, H.N. (1976). A cognitive social-learning approach to morality and selfregulation. In T. Lickona (Ed.), Moral development and behavior: Theory, research, and social issues. New York: Holt, Rinehart and Winston.

Murdoch, I. (1956). II. By Iris Murdoch. In R.W. Hepburn \& I. Murdoch, Symposium: Vision and choice in morality. Aristotelian Society, 30, 14-58.

Murray, J.W. \& Hammons, J.O. (1995). Delphi: A versatile methodology for conducting qualitative research. The Review of Higher Education, 18(4), 423-436.

Nash, R.J. (1991). Three conceptions of ethics for teacher educators. Journal of Teacher Education, 42(3), 163-173.

Nash, R.J. (1996). "Real world" ethics: Frameworks for educators and human service professionals. New York: Teachers College Press.

Noblit, G.W., Dempsey, V.O., et. al (1996). The social construction of virtue: The moral life of schools. Albany, NY: State University of New York Press.

Noddings, N. (1984). Caring, a feminine approach to ethics and moral education. Berkeley, CA: University of California Press. 
Noddings, N. (1986). Fidelity in teaching, teacher education, and research for teaching. Harvard Educational Review, 56, 496-510.

Noddings, N. (1992). Shaping an acceptable child. In A. Garrod (Ed.), Learning for life: Moral education theory and practice. Westport, Connecticut: Praeger.

Noddings, N. (1994). Conversation as moral education. Journal of Moral Education, 23(2), 107119.

Noblit, G.W., Dempsey, V.O., et al. (1996). The social construction of virtue: The moral life of schools. Albany, NY: State University of New York Press.

Novogrodsky, J. (1977). Teachers' moral development and their expressed attitudes toward students. Dissertation Abstracts International, 38, 2006A.

Nucci, L. (1981). Conceptions of personal issues: A domain distinct from moral or societal concepts. Child Development, 52, 114-121.

Nucci, L. P. \& Nucci, M.S. (1982). Children's social interactions in the context of moral and conventional transgressions. Child Development, 53, 403-412.

Nucci, L.P. \& Turiel, E. (1978). Social interaction and the development of social concepts in preschool children. Child Development, 49, 400-407.

Nunner-Winkler, G. (1984). Two moralities? A critical discussion of an ethic of care and responsibility versus and ethic of rights and justice. In W.M. Kurtines \& J.L. Gewirtz (Eds.), Morality, moral behavior, and moral development. New York: John Wiley \& Sons.

Oser, F. (1991). Professional morality: A discourse Approach: The case of the teaching profession. In W.M. Kurtines \& J.L. Gewirtz (Eds.), Handbook of moral behavior and development. Volume 2: Research. Hillsdale, N.J.: Lawrence Erlbaum Associates.

Oser, F. \& Althof, W. (1993). Trust in advance: On the professional morality of teachers. Journal of Moral Education, 22(3), 253-276.

Packer, M.J. (1985). The structure of moral action: A hermeneutic study of moral conflict. New York: Karger.

Peshkin, A. (1988). In search of subjectivity - one's own. Educational Researcher, 17(7), 17-21. 
Piaget, J. (1948). The moral judgment of the child. Glencoe, IL: The Free Press.

Podd, M.H. (1972). Ego identity status and morality: The relationship between two developmental constructs. Developmental Psychology, 6, 497-507.

Pollard, A. (1985). The social world of the primary school. London: Holt, Rinehart, \& Winston.

Pugach, M.C. (1992). Uncharted territory: Research on the socialization of special education teachers. Teacher Education and Special education, 15(2), 133-147.

Rawls, J. (1971). A theory of justice. Cambridge, MA: Harvard University Press.

Rest, J.R. (1979). Development in judging moral issues. Minneapolis: University of Minnesota Press.

Rest, J.R. (1984). The major components of morality. In W.M. Kurtines \& J.L. Gewirtz (Eds.), Morality, moral behavior, and moral development. New York: John Wiley \& Sons.

Rest, J.R. (1994). Background: Theory and research. In J.R. Rest \& D. Narvaez (Eds.), Moral development in the professions: Psychology and applied ethics. Hillside, NJ: Lawrence Erlbaum Associates.

Rest, J.R. \& Narvaez, D. (1994a). Preface. In J.R. Rest \& D. Narvaez (Eds.), Moral development in the professions: Psychology and applied ethics. Hillside, NJ: Lawrence Erlbaum Associates.

Rest, J.R. \& Narvaez, D. (1994b). Summary: What's possible? In J.R. Rest \& D. Narvaez (Eds.), Moral development in the professions: Psychology and applied ethics. Hillside, NJ: Lawrence Erlbaum Associates.

Rich, J.M. \& DeVitis, J.L. (1985). Theories of moral development. Springfield, IL: Charles C. Thomas.

Rothbart, M.K. (1986). Gender differences in moral reasoning. Sex Roles, 15(11), 645-653.

Rulon, D. (1992). The just community: A method for staff development. Journal of Moral Education, 21(3), 217-225.

Salkind, N. (1985). Theories of human development (2nd ed.). New York: John Wiley \& Sons. 
Schempp, P.G., Sparkes, A.C., \& Templin, T.J. (1993). The micropolitics of teacher induction. American Educational Research Journal, 30, 447-472.

Schwartz, S. (1970). Elicitation of moral obligation and self-sacrificing behavior. An experimental study of volunteering to be a bone marrow donor. Journal of Personality and Social Psychology, 15, 283-293.

Seigfried, C.H. (1989). Pragmatism, feminism, and sensitivity to context. In M.M. Brabeck (Ed.), Who cares? Theory, research, and educational implications of the ethics of care. N.Y. : Praeger.

Selman, R.L. (1980). The growth of interpersonal understanding: Developmental and clinical analyses. New York: Academic Press.

Shweder, R.A. (1979a). Rethinking culture and personality theory. Part I: A critical examination of two classical postulates. Ethos, 7, 255-278.

Shweder, R.A. (1979b). Rethinking culture and personality theory. Part II: A critical examination of two more classical postulates. Ethos, 7, 279-311.

Shweder, R.A. (1980). Rethinking culture and personality theory. Part III: From genesis and typology to hermeneutics and dynamics. Ethos, 8, 60-94.

Shweder, R.A. (1982a). Beyond self-constructed knowledge: The study of culture and morality. Merril Palmer Quarterly, January 1982,

Shweder, R.A. (1982b). Liberalism as destiny. (Review of Kohlberg's The philosophy of moral development, Vol. 1.). Contemporary Psychology, 27, 421-424.

Skrtic, T.M. (1995a). Theory /practice and objectivism: The modern view of the professions. In Thomas Skrtic (Ed.), Disability and democracy: Reconstructing (special) education for postmodernity. New York: Teachers College Press.

Skrtic, T.M. (1995b). Power/knowledge and pragmatism: A postmodern view of the professions. In Thomas Skrtic (Ed.), Disability and democracy: Reconstructing (special) education for postmodernity. New York: Teachers College Press. 
Smetana, J.G. (1981a). Preschool children's conceptions of moral and social rules. $\underline{\text { Child }}$ Development, 52, 1333-1336.

Smetana, J.G. (1981b). Reasoning in the personal and moral domains: Adolescent and young adult women's decision-making regarding abortion. Journal of Applied Developmental Psychology, 2. 211-226.

Smetana, J.G. (1982). Concepts of self and morality: Women's reasoning about abortion. New York: Praeger.

Smetana, J.G. (1993). Understanding of social rules. In Bennett, M. (Ed.), The development of social cognition: The child as psychologist. New York: The Guilford Press.

Snarey, J., \& Pavkov, T. (1992). Moral Character education in the United States: Beyond socializtion versus development. In A. Garrod (Ed.), Learning for life: Moral education theory and practice (pp. 25-46). Westport, CT: Praeger.

Sockett, H. (1989). A moral epistemology of practice? Cambridge Journal of Education, 19(1), 33-39.

Sockett, H. (1991). Virtue and wisdom: Teaching as a moral career, paper presented at the annual meeting of the American Educational Research Association, Chicago, Illinois.

Sokoly, M.M. \& Dokecki, P.R. (1992). Ethical perspectives on family-centered early intervention. Infants and Young Children, 4(4), 23-32.

Spradley, J.P. (1979). The ethnographic interview. Fort Worth, TX: Harcourt Brace Jovanovitch College Publishers.

Stahl, N.N. \& Stahl, R.L. (1991). We can agree after all! Achieving consensus for a critical thinking component of a gifted program using the Delphi technique. Roeper Review, 14(2), 79-89.

Stein, C. (1995). Moral reasoning ability in special educators. Unpublished doctoral dissertation, West Virginia University, Morgantown.

Strike, K.A. (1990). The legal and moral responsibility of teachers. In J.I. Goodlad, R. Soder, \& K.A. Sirotnik (Eds.), The moral dimensions of teaching (pp. 130-151). San Francisco: JosseyBass. 
Strike, K.A. \& Soltis, J.F. (1985). The ethics of teaching. New York: Teachers College Press.

Stritter, F.T., Tresolini, C.P., \& Reeb, K.G. (1994). The Delphi technique in curriculum development. Teaching and Learning in Medicine, 6(2), 136-141.

Tappan, M.B. \& Brown, L.M. (1989). Stories told and lessons learned: Toward a narrative approach to moral development and moral education. Harvard Educational Review, 59(2), 182-205.

Tesch, R. (1990). Qualitative research: Analysis types and software tools. New York: Falmer.

Thoma, S.J. (1987). Moral sensitivity and judgment in the development and performance of student teachers. Moral Education Forum, 12, 15-20.

Thoma, S. (1994). Moral judgments and moral action. In J.R. Rest \& D. Narvaez (Eds.), Moral development in the professions: Psychology and applied ethics. Hillside, NJ: Lawrence Erlbaum Associates.

Tippins, Tobin, \& Hook (1993). Ethical decisions at the heart of teaching: Making sense from a constructivist perspective. Journal of Moral Education, 22, 221-240.

Turiel, E. (1976). A comparative analysis of moral knowledge and moral judgment in males and females. Journal of Personality, 44, 195-209.

Turiel, E. (1983). The development of social knowledge. Cambridge: Cambridge University Press.

Turiel, E., Hildebrandt, C., \& Wainryb, C. (1991). Judging social issues: Difficulties, inconsistencies, and consistencies. Monographs of the Society for Research in Child Development, $\underline{56}$ (2, Serial No. 224).

Turiel, S. \& Smetana, J.G. (1984). Social knowledge and action: the coordination of domains. In W.M. Kurtines \& J.L. Gewirtz (Eds.), Morality, moral behavior, and moral development. New York: John Wiley \& Sons.

U.S. Census Bureau (2000). Urban and rural definitions [Internet Web-site]. Available: www.census.gov/population/censusdata/urdef.txt.

Walker, L. (1984). Sex differences in the development of moral reasoning: A critical review. Child Development, 55, 677-699. 
Wark, G. \& Krebs, D.L. (1996). Gender and dilemma differences in real-life moral judgment. Developmental Psychology, 32, 220-230.

Westbrook, T. (1994). Tracking the moral development of journalists: A look at them and their work. In J.R. Rest \& D. Narvaez (Eds.), Moral development in the professions: Psychology and applied ethics. Hillside, NJ: Lawrence Erlbaum Associates.

White, F.A. (1996). Sources of influence in moral thought: The new Moral Authority Scale. Journal of Moral Education, 25(4), 421-441.

Yonovitz, L.B. \& Shipps, T.B. (1992). Ethical decision making: A case for moral plurality. Infant-Toddler Intervention, 2(2), 127-139.

Yost, D.S. (1997). The moral dimensions of teaching and preservice teachers: Can moral dispositions be influenced? Journal of Teacher Education, 48(4), 281-293. 
Perceptions of Moral Agency

Appendix A 
Classification of Moral Judgment into Levels and Stages of Development

LevelsBasis of Moral Judgment Stages of Development

I Moral value resides in external, quasiphysical happenings, in bad acts, or in quasiphysical needs rather than in persons and standards.

II Moral value resides in performing good or right roles, in maintaining the conventional order and the expectancies of others.

III Moral value resides in conformity by the self to shared or sharable standards, rights, or duties.
Stage 1: Obedience and punishment orientation. Egocentric deference to superior power or prestige, or a trouble-avoiding set. Objective responsibility.

Stage 2: Naively egoistic orientation. Right action is that instrumentally satisfying the self's needs and occasionally others'. Awareness of relativism of value to each actor's needs and perspective. Naive egalitarianism and orientation to exchange and reciprocity.

Stage 3: Good-boy orientation. Orientation to approval and to pleasing and helping others. Conformity to stereotypical images of majority or natural role behavior, and judgment by intentions.

Stage 4: Authority and social-order maintaining orientation. Orientation to "doing duty" and to showing respect for authority and maintaining the given social order for its own sake. Regard for earned expectations of others.

Stage 5: Contractual legalistic orientation. Recognition of an arbitrary element or starting point in the rules or expectations for the sake of agreement. Duty defined in terms of contract, general avoidance of violation of the will or rights of others, and majority will and welfare.

Stage 6: Conscience or principle orientation. Orientation not only to actually ordained social rules but to principles of choice involving appeal to logical universality and consistency. Orientation to conscience as a directing agent and to mutual respect and trust.

Rest, J.R. (1979). Development in judging moral issues. Minneapolis: University of Minnesota Press. 
Perceptions of Moral Agency

Appendix B 


\section{Demographic Questionnaire}

Name

Mailing Address

Phone \#

e-mail

Age:

Marital status:

Single ___ Married ___ Divorced ___ Separated

Do you have children of your own? Yes No

In what kind of population area do you work? Urban Rural

Urban $=$ incorporated areas with more than 2,500 inhabitants Rural $=$ incorporated areas with fewer than 2,500 inhabitants, and other unincorporated areas (Source: U.S. Census Bureau)

Highest Educational Level: Major:

B.A./B.S.

M.A./M.S.

Ed. S.

Ph.D./Ed.D

Post-Doctoral 
Years experience in education:

1-5 _ 6-10_ $\quad 11-15 \_\quad 16-20 \_21$ or more

Years in current position:
$1-5$
6-10
$11-15$
$16-20$
21 or more

What certifications/endorsements do you hold?

Would you like to receive the results of this study? Yes

No 


\section{West VirginiaUniversity}

College of Human Resources and Education

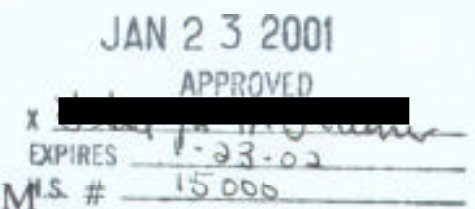

DELPHI CONSENT AND INFORMATION FORM ${ }^{1.5}$ \# 15000 Perceptions of Moral Agency Among Preschool Special Needs Teachers

Introduction. I, have been invited to participate in this research study which has been explained to me by Stephen K. Pavlovic. This research is being conducted to fulfill the requirements for a doctoral dissertation in Special Education in the Department of Educational Theory and Practice at West Virginia University.

Purposes of the Study. The purpose of this study is to gain more understanding of the experience of preschool special needs teachers regarding moral dilemmas that may occur on the job, and how teachers view and resolve these dilemmas.

Description of Procedures. The study will be carried out using a method known as a Delphi Procedure. It was explained to me that this procedure consists of three questionnaires. The first questionnaire (see enclosure) asks participants to describe a real life experience of a moral dilemma which occurred on the job, and to answer a few questions regarding that dilemma. The second questionnaire will consist of lists of scenarios gathered from the responses to Questionnaire 1, and several lists of factors relating to the resolution of moral dilemmas, also gathered from Questionnaire 1. For each scenario, participants will be asked to indicate whether the scenario would pose a moral dilemma for them. Participants will also be asked to rank the factors according to the participant's perception of their importance in resolving moral dilemmas. The third questionnaire will contain the results of the analysis of responses to Questionnaire 2 and provide an opportunity for participants to respond to these results. Questionnaire 1 will take approximately 30 minutes to complete. Questionnaires 2 and 3 are expected to take approximately 15 minutes each. In addition, each participant will be requested to complete a demographic questionnaire which will take only 5 minutes to complete. Some individuals may also be contacted for later interviews. I had the opportunity to review Questionnaire 1 and the Demographic Questionnaire before I signed this consent to participate. I understand that I do not have to answer all the questions. I understand that $I$ am not required to participate in Questionnaires 2 and 3. I understand that approximately 15-30 individuals will be included in this study.

Risks and Discomforts. There are no known or expected risks from participating in this study, except for the difficulties associated with recalling events and constructing a narrative.

Alternatives. I understand that I do not have to participate in this study and that my participation is entirely voluntary.

Benefits. I understand that this study is not expected to be of direct benefit to me, but the knowledge gained may be of benefit to others.

initials date 
$\underline{\text { Perceptions of Moral Agency Among Preschool Special Needs Teachers }}$

Financial Considerations. I understand that completion of the Delphi Procedure will qualify me for a drawing for $\$ 100.00$. I must return all of the questionnaires to be eligible for the drawing.

Contact persons. For more information about this research, I can contact Stephen K. Pavlovic at 304-292-5287, or his supervisor, Dr. Barbara Ludlow at 304-293-3450. For information regarding my rights as a research subject, I may contact the Executive Secretary of the Institutional Review Board at 304-293-7073.

Confidentiality. I understand that any information about me obtained as a result of my participation in this research will be kept as confidential as legally possible. I understand that my research records, just like hospital records, may be subpoenaed by court order or may be inspected by federal regulatory authorities. In any publications that result from this research, neither my name nor any information from which I might be identified will be published without my consent.

Voluntary Participation. Participation in this study is voluntary. I understand that I am free to withdraw my consent to participate in this study at any time. Refusal to participate or withdrawal will involve no penalty or loss of benefits other than my loss of qualification for the monetary drawing. I have been given the opportunity to ask questions about the research, and I have received answers concerning areas I did not understand. I understand that I do not have to answer any questions which make me uncomfortable.

Upon signing of this form, I will receive a copy.

I willingly consent to participate in this research.

\begin{tabular}{c}
\hline Signature of Subject \\
\hline Signature of Investigator
\end{tabular}

Signature of Investigator
Date

Date

January 22, 2001

Page 2 of 2 
January 22, 2001

Dear Preschool Special Needs Teacher,

I am writing to you to ask for your help. I am a doctoral student at West Virginia University in the Special Education Program of the Department of Educational Theory and Practice. To complete my program of study, I am carrying out a research project to examine the perceptions of preschool special needs teachers in West Virginia.

Special education teachers are frequently called upon to mediate between conflicting interests, values, and priorities. The purpose of this study is to gain a better understanding of the experience of preschool special needs teachers regarding moral dilemmas that may occur on the job, and how teachers view and resolve these dilemmas.

The study will be carried out using a method known as a Delphi Procedure. This procedure consists of three questionnaires. Details regarding this procedure can be found in the Consent Form which accompanies this letter. Questionnaire 1 will take approximately 30 minutes to complete, Questionnaires 2 and 3 are expected to take approximately 15 minutes each. In addition I am requesting that you complete a demographic questionnaire which will take only 5 minutes to complete. Some individuals may also be contacted for later interviews.

Your participation in this study is vital to its success. Your responses will contribute to our understanding of the experiences of preschool special needs teachers. Rest assured that your responses will remain confidential and names will not be used in the final report of the results of this study. I will be the only person who reviews your questionnaires.

If you choose to participate in this study, please return to me the following materials which accompany this letter:

\section{Consent Form \\ 2. Demographic Information Form \\ 3. Questionnaire 1}

A self addressed stamped envelope has been enclosed for this purpose. Keep in mind that your participation in this study is entirely voluntary and you do not have to answer any questions which make you uncomfortable.

All participants who return all three questionnaires will be eligible for a drawing for a prize of $\$ 100.00$. This drawing will be held immediately after all three questionnaires have been returned from all those who have agreed to participate.

Thank you very much for your time and your assistance with this study. If you have any questions regarding this research, please contact Mr. Pavlovic at 304-292-5287 or Dr. Ludlow at 304-293-3450.

Sincerely,

Stephen K. Pavlovic

Dr. Barbara Ludlow

Researcher 
Name

\section{Questionnaire 1}

Everyone has had the experience of being in a situation where they had to make a decision, but weren't sure what they should do. Please describe one event which occurred on the job, when you faced a moral conflict and you had to make a decision. Please read all of the questions before you begin your answers.

Q1.1 Please describe the events which brought about the situation, and who was involved.

Q1.2 What was the conflict for you in that situation? Why was it a conflict?

Q1.3 What aspects of this situation made it a moral dilemma for you?

Q1.4 In thinking about what to do, what did you consider? Why?

Q1.5 What did you decide to do? What happened? 
Q1.6 Do you think it was the right thing to do? Why/why not? What were the alternative choices?

Q1.7 What was at stake for you in this dilemma? What was at stake for others?

What was at stake in general?

Q1.8 How did/do you feel about this dilemma? and the choice you made?

Q1.9 What was/were the deciding factor(s) in your decision to take the action which you took? Please be specific about reasons for acting and reasons for not acting.

\section{Thank you for your help. Please return by}


Name

Questionnaire 2

Q2.1 Following is a list of characteristics which survey participants indicated will signal that a dilemma is a specifically moral dilemma. Please indicate the importance to you of each characteristic in identifying a moral dilemma. The list is in no particular order and more than one characteristic may be ranked at each level of importance.

(Not important) (slightly important) (moderately important) (very important) (essential) 1
2
3
$4 \quad 5$

A conflict of values.

$\begin{array}{lllll}1 & 2 & 3 & 4 & 5\end{array}$

A risk of damage to an individual's

reputation (including your own).

$\begin{array}{lllll}1 & 2 & 3 & 4 & 5\end{array}$

A threat to fairness.

$\begin{array}{lllll}1 & 2 & 3 & 4 & 5\end{array}$

A risk of damage to an individual's self respect (including your own).

$\begin{array}{lllll}1 & 2 & 3 & 4 & 5\end{array}$

Questions of self determination.

$\begin{array}{lllll}1 & 2 & 3 & 4 & 5\end{array}$

A conflict between two or more obligations.

$\begin{array}{lllll}1 & 2 & 3 & 4 & 5\end{array}$

A risk of bias or the appearance of bias.

$\begin{array}{lllll}1 & 2 & 3 & 4 & 5\end{array}$

A conflict between two or more responsibilities.

$\begin{array}{lllll}1 & 2 & 3 & 4 & 5\end{array}$

Risk of conflict with colleagues.

$\begin{array}{lllll}1 & 2 & 3 & 4 & 5\end{array}$

A conflict between two or more duties.

$\begin{array}{lllll}1 & 2 & 3 & 4 & 5\end{array}$

A conflict between obligations and self interest (job loss, safety, convenience, self esteem).

$\begin{array}{lllll}1 & 2 & 3 & 4 & 5\end{array}$

Risk of harm to others.

$\begin{array}{lllll}1 & 2 & 3 & 4 & 5\end{array}$

A conflict between responsibilities and self interest. $\begin{array}{llllll}1 & 2 & 3 & 4 & 5\end{array}$

A violation of law, regulation, or policy. $\quad \begin{array}{lllll}1 & 2 & 3 & 4 & 5\end{array}$

$\begin{array}{llllll}\text { A conflict between duties and self interest. } & 1 & 2 & 3 & 4 & 5\end{array}$

$\begin{array}{llllll}\text { A risk to relationship between individuals. } & 1 & 2 & 3 & 4 & 5\end{array}$

Individuals' rights are ignored.

$\begin{array}{lllll}1 & 2 & 3 & 4 & 5\end{array}$ 
Q2.2 Following is a list of processes which survey participants indicated they use (separately or together) when determining what action to take when confronted with a moral dilemma. Please indicate how likely you would be to do each. The items are in no particular order.

(Not likely) (somewhat likely) (moderately likely) (very likely) (definitely would)

1 2
4

$\begin{array}{lllll}1 & 2 & 3 & 4 & 5\end{array}$

Decide without consultation with others.

Seek advice from supervisor.

Seek advice from colleagues.

Consider the concerns of all those involved.

Request further information.

Provide information to persuade other parties.

Require that decisions be made as a team.

Base decision solely on welfare of child.

Base decision soley on basis of legal obligations.

Seek help from other service agencies.

Find safe way to postpone decision.

Gather documentation.

Weigh the risks and benefits of various actions.

Compromise. $\begin{array}{lllll}1 & 2 & 3 & 4 & 5\end{array}$

$\begin{array}{lllll}1 & 2 & 3 & 4 & 5\end{array}$

$\begin{array}{lllll}1 & 2 & 3 & 4 & 5\end{array}$

$\begin{array}{lllll}1 & 2 & 3 & 4 & 5\end{array}$

$\begin{array}{lllll}1 & 2 & 3 & 4 & 5\end{array}$

$\begin{array}{lllll}1 & 2 & 3 & 4 & 5\end{array}$

$\begin{array}{lllll}1 & 2 & 3 & 4 & 5\end{array}$

$\begin{array}{lllll}1 & 2 & 3 & 4 & 5\end{array}$

$\begin{array}{lllll}1 & 2 & 3 & 4 & 5\end{array}$

$\begin{array}{lllll}1 & 2 & 3 & 4 & 5\end{array}$

$\begin{array}{lllll}1 & 2 & 3 & 4 & 5\end{array}$

$\begin{array}{lllll}1 & 2 & 3 & 4 & 5\end{array}$

$\begin{array}{lllll}1 & 2 & 3 & 4 & 5\end{array}$

$\begin{array}{lllll}1 & 2 & 3 & 4 & 5\end{array}$ 
Q2.3 After an individual has made a judgment about what action would be best to take concerning a moral dilemma, there are sometimes considerations which influence whether they will actually take that action. Following is a list of factors which survey participants indicated might influence whether they actually took what they considered the best action regarding a moral dilemma. Please indicate whether you would consider these when deciding whether to act or not. These items are in no particular order.

(Not likely) (somewhat likely) (moderately likely) (very likely) (definitely would)
1
2
3
4
5

Your role as a member of a team.

$\begin{array}{lllll}1 & 2 & 3 & 4 & 5\end{array}$

The responsibility of others to resolve the dilemma. $\begin{array}{llllll}1 & 2 & 3 & 4 & 5\end{array}$

The feelings of those involved.

$\begin{array}{lllll}1 & 2 & 3 & 4 & 5\end{array}$

Your personal reputation.

$\begin{array}{lllll}1 & 2 & 3 & 4 & 5\end{array}$

The interests of those involved.

$\begin{array}{lllll}1 & 2 & 3 & 4 & 5\end{array}$

Consequences to others of acting or not acting.

$\begin{array}{lllll}1 & 2 & 3 & 4 & 5\end{array}$

The rights of those involved.

$\begin{array}{lllll}1 & 2 & 3 & 4 & 5\end{array}$

Your relationship with the individuals involved.

$\begin{array}{lllll}1 & 2 & 3 & 4 & 5\end{array}$

Your relationship with colleagues.

$\begin{array}{lllll}1 & 2 & 3 & 4 & 5\end{array}$

Consequences to yourself of acting or not acting

(job loss, safety, convenience, self esteem).

$\begin{array}{lllll}1 & 2 & 3 & 4 & 5\end{array}$

Personal responsibility vs. professional

responsibility.

$\begin{array}{lllll}1 & 2 & 3 & 4 & 5\end{array}$

Your personal values.

$\begin{array}{lllll}1 & 2 & 3 & 4 & 5\end{array}$

Responsibility to employer.

$\begin{array}{lllll}1 & 2 & 3 & 4 & 5\end{array}$

The best interest of the child (if in conflict with responsibility, law, etc.)

$\begin{array}{lllll}1 & 2 & 3 & 4 & 5\end{array}$ 
Q2.4 Listed below are the same items listed in Q2.3. Please place a star beside those items which you rated as 5 (definitely would consider). Once you have done this, please rank these items in the order of importance to you, that is, the degree to which they might influence your decision to act or not to act. The purpose of this question is to gain some insight into how individuals prioritize competing values, risks, and benefits.

Rank the items from 1 - 5 with $5=$ most important and $1=$ least important.

Your role as a member of a team.

$\begin{array}{lllll}1 & 2 & 3 & 4 & 5\end{array}$

The responsibility of others to resolve the dilemma. $\begin{array}{llllll}1 & 2 & 3 & 4 & 5\end{array}$

The feelings of those involved.

$\begin{array}{lllll}1 & 2 & 3 & 4 & 5\end{array}$

Your personal reputation.

$\begin{array}{lllll}1 & 2 & 3 & 4 & 5\end{array}$

The interests of those involved.

$\begin{array}{lllll}1 & 2 & 3 & 4 & 5\end{array}$

Consequences to others of acting or not acting.

$\begin{array}{lllll}1 & 2 & 3 & 4 & 5\end{array}$

The rights of those involved.

$\begin{array}{lllll}1 & 2 & 3 & 4 & 5\end{array}$

Your relationship with the individuals involved.

$\begin{array}{lllll}1 & 2 & 3 & 4 & 5\end{array}$

Your relationship with colleagues.

$\begin{array}{lllll}1 & 2 & 3 & 4 & 5\end{array}$

Consequences to yourself of acting or not acting (job loss, safety, convenience, self esteem).

$\begin{array}{lllll}1 & 2 & 3 & 4 & 5\end{array}$

Personal responsibility vs. professional responsibility.

$\begin{array}{lllll}1 & 2 & 3 & 4 & 5\end{array}$

Your personal values.

$\begin{array}{lllll}1 & 2 & 3 & 4 & 5\end{array}$

Responsibility to employer.

$\begin{array}{lllll}1 & 2 & 3 & 4 & 5\end{array}$

The best interest of the child (if in conflict with responsibility, law, etc.)

$\begin{array}{lllll}1 & 2 & 3 & 4 & 5\end{array}$ 
Perceptions of Moral Agency

\section{Appendix C}




\section{WestVirginiaUniversity}

College of Human Resources and Education

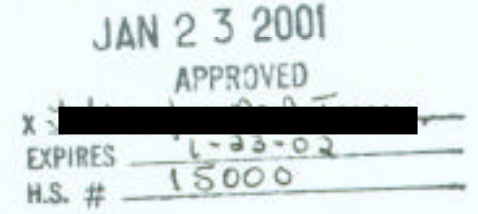

INTERVIEW CONSENT AND INFORMATION FORM Perceptions of Moral Agency Among Preschool Special Needs Teachers

Introduction. I, , have been invited to participate in this research study which has been explained to me by Stephen K. Pavlovic. This research is being conducted to fulfill the requirements for a doctoral dissertation in Special Education in the Department of Educational Theory and Practice at West Virginia University.

Purposes of the Study. The purpose of this study is to gain more understanding of the experience of preschool special needs teachers regarding moral dilemmas which may occur on the job, and how teachers view, and resolve these dilemmas.

Description of Procedures. I have already participated in the Delphi procedure phase of this research. I am now being asked to participate in the following:

1. A face to face interview with Stephen Pavlovic to discuss moral dilemmas which 1 have experienced on the job, and my sense of morality in general. This interview is expected to last 1-2 hours and will be audio taped for transcription.

2. An opportunity for me to examine the transcript of the interview for accuracy and clarifications.

3. A second interview with Stephen Pavlovic to continue the discussion of moral dilemmas. This interview is expected to last 1-2 hours and will also be audio taped.

4. An opportunity to review the transcript of the second interview.

5 . An opportunity to review the rough draft of a summary of the discussion themes. This summary will appear in the results section of Mr. Pavlovic's dissertation.

6. An opportunity to review the final draft of the summary and discuss the results with Mr. Pavlovic.

These meetings and discussions will occur at a time and place of my choosing. Four (4) individuals will be included in this part of the study.

Risks and Discomforts. There are no known or expected risks from participating in this study, except for the difficulties associated with recalling events and constructing a narrative.

Alternative. I understand that I do not have to participate in this study and that my participation is entirely voluntary.

Benefits. I understand that this study is not expected to be of direct benefit to me, but the knowledge gained may be of benefit to others.

Contact persons. For more information about this research, I can contact Stephen K. Pavlovic at 304-292-5287, or his supervisor, Dr. Barbara Ludlow at 304-293-3450. For information regarding my rights as a research subject, I may contact the Executive Secretary of the Institutional Review Board at 304-293-7073.

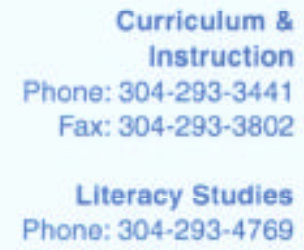

Special Education Phone: 304-293-3450

Fax: 304-293-6834

$\quad \begin{aligned} & \text { December 1, 2000 Page } 1 \text { of } 2 \\ & \text { Educational Theory \& Practice }\end{aligned}$
PO Box 6122
Morgantown, WV 26506-6122

December 1, $2000 \quad$ Page 1 of 2

initials

date 
Perceptions of Moral Agency Among Preschool Special Needs Teachers

Confidentiality. I understand that any information about me obtained as a result of my participation in this research will be kept as confidential as legally possible. I understand that my research records, just like hospital records, may be subpoenaed by court order or may be inspected by federal regulatory authorities. In any publications that result from this research, neither my name nor any information from which I might be identified will be published without my consent. The audiotapes of interviews will be stored in a locked cabinet and will be destroyed upon completion of the study.

Voluntary Participation. Participation in this study is voluntary. I understand that I am free to withdraw my consent to participate in this study at any time. Refusal to participate or withdrawal will involve no penalty or loss of benefits. I have been given the opportunity to ask questions about the research, and I have received answers concerning areas I did not understand.

Upon signing of this form, I will receive a copy.

I willingly consent to participate in this research.

\begin{tabular}{clc}
\hline Signature of Subject & & Date \\
\cline { 1 - 1 } & & Date
\end{tabular}

December 1, 2000

Page 2 of 2 
Perceptions of Moral Agency

Appendix D 
Date

Stephen Pavlovic,

You are permitted to contact the preschool special needs teachers of County schools for the purpose of recruiting subjects to participate in a sequence of three (3) questionnaires. These questionnaires are part of a doctoral dissertation study examining the perceptions of preschool special needs teachers regarding moral dilemmas which may occur on the job.

Sincerely,

Signature

Position 


\author{
STEPHEN K PAVLOVIC \\ 230 Waitman Street \\ Morgantown, WV 26501
}

(304) 292-5287/spavlovi@wvu.edu

\section{EDUCATION}

Ed.D.

Masters

Masters

$B A$
Early Childhood Special Education (Major) Child Development and

$$
\text { Family Resources (Minor) }
$$

West Virginia University

Morgantown, WV

Dissertation Title: Perceptions of Moral Agency Among Some

Preschool Special Needs Teachers

Early Intervention Special Education

West Virginia University

Morgantown, WV

Fine Art

University of North Carolina

Chapel Hill, NC

Liberal Arts (Fine Arts Major)

Kenyon College

Gambier, $\mathrm{OH}$

May 2002

May 1993

May 1977

May 1973

\section{CAREER RELATED EXPERIENCE}

2000 - Present

$1999-2000$

$1994-1999$
Teacher - Preschool Special Needs. Jakes Run Early Childhood Center, Jakes Run, WV.

Duties: Plan and implement classroom instruction for 3, 4, and 5 year old children with developmental delays; deliver specialized instruction to identified children who are 5 years old and in kindergarten; homebased instruction to medically fragile students.

Teacher - Severe and Multiple Disabilities. Morgantown High School, Morgantown, WV.

Duties: Plan and implement instruction of students with severe and moderate disabilities grades 9 - 12; use sign language to deliver instruction and orient students with communication delays; train staff in use of sign language.

Lecturer. Department of Special Education, West Virginia University, Morgantown, WV.

Duties: Assist Program Coordinator of Early Intervention Special Education, and Severe and Multiple Disabilities masters degree programs as practicum coordinator, advisor, lead grader and on-site practicum supervisor. Teaching duties as required by the programs. 
Early Intervention Specialist. Early Intervention Program, Valley Comprehensive Community Mental Health Center, Morgantown, WV.

Duties: Included center based programming, in home intervention, parent education, case management and child assessment.

Fine Art for Children. Cortesi Gallery, Highland Park, IL. Duties: An exhibition of paintings created for young children. Winston-Salem, NC. (Program funded by the Nelson Rockefeller Foundation).

Duties: An exhibition of paintings; lectures and meetings with students.

\section{PUBLICATIONS}

Pavlovic S. K. \& Friedland, B. (1998). Promoting greater reflectivity in rural in-service practicum experiences. Proceedings of the 1998 ACRES Conference. Charleston, SC: American Council on Rural Special Education.

Pavlovic S. K. \& Friedland, B. (1997). Reflective teaching and supervision. Proceedings of the 1997 ACRES Conference. San Antonio: American Council on Rural Special Education.

Pavlovic, S. K., Review of Johnson, L. J., Gallagher, R. J., Montagne, M. J., Jordan, J. B., Gallagher, J. J., Hutinger, P. A., \& Kames, M. B. (Eds.) (1994). Meeting Early Intervention Challenges: Issues from Birth to Three (2nd. ed). Education and Treatment of Children, 19, 1.

\section{PRESENTATIONS}

Friedland, B., \& Pavlovic S.K. (1997). Reflective teaching and supervision. Research presentation at the American Council on Rural Special Education Conference, San Antonio, Texas.

Pavlovic, S.K., \& Ludlow, B.L. (1996, December). Developmentally appropriate practice: Strategies for managing challenging behaviors in young children. Poster session presented at the Division of Early Childhood International Early Childhood Conference on Children with Special Needs, Phoenix, AZ.

Weigle, K., Pavlovic, S.K., Ray, L., \& Cippaloni, H. (1995). Promoting family rapport. A training session to improve interviewing skills and family rapport in early intervention programs. Presented at the Statewide Early Intervention Conference, Snowshoe, WV. 


\section{PROFESSIONAL SERVICE}

1997

1998

$1998-2000$

$2000-2001$
Reviewer, Conference proposals for the 1998 conference of the American Educational Research Association.

Reviewer, Manuscript submitted for publication in Education and Treatment of Children. Historian, Phi Delta Kappa, Chapter 0133.

Co-chairperson, Phi Delta Kappa, Chapter 0133.

\section{PROFESSIONAL ORGANIZATIONS}

Council for Exceptional Children

Division: DEC (Division of Early Childhood)

Phi Delta Kappa, Chapter 0133 